University of Tennessee Health Science Center

UTHSC Digital Commons

$12-2008$

\title{
The Relationships Among Adaptive Behaviors of Children with Autism Spectrum Disorder, Their Family Support Networks, Parental Stress, and Parental Coping
}

Heather Roberts Hall

University of Tennessee Health Science Center

Follow this and additional works at: https://dc.uthsc.edu/dissertations

Part of the Congenital, Hereditary, and Neonatal Diseases and Abnormalities Commons, and the Pediatric Nursing Commons

\section{Recommended Citation}

Hall, Heather Roberts , "The Relationships Among Adaptive Behaviors of Children with Autism Spectrum Disorder, Their Family Support Networks, Parental Stress, and Parental Coping" (2008). Theses and Dissertations (ETD). Paper 344. http://dx.doi.org/10.21007/etd.cghs.2008.0123. 


\title{
The Relationships Among Adaptive Behaviors of Children with Autism Spectrum Disorder, Their Family Support Networks, Parental Stress, and Parental Coping
}

\begin{abstract}
Purpose: The purpose of this study was to examine the adaptive behaviors of children with Autism Spectrum Disorder (ASD), their family support networks, parental stress, and parental coping and the relationships among these variables.

Background: Autism is the fastest growing diagnosed developmental disorder. When parents receive a diagnosis of autism for their child, mothers and fathers are affected differently. The costs to families of children with autism are personal, social, and affect family finances and day to day living. Parents of a child with autism are at high risk for increased stress levels. The child's socially unacceptable behaviors and communication problems contribute to parental stress. Available and accessible support services for children with autism, their caregivers, and families are often inadequate to address the increasing numbers of children being diagnosed with autism.

Methods: A descriptive, correlational, cross-sectional study was conducted with a purposive sample of 75 parents/primary caregivers of children with ASD. Parents provided information about the adaptive behaviors of their child with autism, family support networks, parental stress, and parental coping. Pearson product-moment correlation was used to identify the relationships between the variables. Multiple regression analysis was performed to identify which of the independent variables better predicted parental coping patterns.

Findings and Conclusion: The adaptive behaviors of children with autism were negatively correlated with parental behaviors which focused on continuing to seek and use social support, self-respect, and emotional strength. Parents' views of the support their family received were positively correlated with parental behaviors that concentrated on family adjustment, teamwork, and a positive meaning of the situation. A trend toward significance was found between adaptive behaviors of the child with autism and paternal stress. These results bring new challenges and thoughts about how the children with autism and their families can be assisted. Parents who are coping with the added stresses in their lives need support that addresses the abilities of their child with autism, their own patterns of coping, and the resources available to their family.
\end{abstract}

Document Type

Dissertation

Degree Name

Doctor of Philosophy (PhD)

Program

Nursing

Research Advisor

J. Carolyn Graff, Ph.D.

Keywords

Autism Spectrum Disorder, Parental Coping, Parental Stress, Support Networks 


\section{Subject Categories}

Congenital, Hereditary, and Neonatal Diseases and Abnormalities | Diseases | Medicine and Health Sciences | Nursing | Pediatric Nursing 


\title{
THE RELATIONSHIPS AMONG ADAPTIVE BEHAVIORS OF CHILDREN WITH AUTISM SPECTRUM DISORDER, THEIR FAMILY SUPPORT NETWORKS, PARENTAL STRESS, AND PARENTAL COPING
}

\author{
A Dissertation \\ Presented for \\ The Graduate Studies Council \\ The University of Tennessee \\ Health Science Center
}

\author{
In Partial Fulfillment \\ Of the Requirements for the Degree \\ Doctor of Philosophy \\ From The University of Tennessee
}

By

Heather Roberts Hall

December 2008 
Copyright (C) 2008 by Heather R. Hall All rights reserved 


\section{DEDICATION}

This dissertation is dedicated to

my husband, Frederick Hall,

who has given me love and encouragement throughout this journey, and to my parents, Helen and Jimmy Roberts, who have always given me love and support, and who inspired me to achieve every goal in my life. 


\section{ACKNOWLEDGEMENTS}

I would like to thank my mentor and chair of my dissertation committee, Dr. Carolyn Graff, for her leadership, guidance, support, and patience that assisted me in achieving this goal. I would also like to express thanks and appreciation to the entire committee for giving their time, support, and comments: Dr. Michael Carter, Dr. Ann Cashion, Dr. Sharon Husch, Dr. Teena McGuinness, and Dr. Mona Wicks. The assistance given by the entire committee was a great asset to the success of this dissertation.

I express my appreciation to Dr. Hamilton I. McCubbin for granting me permission to use the Coping Health Inventory for Parents (CHIP) as an instrument in this study.

Special appreciation is extended to the parents who willingly participated in this study and shared their invaluable perspectives and experiences.

An expression of gratitude is extended to the Lauralee Larrabee Adolescent Research Endowment and The University of South Alabama College of Nursing Dean's Grant for providing funding for this research. 


\begin{abstract}
Purpose: The purpose of this study was to examine the adaptive behaviors of children with Autism Spectrum Disorder (ASD), their family support networks, parental stress, and parental coping and the relationships among these variables.

Background: Autism is the fastest growing diagnosed developmental disorder. When parents receive a diagnosis of autism for their child, mothers and fathers are affected differently. The costs to families of children with autism are personal, social, and affect family finances and day to day living. Parents of a child with autism are at high risk for increased stress levels. The child's socially unacceptable behaviors and communication problems contribute to parental stress. Available and accessible support services for children with autism, their caregivers, and families are often inadequate to address the increasing numbers of children being diagnosed with autism.
\end{abstract}

Methods: A descriptive, correlational, cross-sectional study was conducted with a purposive sample of 75 parents/primary caregivers of children with ASD. Parents provided information about the adaptive behaviors of their child with autism, family support networks, parental stress, and parental coping. Pearson product-moment correlation was used to identify the relationships between the variables. Multiple regression analysis was performed to identify which of the independent variables better predicted parental coping patterns.

Findings and Conclusion: The adaptive behaviors of children with autism were negatively correlated with parental behaviors which focused on continuing to seek and use social support, self-respect, and emotional strength. Parents' views of the support their family received were positively correlated with parental behaviors that concentrated on family adjustment, teamwork, and a positive meaning of the situation. A trend toward significance was found between adaptive behaviors of the child with autism and paternal stress. These results bring new challenges and thoughts about how the children with autism and their families can be assisted. Parents who are coping with the added stresses in their lives need support that addresses the abilities of their child with autism, their own patterns of coping, and the resources available to their family. 


\section{TABLE OF CONTENTS}

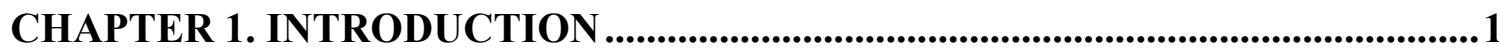

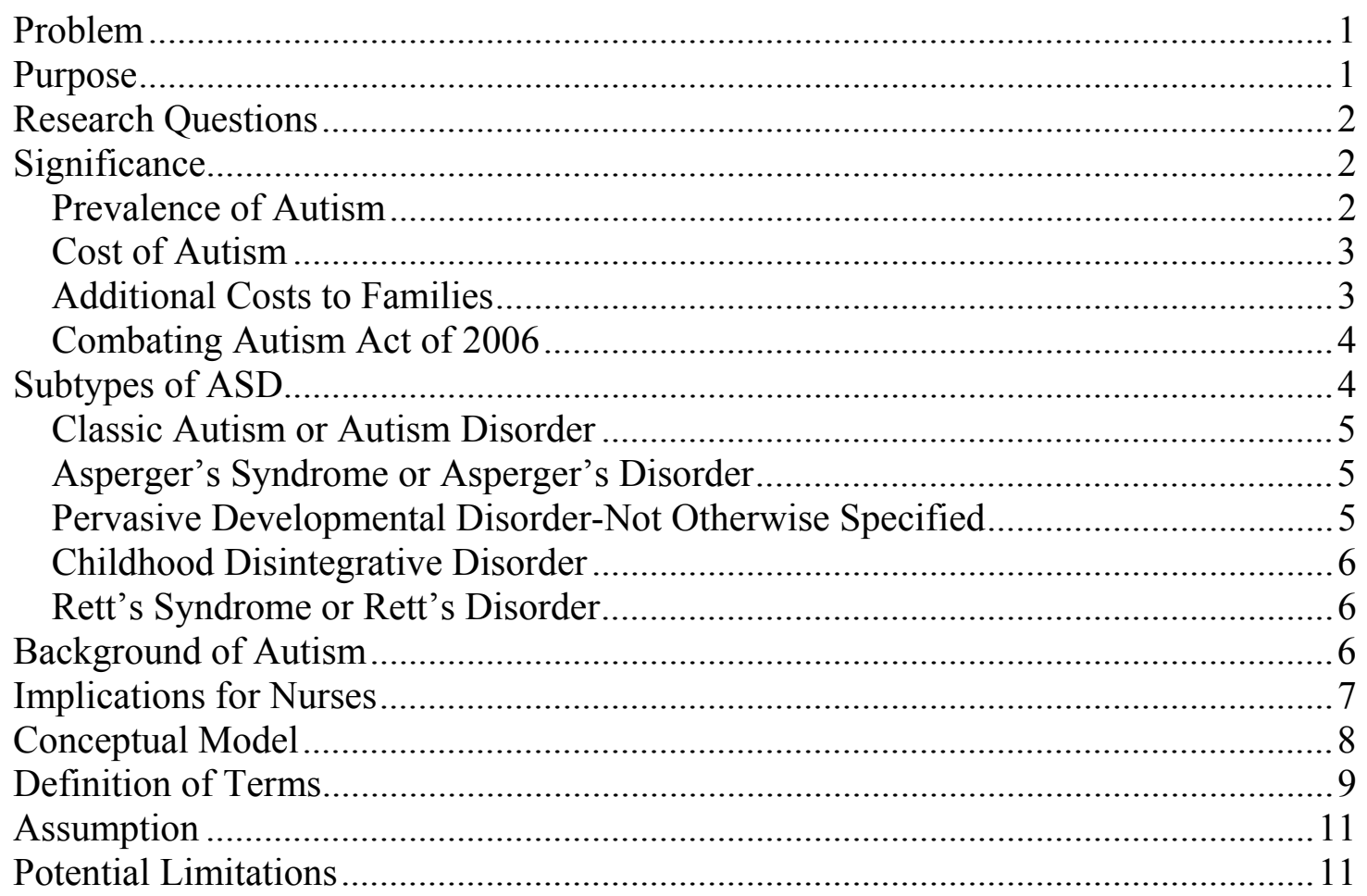

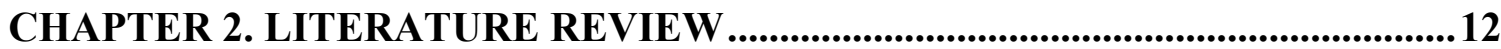

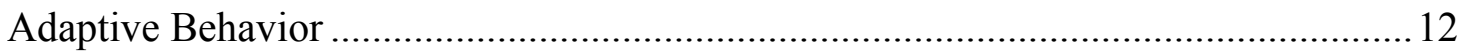

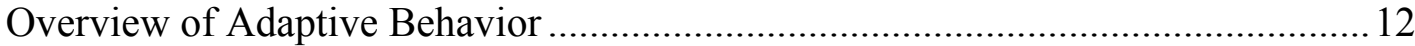

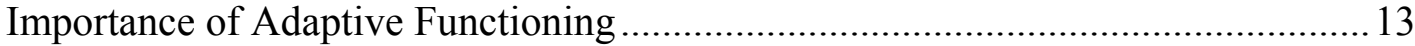

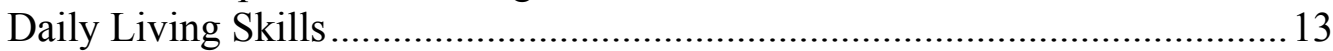

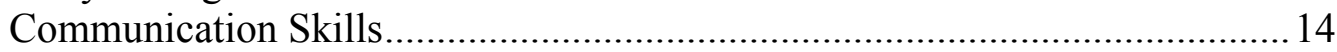

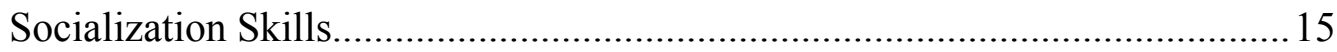

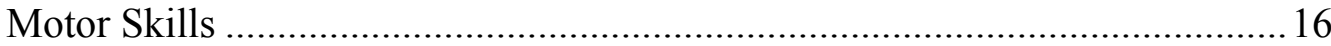

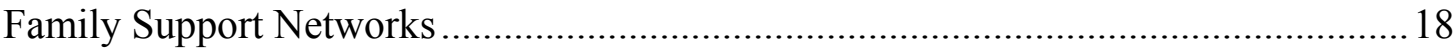

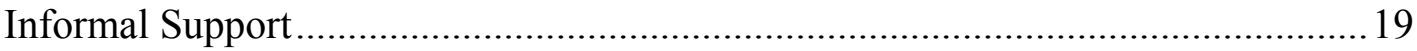

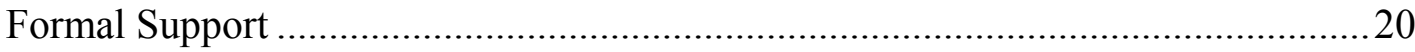

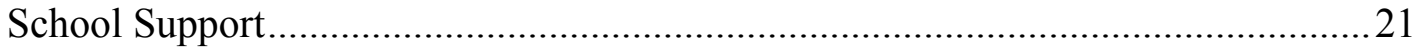

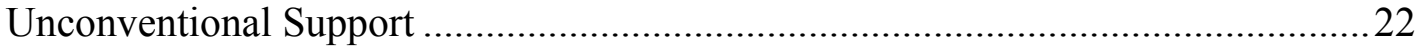

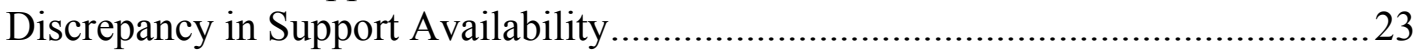

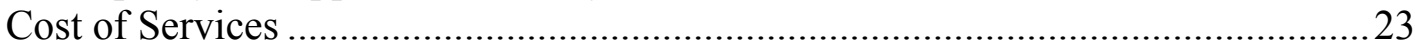

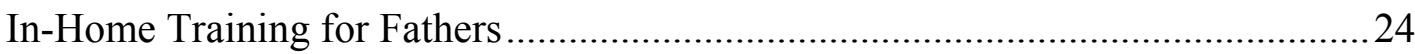

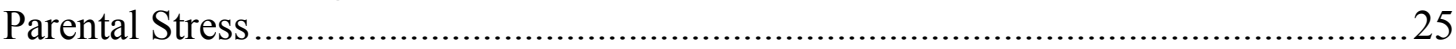

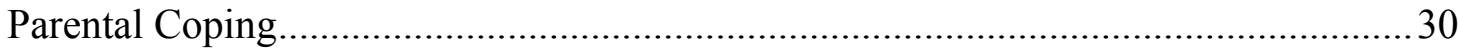

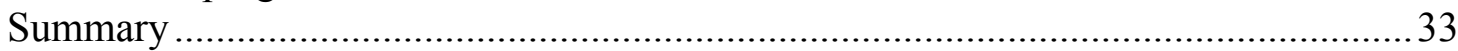




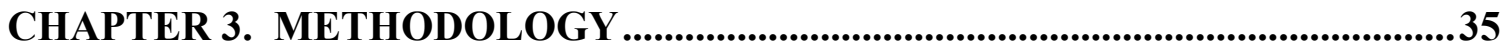

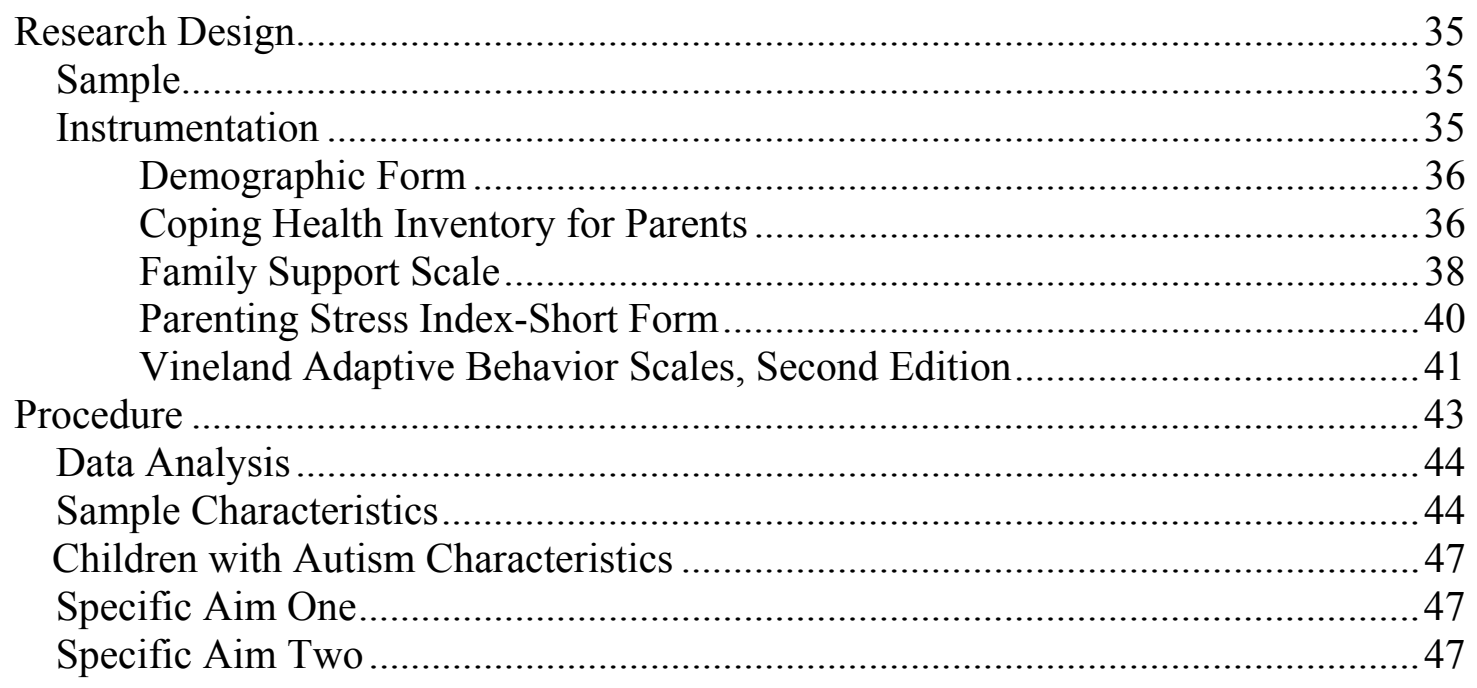

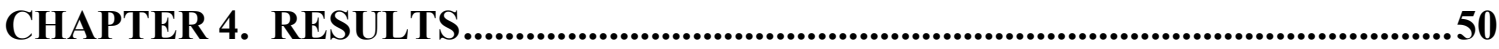

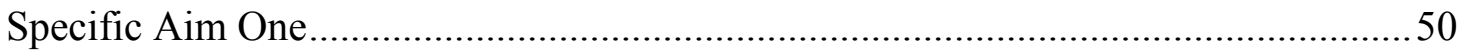

Research Question 1a and Findings .....................................................................5

Findings: Adaptive Behaviors of Children with Autism .................................50

Findings: Family Support Networks .........................................................50

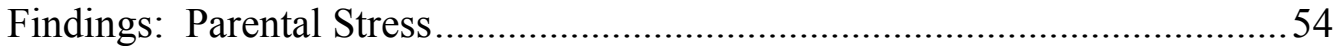

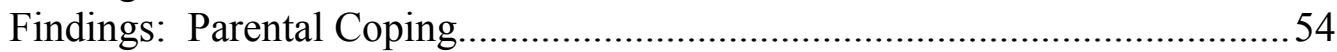

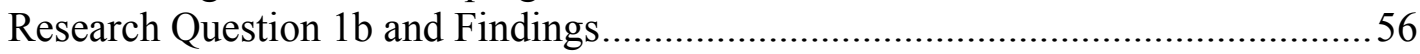

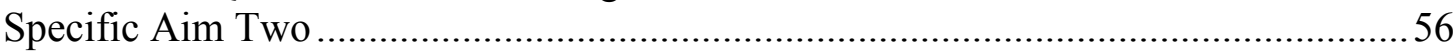

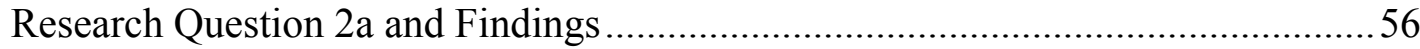

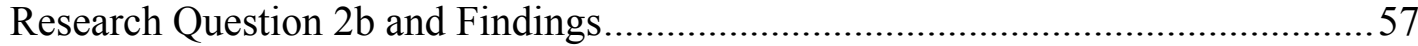

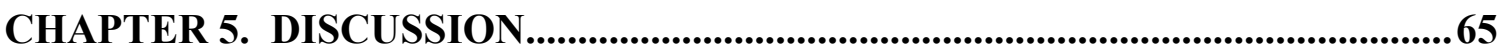

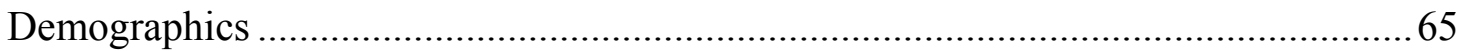

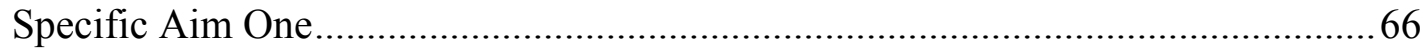

Adaptive Behaviors of Children with Autism ...................................................66

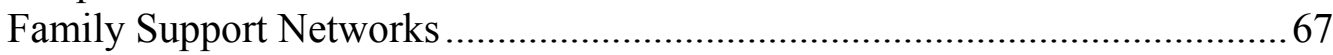

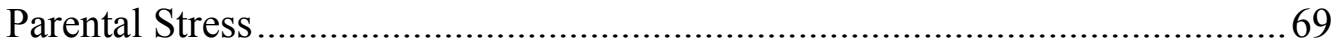

Parental Coping...................................................................................

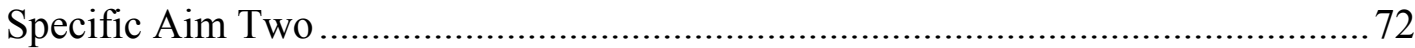

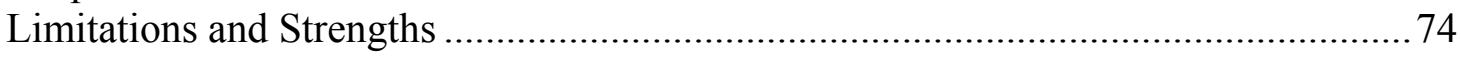

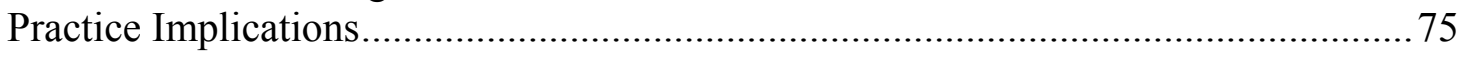

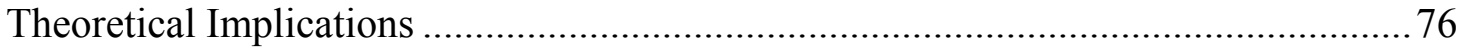

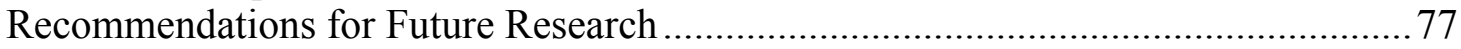

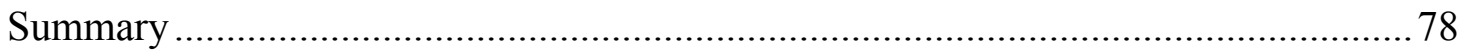


LIST OF REFERENCES.................................................................................................79

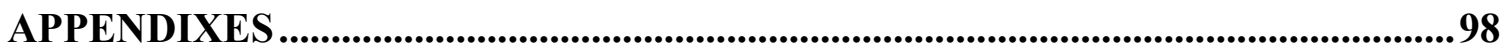

Appendix A. Demographic Form ............................................................................99

Appendix B. Coping Health Inventory for Parents.................................................... 101

Appendix C. Family Support Scale ....................................................................... 106

Appendix D. Permission Letter to Use Coping Health Inventory for Parents

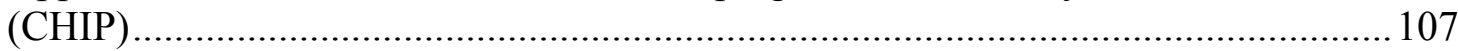

Appendix E. Institutional Review Board Approval Letter ......................................... 108

Appendix F. Advertisement for Research Study Participants .................................... 109

Appendix G. Institutional Review Board Research Consent Statement......................110

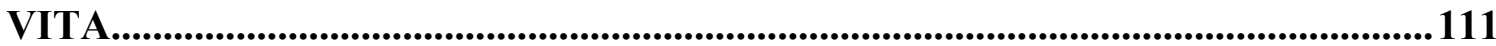




\section{LIST OF TABLES}

Table 3-1. Demographic Characteristics of Participants 45

Table 3-2. Children With and Without Autism Spectrum Disorder by Age Groups.......46

Table 3-3. Demographic Characteristics of Participants' Children with Autism Spectrum Disorder

Table 4-1. Vineland-II Domain and Adaptive Behavior Composite Behavior Scores for Sample, Mothers, Fathers, and Others................................................51

Table 4-2. Family Support Scale Subscale Item Scores for the Sample, Mothers, Fathers, and Others

Table 4-3. Parenting Stress Index-Short Form Scale and Total Scores for the Sample, Mothers, Fathers, and Others

Table 4-4. Parental Coping Patterns as Measured by the Coping Health Inventory for Parents

Table 4-5. Correlations Among Adaptive Behaviors of Children with Autism, Their Family Support Networks, and Parental Stress and Coping: Pearson Correlation, $\mathrm{p}$-value

Table 4-6. Correlations Among Adaptive Behaviors of Children with Autism, Their Family Support Networks, and Maternal Stress and Coping: Pearson Correlation, p-value.

Table 4-7. Correlations Among Adaptive Behaviors of Children with Autism, Their Family Support Networks, and Paternal Stress and Coping: Pearson Correlation, $\mathrm{p}$-value.

Table 4-8. Multiple Regression Analyses Results Predicting Parental Coping Patterns by Adaptive Behaviors of Children with Autism, Family Support Networks, Parental Stress and Other Parental Coping Behaviors $(n=73) \ldots . . .61$ 


\section{LIST OF ABBREVIATIONS}

$\begin{array}{ll}\text { ADDM } & \text { Autism and Developmental Disabilities Monitoring } \\ \text { AD } & \text { Asperger's Disorder } \\ \text { APA } & \text { American Psychiatric Association } \\ \text { AS } & \text { Asperger's Syndrome } \\ \text { ASD } & \text { Autism Spectrum Disorder } \\ \text { CDC } & \text { Centers for Disease Control and Prevention } \\ \text { CDD } & \text { Childhood Disintegrative Disorder } \\ \text { CHIP } & \text { Coping Health Inventory for Parents } \\ \text { CPI } & \text { Coping Pattern I of the Coping Health Inventory for } \\ & \text { Parents } \\ \text { CPII } & \text { Coping Pattern II of the Coping Health Inventory for } \\ & \text { Parents } \\ \text { CPIII } & \text { Coping Pattern III of the Coping Health Inventory for } \\ & \text { Parents } \\ \text { DC } & \text { Difficult Child } \\ \text { DD } & \text { Developmentally Delayed } \\ \text { DLD } & \text { Developmental Language Disorder } \\ \text { FES } & \text { Family Environment Scale } \\ \text { FM } & \text { Fine Motor } \\ \text { FSS } & \text { Family Support Scale } \\ \text { GAO } & \text { U. S. Government Accountability Office } \\ \text { GM } & \text { Gross Motor } \\ \text { HFA } & \text { High Functioning Autism } \\ \text { NICHD } & \text { National Institute of Child Health and Human Development } \\ \text { NIH } & \text { National Institutes of Health } \\ \text { NIMH } & \text { National Institute of Mental Health } \\ \text { NINDS } & \text { National Institute of Neurological Disorders and Stroke } \\ \text { P-CDI } & \text { Parent-Child Dysfunctional Interaction } \\ \text { PD } & \text { Parental Distress } \\ \text { PDD } & \text { Pervasive Developmental Disorder } \\ \text { PDD-NOS } & \text { Pervasive Developmental Disorder-Not Otherwise } \\ \text { PSI } & \text { Specified } \\ \text { PSI-SF } & \text { Parenting Stress Index } \\ \text { VABS } & \text { Parenting Stress Index-Short Form } \\ \text { Vineland-II } & \text { Vineland Adaptive Behavior Scales } \\ & \text { Vineland Adaptive Behavior Scales, Second Edition } \\ & \end{array}$




\section{CHAPTER 1. INTRODUCTION}

\section{Problem}

Many parents continue to hear from health-care providers that their child is diagnosed with a lifetime developmental disorder named autism spectrum disorder (ASD) (Stevens et al., 2007) and that this disorder will cause adaptive behavior problems for their child, especially in the areas of social skills, communication skills, and daily living skills (American Psychiatric Association [APA], 2000). Autism is recognized as a complex developmental disability because similar symptoms range from minor to severe in different individuals; thus, autism is a spectrum disorder, and is currently referred to as autism spectrum disorder (National Institute of Child Health and Human Development [NICHD], 2007). In this paper, the term ASD and autism will be used synonymously. Currently, the Centers for Disease Control and Prevention [CDC] (2006) estimate the economic cost of ASD to be $\$ 35$ billion a year (Stevens et al.), and there is no known cure for the disorder (NICHD, 2007; National Institute of Neurological Disorders \& Stroke [NINDS], 2008). A year's special education program for a child with ASD costs more than $\$ 8,000$ (CDC) above the estimated $\$ 6,556$ for regular educational expenses (U.S. Government Accountability Office [GAO], 2005). If additional programs are required, the cost may rise to as much as $\$ 30,000$ a year per child (CDC). If a facility outside the family home is required for the child, the estimated cost may be as much as $\$ 90,000$ or more per year (CDC).

One of the child's parents may be required to either change jobs or stop working outside the home completely to accommodate the needs of the child with ASD (Montes \& Halterman, 2008). Stressors continue to develop, and stress levels rise as parents try to cope with the diagnosis and wonder how family and friends will respond to the news (Krausz \& Meszaros, 2005) and what the future outcome will be not only for the child but also for their family (Akshoomoff \& Stahmer, 2006). In order for these parents to develop and use effective coping strategies, they depend on family support networks for assistance. Family support networks must react and respond to this family crisis as soon as possible to relieve some of the stress and assist the parents in learning to use effective coping strategies as they strive to accommodate the needs of their child with ASD (Weiss, 2002).

\section{Purpose}

The purpose of this descriptive, correlational, cross-sectional study was to examine the adaptive behaviors of children with ASD, family support networks, parental stress, parental coping, and the relationships among these variables. In the current study, variables were examined within each participating family of children diagnosed with ASD. This study was designed to examine parental views on variables in one setting from each participant. 
The specific aims of this study were to examine

(1) the parental views of adaptive behaviors of children with autism, family support networks, parental stress, and parental coping; and

(2) the relationships among the adaptive behaviors of children with autism, family support networks, parental stress, and patterns of coping.

\section{Research Questions}

Research questions for this study were as follows:

(1) (a) In families of children with autism, how do parents view the adaptive behaviors of their child with autism, the support for their family, parental stress, and their patterns of coping? (b) What do parents report as the autism-related resources used and needs for themselves, their children with autism, and their family?

(2) (a) What are the relationships among adaptive behaviors of children with autism, family support networks, parental stress, and patterns of coping? (b) Which predictor, adaptive behaviors of children with autism or family support, better predicts the criterion parental coping?

\section{Significance}

Autism is the fastest growing diagnosed developmental disorder (Luther, Canham, \& Cureton, 2005). In 2000, families and communities were spending approximately $\$ 2$ million to provide lifetime care for each person diagnosed with moderate to severe autism (Desorgher \& Desorgher, 2000). Average yearly cost of health care does not get smaller as the child ages; instead, the cost increases to approximately $\$ 4,256$ per year for adolescents (Croen, Najjar, Ray, Lotspeich, \& Bernal, 2006). The cost of educating one child with autism is approximately three times more than the cost of educating a typical child (GAO, 2005).

\section{Prevalence of Autism}

The diagnosis of autism in children has risen over the past 15 years and continues to rise (Baron-Cohen, 2004). Children aged 6-21 served by the Individuals with Disabilities Education Act (IDEA) has increased more than 500\% in the last 10 years (GAO, 2005). The CDC created the Autism and Developmental Disabilities Monitoring (ADDM) Network as a shared system to establish the prevalence of ASD in the United States (Stevens et al., 2007). According to Stevens et al., the exact number of individuals with ASD in the United States is not known. However, the CDC in 2007 reported that 
ASDs appear not only in all races and ethnic groups but also in all socioeconomic groups; and ASDs are four times more likely to occur in males than in females. Using prevalence statistics that 1 of every 150 children has ASD, ADDM estimates that 560,000 children (ages 0-21) have ASD (Stevens et al.).

\section{Cost of Autism}

Parents find that their household expenses rise when a child has autism or another ASD, while the family's income often diminishes (Montes \& Halterman, 2008). Montes

and Halterman suggested that lower income levels could be the result of parents having to make changes in employment to accommodate the needs of their child with autism. Raising a child with severe autism can cost as much as $\$ 90,000$ per year (CDC, 2006). The CDC estimates that autism-related economic costs are $\$ 35$ billion per year (Stevens et al., 2007). The estimate comprises the costs of education and treatments to help decrease the symptoms of ASD. Families pay for some of these services, but public and private organizations help families by paying for many of them. Professionals, support network sources, and researchers need to be kept informed of the number of diagnosed cases of ASD. The continuous rise in ASD promotes allegiance from individuals and organizations to encourage them to strive diligently to find better interventions and possibly either a way to prevent or to cure ASD (Stevens et al.).

\section{Additional Costs to Families}

Money is not the only cost to mothers and the family. Other costs include: day to day living, stress and coping; giving up various social events; securing competent care; serving as continual teacher; modifying expectations; fearing for the child's safety; worrying about receiving approval from family, friends, and strangers; caring for the entire family including the spouse; and learning to embrace the child (Krausz \& Meszaros, 2005). Gray (2003) found that when parents receive a diagnosis of autism for their child, mothers and fathers are affected differently. Fathers admitted that the children's autism caused problems for the family, but they were reluctant to acknowledge that their children's developmental disorders had any personal effect on them. Mothers, on the other hand, confessed that their children's disabilities had significant personal effects on them. Gray discovered that fathers often concealed their true feelings. Fathers disclosed that they often released their pent-up anxieties through anger tirades. Mothers did not attempt to hide their emotions. Gray's data showed that fathers most likely did not quit full-time employment to become the primary care-giver for children diagnosed with autism. Actually, some fathers admitted to Gray, that the problems at home caused them to work longer hours so they were out of the home environment. Montes and Halterman (2006) found a different scenario when they compared a group of fathers of children with autism to a group of fathers of children without autism. They found the fathers of the children with autism were less likely to have full-time employment (Montes \& Halterman). Mothers were often required to accept part-time work or even give up on employment outside the home (Gray). 
Parents of a child with autism are at high risk for increased stress levels (Hastings \& Johnson, 2001; McConachie \& Diggle, 2006; Rivers, 2003; Tarakeshwar \& Pargament, 2001). Some of the reasons parents become stressed include their children's problems with socially unacceptable behaviors, communication problems (Autism NSW, 2004); excitability, emotional indifference, self-destructive conduct, eating problems (Williams, Dalrymple, \& Neal, 2000), sleeping problems (Williams, Sears, \& Allard, 2004), and toilet training (Keen, Brannigan, \& Cuskelly, 2007). Stress at home spreads into schools and communities; therefore, autism is not just a family problem; it is a social problem for society (Dyches, Wilder, Sudweeks, Obiakor, \& Algozzine, 2004).

This research corresponds with the mission of the National Institute of Mental Health (NIMH) and its sponsored research on ASDs in the areas of interventions and services (NIMH, 2008b). Research has documented the effectiveness of intensive early intervention in improving outcomes (Eikeseth, Smith, Jahr, \& Eldevik, 2002; Howard, Sparkman, Cohen, Green, \& Stanislaw, 2005). Proper diagnosis for most children can occur before the child's third birthday (Sheehan, 2004). Without proper intervention, the children's condition will worsen, because the symptoms will not lessen as the children get older. Professionals throughout society must become aware that children with ASD need assistance. Children with ASD need support in developing adaptive behaviors, parents are stressed and may need better ways to cope, and efficient, accessible family support networks are needed to provide the best assistance to these families (Sheehan).

\section{Combating Autism Act of 2006}

This study is timely and correlates with action taken on December 19, 2006 when U.S. President George Bush signed the bill titled Combating Autism Act of 2006 (OLPABill Tracking, 2006). Congress and the nation's President recognized autism as a major problem for families in the U.S. and passed S.843, the Combating Autism Act of 2006 that requires the Director of the National Institutes of Health (NIH) to organize, increase, strengthen, and direct autism spectrum disorder-related research (OLPA-Bill Tracking). This law provided $\$ 147$ million in 2007 and will provide approximately $\$ 1$ billion over a five-year period (2007-2011) to finance and support further research to provide support for families with a child or children diagnosed with autism (GovTrack.us.S.843-109 ${ }^{\text {th }}$ Congress, 2006). The Combating Autism Act authorized the return of the Interagency Autism Coordinating Committee (IACC) to organize ASD research and other endeavors within the Department of Health and Human Services [HHS] (NIMH, 2008a).

\section{Subtypes of ASD}

The $4^{\text {th }}$ edition of the Diagnostic and Statistical Manual of Mental Disorders [DSM-IV-TR] (APA, 2000) identifies ASD as part of a larger grouping known as Pervasive Developmental Disorders (PDD). DSM-IV-TR recognizes five subtypes of ASD: (a) classic autism or autistic disorder; (b) Asperger's syndrome (AS) or Asperger's disorder (AD); (c) Pervasive Developmental Disorder-Not Otherwise Specified (PDDNOS), (d) Childhood Disintegrative Disorder (CDD), and (e) Rett's Syndrome (APA). 
The unique characteristics of each subtype gives professionals data they need to diagnose the specific disorder (Sevin, Knight, \& Braud, 2007). Concise descriptions of each subtype are presented in the following paragraphs.

\section{Classic Autism or Autism Disorder}

Autism, also known as classic autism or autism disorder, is the most frequently diagnosed ASD (NINDS, 2008). Autism presents itself early in the child's life (National Research Council [NRC], 2001), and the child's behaviors are the foundation of the diagnosis (Gomez \& Baird, 2005). Early diagnosis is essential to begin intervention and treatment as soon as possible to help the child succeed in as many accomplishments as possible (Stevens et al., 2007). Autism is diagnosed in all socioeconomic areas, cultures, and territories throughout the world (Bryson, Rogers, \& Fombonne, 2003).

\section{Asperger's Syndrome or Asperger's Disorder}

Behavioral characteristics of Asperger's syndrome (AS) or Asperger's disorder (AD) include observable problems in the areas of social skills, behaviors, inattention to surroundings and people, and reasonably good language skills (APA, 2000). Hans Asperger devoted his life and his work to investigating children who showed symptoms of a form of the disorder that both he and Leo Kanner investigated (Frith, 1996). Frith's translation of Asperger's work explained that the children Asperger studied presented symptoms less severe than Kanner's subjects. Children with AS may be observed as being: (a) socially clumsy although they are interested in being involved, (b) articulate but not easily understood, (c) tactless and unreasonable, (d) professionals or masters in uncommon professions, (e) self-absorbed and continually talk about their own interests, (f) obsessive compulsive behaviors, (g) sensitive to sensory experiences to the point of pain, and (h) emotional and prone to experiencing panic attacks (Frith).

\section{Pervasive Developmental Disorder-Not Otherwise Specified}

When a child exhibits symptoms of autism but the characteristics for a specific PDD are not present, the child is diagnosed with pervasive developmental disorder -not otherwise specified [PDD-NOS] (APA, 2000). Specific symptoms of PDD-NOS are not presented in the DSM-IV-TR (APA). Literature defining primary characteristics of PDDNOS is difficult to find (Tidmarsh \& Volkmar, 2003). Consequently, clinicians become responsible for interpretation and diagnosis of symptoms, which has lead to exasperation for professionals and families (Tidmarsh \& Volkmar). Some PDD-NOS symptoms include: problems with communication, maladaptive behaviors, or a tic disorder (Sevin et al., 2007). PDD-NOS is considered to be the ASD most commonly diagnosed; however, it is researched less than other forms of ASD (Matson \& Boisjoli, 2007). 


\section{Childhood Disintegrative Disorder}

A child is diagnosed with childhood disintegrative disorder (CDD) when the child has at least two years of normal development and then noticeably regresses in more than one area of developmental performance (APA, 2000). One symptom of CDD is the worsening of the child's ability to speak, which may weaken to the point of the child not speaking at all. This symptom is a major feature that distinguishes CDD from autism (Sevin et al., 2007).

\section{Rett's Syndrome or Rett's Disorder}

Rett's syndrome is a developmental disability limited to females. The child will progress in a normal developmental pattern and then the child's development will regress (Einspieler, Kerr, \& Prechtl, 2005). During the first five months of life, the child's development appears to be normal. Beginning with the $6^{\text {th }}$ month and continuing through the $18^{\text {th }}$ month, the child's development will either slow down or stop. Then, regression begins. Definite regressions include: (a) head growth will slow down; (b) hand skills will be lost; (c) body movements are uncoordinated (Glaze, 2004; Kerr \& Prescott, 2005; Trevarthen \& Daniel, 2005); (d) stereotypical hand actions appear (Charman et al., 2002; Glaze; Kerr \& Prescott; Nomura, 2005); (e) social awareness disappears, and (f) serious trouble in communication and cognitive skills appear (APA, 2000). Other characteristics of Rett's syndrome include epilepsy, scoliosis, breathing irregularities, persistent constipation (Glaze; Kerr \& Prescott; Nomura), and difficulty in learning to crawl and walk (Segawa, 2005).

\section{Background of Autism}

The first clinical report on autism was written by Leo Kanner in 1943 at the Johns Hopkins School of Medicine when he described the behaviors of 11 boys who demonstrated a strong desire to be alone and an obsessive requirement for things to stay the same (Kanner, 1973). Kanner observed astounding memorization abilities among the children; however, the children had difficulty communicating with people. Kanner's simple description of behaviors of a child with autism include: (a) being unaware of another person's presence; (b) speaking by repeating words they just heard (parroting) or not speaking at all; (c) spending long periods of time lining up objects; or (d) remembering worthless facts accurately (Frith, 1996). Parents reported to Kanner that their children seemed to be in a world of their own (Kanner).

Kanner (1973) gives Bleuler the credit for coining the term "autism" in 1911. Kanner disagreed with Bleuler's definition of autism, but he could not think of a different term to use; therefore, the term autism remained (Kanner). The history of autism has evolved from a period when professionals blamed the behavior problems of the child on negative parenting (Sheehan, 2004). Professionals now understand that autism is not caused by poor parenting. 
Inheritance and environmental risk factors contribute to autism (Newschaffer, Fallin, \& Lee, 2002; Rodier \& Hyman, 1998). The molecular origin of autism is not known; however, studies of families and twins revealed that inheritance contributes significantly to autism (Bailey, et al., 1995; Spiker, et al., 1994). The genetics of autism consist of numerous loci and interaction of various genes (Risch et al., 1999). The most promising regions among the detected lico were found on chromosome 7q (Ashley-Koch et al., 1999; Buxbaum et al., 2001; Shao et al., 2002). Environmental factors identified as contributors to autism include intrauterine rubella (Chess, 1997), thalidomide taken during pregnancy (Zwaigenbau et al., 2002), and cytomegalovirus infection (Stubbs, Ash, \& Williams, 1984). The measles, mumps, and rubella vaccines have been blamed with causing autism; however, research has not determined any connection between the vaccines and autism (Dales, Hammer, \& Smith, 2001; Taylor et al., 2002).

Healthcare professionals remain for the most part untrained in the detection of autism (Pinto-Martin, Dunkle, Earls, Fliedner, \& Landes, 2005). Sand et al. (2005) reported that approximately $20 \%$ of healthcare providers use screening instruments for ASD in their practices. Pinto-Martin, Dunkle, et al. believe healthcare providers' scheduled time for yearly check-ups for children are too short and do not allow ample time for adequate screening. In addition to short schedule times, many insurance companies will not sufficiently fund these screenings to pay the providers. Another dilemma for healthcare providers today is their reluctance to make a diagnosis of ASD, especially with younger children. There remains the hope that the child is just slow in development and will catch-up; regardless, early diagnosis and early intervention are imperative for children with ASD and their families (Pinto-Martin, Dunkle, et al.).

\section{Implications for Nurses}

Nurses play a significant role in the care of the child with autism in each of the three specific areas of concern in this study: the child with autism, the parent who experiences stress and/or stress-related illness, and the family support network. The nurse may be involved either in a primary care setting such as a professional-care office (PintoMartin, Sauders, Giarelli, \& Levy, 2005), acute care settings such as hospitals, state or federal programs, or in educational settings as the school nurse. Therefore, nurses should be actively involved in the process of early diagnosis of autism and intervention. Nurses can play a valuable role by directing the family to behavioral services, specialists in autism, and therapists who are well versed in autistic spectrum disorders (Cade \& Tidwell, 2001). Nurse practitioners should listen and act upon parents' concerns about their child's communication limitations, play, and behavior problems by completing additional testing that could provide early diagnosis of autism. Parents expect nurse practitioners to be informed about interventions of therapy and treatment programs that are available for their child (Blackwell \& Niederhauser, 2003).

McGuinness (2007) identified particular ways nurses can assist children with ASD and their families. Nurses should read and become knowledgeable regarding the

behaviors and characteristics associated with ASD to better direct the family in the areas 
of treatment and family support. To guide families toward specific supports, nurses must know what resources are available in the immediate and surrounding areas. McGuinness advised against waiting to interview parents about specific concerns and issues related to their children with ASD; therefore, when possible, nurses should call before the initial appointment to ascertain information about the children before they arrive. Talking to parents before clinic arrival is more respectful to the children involved and to the parents, because information can be openly discussed without the children being present. All children with ASD do not communicate the same way; therefore, obtaining this information about the children ahead of appointment time can help alleviate potential problems. McGuinness stressed the need for nurses to be self-confident and controlled in a situation that might not be as calm as desired. Children might or might not be in a cooperative mood; therefore, nurses need to be prepared to take control and lead (McGuinness).

Graff et al. (2007) maintained that persons with intellectual and developmental disabilities deserve superior health care. Graff et al. emphasized the necessity of nurses participating in professional development activities that enhance their skills and understanding of intellectual and developmental disabilities. Nurses should assist patients and their families in taking full advantage of available support systems to enhance not only the patients' health and well-being but also the health of their families (Graff et al.).

\section{Conceptual Model}

A conceptual model or conceptual framework offers exclusive attention to the concepts characterizing the subject matter, provides focus to the exploration for significant questions about the phenomena of concern, and proposes clarification or answers to problems (Fawcett, 2005). This study utilized the post-crisis component of the Double ABCX Model of family behavior (McCubbin \& Patterson, 1983) to guide this descriptive, correlational, cross-sectional study among parents of children with ASD. The Double ABCX Model served as the conceptual framework for this study and provided the basis for variables studied (adaptive behaviors of children with ASD, family support networks, and parental stress and coping), study aims, and instruments chosen. Researchers have used the Double ABCX Model as a framework in studies of (a) parents of children with ASD and intellectual disabilities (White \& Hastings, 2004), (b) interventions conducted with parents of children with ASD in their homes (Hastings \& Johnson, 2001), (c) parental depression and the association of increased stress on parents of children with ASD (Benson, 2006), (d) the effects of support networks on maternal stress of children with ASD and intellectual disabilities (Weiss, 2002), and (e) adaptation of mothers as caregivers of children with Asperger syndrome (Pakenham, Samios, \& Sofronoff, 2005).

The objective of this study was to gain an understanding of parental views of adaptive behaviors of children with ASD, family support networks, parental stress, and parental coping. The four variables represented factors of the Double ABCX Model (McCubbin \& Patterson, 1983) displayed in Figure 1-1 by using instruments that were completed by parents or primary caregivers of children identified with ASD. In the 
current study, the researcher examined the Double $\mathrm{ABC}$ Factors and the coping concept of the Double ABCX Model. The "aA" Factor of the Double ABCX Model represented a "pile-up of stressors and strains" (McCubbin \& Patterson, p. 11). In this study, the "aA" Factor denoted the adaptive behaviors of the child with autism. The Vineland Adaptive Behavior Scales, Second Edition [Vineland-II] (Sparrow, Cicchetti, \& Balla, 2005) was used to measure the child's adaptive behaviors. The "bB" Factor of the Double ABCX Model represented resources presently used by the family and any new supports that may be added (McCubbin \& Patterson). The family support networks represented the "bB" Factor in the current study. Family support was measured by the completion of the Family Support Scale [FSS] (Dunst, Jenkins, \& Trivette, 1984) by each parent. The "cC" Factor of the Double ABCX Model represented the parent's view of the entire stressful condition (McCubbin \& Patterson). The Parenting Stress Index-Short Form [PSI-SF] (Abidin, 1995) was used to measure the parent's stress level. The coping concept of the Double ABCX Model represented a family's attempt to accomplish stability in their family (McCubbin \& Patterson). Parental coping was measured using the Coping Health Inventory for Parents [CHIP] (McCubbin, McCubbin, Nevin, \& Cauble, 1981).

\section{Definition of Terms}

Following are key terms used during this study:

- Autism Spectrum Disorders (ASD) - ASD are a component of a larger group of disorders named Pervasive Developmental Disorders (PDD). ASD includes: (a) Classic Autism, (b) Asperger's Syndrome (AS) or Asperger's Disorder (AD), (c) Pervasive Developmental Disorder-Not Otherwise Specified (PDD-NOS), (d) Childhood Disintegrative Disorder (CDD), and (e) Rett's Syndrome (APA, 2000). For purposes of this paper, the term ASD and the word autism are used synonymously or as reported by researchers describing their findings.

- Adaptive Behaviors - Adaptive behavior has been defined as the maturity and use of the skills necessary for the accomplishment of an individual's selfsufficiency and social competence (Sparrow et al., 2005). Adaptive behaviors of the children with ASD were evaluated by responses given by parents of the children on the Vineland-II (Sparrow et al.), a revision of the original Vineland Adaptive Behavior Scales [VABS] (Sparrow et al.).

- Coping - Coping means that an individual effectively controls stress and reduces distress, thereby improving his or her circumstances (Folkman, Lazarus, Gruen, \& DeLongis, 1986). Parental coping was measured in this study by the CHIP (McCubbin et al., 1981).

- Parent - For this study, the word parent denotes all respondents in the sample who were the biological, adaptive, foster, step-parent of the child with ASD

- Stress - Abidin (1995) described stress as excessive uneasiness and anxiety associated with being a parent and with parent-child relationships. Stress was 


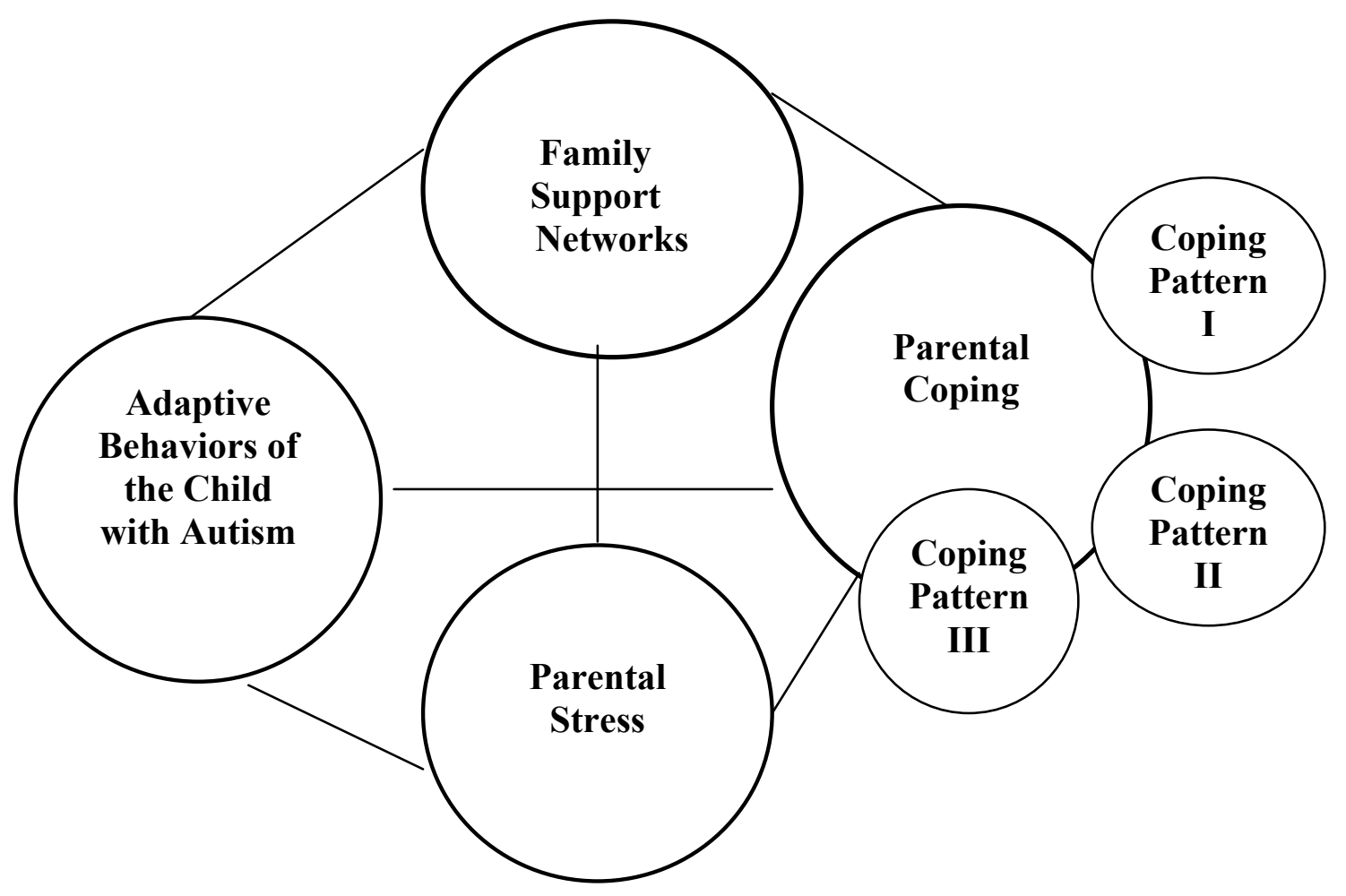

Figure 1-1. Conceptual Framework of Study Showing the Relationships among Adaptive Behaviors of a Child with ASD, Family Support Networks, Parental Stress, and Parental Coping 
measured in this study by the PSI-SF, a derivative of the Parenting Stress Index [PSI] (Abidin).

- Support Networks - Support networks are described as affectionate, rational, sensitive, real, effective, engaged, and useful assistance and aid (Dunst, Trivette $\&$ Hamby, 1994). Family support networks were measured in this study by the FSS (Dunst et al., 1984).

\section{Assumption}

After reviewing the literature, the following assumption related to parental stress was formulated: Parents raising a child diagnosed with autism with low or moderately low adaptive behaviors will experience greater stress than parents raising a child diagnosed with autism with moderately high or high adaptive behaviors.

\section{Potential Limitations}

Limitations of this study are:

(1) This research study contains data for children with ASD from Alabama, Mississippi, and Florida and therefore may not be relevant to children and families in other geographical locations.

(2) Purposive sampling, a non-probability sampling method, was used because the participants needed to have experience being a primary care provider or parent of a child diagnosed with autism. However, this method of sampling limits the ability to evaluate the distinctive characteristics of the participants (Polit \& Beck, 2008).

(3) The sample size $(\mathrm{N}=75)$ is small and therefore may not be representative. Cohen (1992) discussed the appropriate sample size needed to obtain a power of .80 and a medium effect size in behavioral sciences research. When using multiple regression analyses with three independent variables a sample of 76 is needed (Cohen). 


\section{CHAPTER 2. LITERATURE REVIEW}

Current research studies covering the conceptual framework components of the Double ABCX Model of family behavior (McCubbin \& Patterson, 1983) used in this study were discovered through a literature review of peer-reviewed journal articles, textbooks, and the World Wide Web. A short synopsis presents procedures and results for the studies that explored the following variables: (a) adaptive behaviors of children with ASD; (b) support networks used by families of children with ASD; (c) parental stress associated with raising a child with ASD; and (d) parental coping techniques used when raising a child with ASD. Though the literature review was thorough, the probability remains that the review is not exhaustive.

The researcher found hundreds of studies that have examined the four variables of the current study. Rector (2005) stated that one standard for a good literature review included concentration on current articles that provide the researcher with new, recent data; because current research incorporates and broadens earlier findings. Therefore, the literature review focused on research studies reported between 2001 and 2008 and included select earlier studies that examined the variables in the current study. Following a review of each of the above variables, a summary of the research is presented.

\section{Adaptive Behavior}

\section{Overview of Adaptive Behavior}

Literature supports the belief that children with autism have difficulties in three main areas: (a) socialization, (b) communication, and (c) behavior (Dyches et al., 2004). Adaptive behaviors consist of those skills that make an individual self-sufficient and socially competent (Sparrow et al., 2005). The severity of adaptive behavior symptoms is different with each child with autism, and these symptoms change as the child matures (Akshoomoff \& Stahmer, 2006). In 1991, Rodrigue, Morgan, \& Geffken found that adaptive behavior skill achievement for the child with autism was varied and unpredictable. Limitations in development of adaptive behaviors may result in maladaptive behaviors: (a) insistence on sameness (i.e., clothing, schedules, or food), (b) obsession with routines (i.e., memorizing schedules, washing hands, brushing teeth), (c) fascination with self-stimulating behaviors (i.e., hand-flapping, noise-making, stacking objects), or (d) inappropriate response to sounds, pain, touch, or light (Akshoomoff \& Stahmer).

Approximately $75 \%$ of children with autism are diagnosed with an intellectual disability (Akshoomoff \& Stahmer, 2006). However, it is not unusual for children with autism to perform poorly in certain academic subjects and perform at or above average in other areas. Another unusual feature is that children with autism may earn average or above average scores on standardized tests administered at school, but they may require 
special education services to help them perform successfully in their daily academic program (Akshoomoff \& Stahmer).

\section{Importance of Adaptive Functioning}

According to the Double ABCX Model of family behavior (McCubbin \& Patterson, 1983), one family member whose needs are excessive and continuous can cause a family to experience a "pile-up" (McCubbin \& Patterson, p. 11) of stress. Liss et al. (2001) maintained that evaluating adaptive performance permits more accurate determination of an individual's role in their everyday life and in their ability to meet everyday challenges. Because children with autism may one day find taking complete control of their lives a difficult or an impossible task, researchers stress that early evaluation of adaptive skills for this group of children is very important. As children age, the chances of assisting them to learn different ways to express themselves become more complicated; therefore, intervention must begin early. An individual's adaptive behavior score gives the evaluator data needed to make a determination if the individual requires continuous guardianship or if the individual has the capacity to take more control of everyday life. Because of the importance of adaptive functioning, there is a need for research on adaptive behaviors (Liss et al.).

The current study examined the adaptive behaviors of children with ASD, family support networks, parental stress, parental coping, and the relationships among these variables. A current literature review (2001-2008) was performed to investigate research conducted to explore the adaptive behaviors of children with ASD.

\section{Daily Living Skills}

If children are successful in mastering daily living skills, their ability to function successfully as adults also improves (Carothers \& Taylor, 2004). Adaptive behaviors consist of daily living skills (i.e., walking, speaking, and dressing). A child's ability to perform these adaptive behaviors assists in determining if the child is developing appropriately (Sparrow et al., 2005). Children with autism often find daily living skills difficult to master, and they are unable to perform these functions without assistance (Carothers \& Taylor). Daily living skills change as an individual ages; therefore, instruction must also change. In order for skills to be retained, children with autism must be taught repetitively by various instructors and in numerous settings so the children can understand the use of the skills throughout the different phases and events in their lives (Carothers \& Taylor).

Liss et al. (2001) examined the association between adaptive behaviors of two groups of nine-year-old children with autism: (a) 35 children with high-functioning autism compared with 31 children with Developmental Language Disorder, and (b) 40 children with low-functioning autism compared with 17 children with low IQ scores. Liss et al. concluded that the association between IQ and adaptive functioning in children with autism is greatest among low-functioning children; and maladaptive behaviors rather than 
IQ appear to interfere with adaptive functioning developments in the high-functioning children (Liss et al.). Fenton et al. (2003) corroborated these results with a study of 50 Italian children with autism to show that IQ and adaptive functioning are more clearly correlated in low-functioning children with autism than those children categorized as high-functioning. Liss et al. found that both groups of children with autism were notably worse than the control groups in socialization and daily living skills but not in communication.

An individual's executive function concerns the planning ability, motivation, time concept, and ability to shift attention (Gillberg, 2007). Gilotty, Kenworth, Sirian, Black, and Wagner (2002) conducted a study to explore the correlation between executive behaviors and adaptive behavior in 35 school-aged children with ASD. Gilotty et al. used two instruments to evaluate daily functioning: the Vineland Adaptive Behavior Scales Interview Edition (VABS) and the Behavior Rating Inventory of Executive Function. Results showed that limitations in executive functioning contribute to adaptive behavior problems in high-functioning children with ASD (Gilotty et al). Another study that used the VABS and examined executive functioning of high-functioning children with autism and AS (aged 5-17 years) found that the children's scores were too low to allow them to execute assignments successfully that required organization skills (Kenworthy et al., 2005).

\section{Communication Skills}

Kjelgaard and Tager-Flusberg (2001) emphasized that parents reported that speech and language problems were their first indications that their child could have autism. Parents described how the deficiencies in language skills caused them their greatest stress and encouraged them to seek medical help for their child (Gray, 1994). About $30 \%$ of children with autism acquire no language (Akshoomoff \& Stahmer, 2006). Children who do develop speech often develop: (a) non-communicative speech patterns, (b) barely any language, or (c) repetitive language. Children who do speak regularly use echolalia, the duplication of sounds they hear from other people's speech (Akshoomoff \& Stahmer).

Stone and Yoder (2001) studied issues connected to learning to use words to communicate between the ages of 2 and 4 for children diagnosed with autism before they reached the age of 3 . Researchers observed and studied playing, imitating and attending along with socioeconomic levels and any professionally delivered therapy they received in the areas of speech and language for 35 children ( 27 boys and 8 girls). Researchers found that those children with greater imitation abilities at the age of 2 and those who received greater amounts of professional speech or communication therapy before the age of 4 were the children who used language more successfully by the age of 4 (Stone \& Yoder).

Parents and professionals question whether children with autism continue to develop in the cognitive and language areas between preschool and adolescence. Sigman and McGovern (2005) collected data in a longitudinal study of 48 adolescents with 
autism to determine growth in their cognitive and language areas of development. Assessment of this data showed that between preschool and mid-elementary school, about one-third of the children made noticeable improvements. Yet, between midelementary school and adolescence, their cognitive and language abilities either remained about the same or weakened. Researchers found few adolescents who improved their IQ above 10 points, and none of the participants changed their level of intellectual disability (Sigman \& McGovern). McGovern and Sigman (2005) used data collected from the 48 adolescents (42 males and 6 females) with autism to make a determination concerning children having the ability to outgrow their autism diagnosis. Parents often report observing improvements in their children's signs of autism, adaptive functioning, and compassion for others, and parents wonder if their children no longer have autism. Researchers concluded that most adolescents diagnosed with autism as young children retained their diagnosis. Improvements that occurred during adolescence most often appeared in those adolescents diagnosed with high-functioning autism (McGovern \& Sigman).

\section{Socialization Skills}

Social limitations in children with autism influence social behaviors that result in significant differences in developmental evaluations and summaries (Klin, Volkmar, \& Sparrow, 1992; Volkmar, Carter, Sparrow, \& Cicchetti, 1993). Limitations in socialization skills in children with autism are often displayed in evasion of eye contact, inability to relate to peers, refusal to accept affection, preferring to play alone, and exhibiting inadequate ability to play (Akshoomoff \& Stahmer, 2006). Because of their specific characteristics, children with autism may prefer to play alone rather than play with other children - even when the other children are nearby and are of the same age group (Anderson, Moore, Godfrey, \& Fletcher-Flinn, 2004; Owen-DeSchryver, Carr, Cale, \& Blakeley-Smith, 2008). Anderson et al. videotaped five and one-half days of recess time for targeted, school-age children with autism to investigate their contacts and communications with typical peers and with adults. They found that the children with autism communicated verbally with adults approximately 67.8 times per hour compared to 6.8 times per hour with their peers, and in $85 \%$ of the adult communication, the adult made the first move. Anderson et al. concluded that children with autism communicated socially and playfully very differently from their peers. From data gathered, researchers also concluded that the teaching of children with autism to socialize with their peers by an untrained, paraprofessional employee needs to be reconsidered, because researchers did not find that the children with autism were receiving proper support (Anderson et al.).

Social interest for children with autism improves when imitation skills are enhanced (Heimann, Laberg, \& Nordøen, 2006). Twenty participants with autism who were either mute or almost mute, with a mean age of about 6.5 years and a mean developmental age of approximately 25 months, participated in a study to investigate this theory and found that imitation interaction could offer support for parents and children with autism to increase social interest like touching or looking at a person (Heimann et al.). Researchers reported that their results replicate findings of two prior studies (Escalona Field, Nadel, \& Lundy, 2002; Field, Field, Sanders, \& Nadel, 2001). 
Researchers have found that using peers as teachers of children with autism does increase social communications between not only the peer teachers but also other peers (Kamps et al., 2002; Owen-DeSchryver et al., 2008). DiSalvo and Oswald (2002) suggested that peer teachers be taught to start the interactions often with children of autism so these children have greater opportunities to be involved socially with others. Each appropriate interaction reinforces social communication; therefore, the more the children practice, the better they will become at communicating properly (DiSalvo \& Oswald). Parents vehemently reported that two of the most important needs of their children with autism were their social and communication skills; however, almost half of these parents reported that their children's schools did not spend a considerable amount of time teaching their children in these areas (Spann, Kohler, \& Soenksen, 2003).

\section{Motor Skills}

Another adaptive behavior skill is motor skill development (Sparrow et al., 2005). Although motor skill development is not regarded as a principal component in the diagnosis of children with ASD (Provost, Lopez, \& Heimerl, 2007), fundamental motor skill deficiencies appear in children with ASD (Dziuk et al., 2007). Early intervention resources are available for young children with at least a $25 \%$ delay in at least one developmental area, including motor skill development (Provost, Lopez, et al.). Therefore, Provost, Lopez, et al. encouraged including an assessment of motor skills when children receive other developmental assessments. Successful play time with peers for young children becomes an educational opportunity for the development of socialization skills, and the ability or inability to perform motor skills required to participate in the play may inhibit or strengthen children's socialization growth and development (Provost, Lopez, et al.). Physical and occupational therapy provided for children with autism could assist in early identification of motor skill deficiencies, provision of intervention procedures, and assessment of growth and development (Quinn \& Gordon, 2003).

Findings from past research showed how motor skill development for children with ASD has been determined to be an integral part of the children's adaptive behavior. Rinehart, Bellgrove, et al. (2006) conducted a study to determine whether motor irregularities are similar in children with autism and children with AS. Two groups of participants with a verbal IQ over 70 included: (a) Group 1 - 12 children (10 males; 2 females; mean age 8.1 years) with high functioning autism (HFA) and 12 control participants of similar age, sex, and IQ; (b) Group 2 - 12 children (10 males; 2 females; mean age of 12.0) with AS and 12 control participants matched by age, sex, and IQ. Researchers hypothesized that qualitative results would report differences between children with HFA and children with AS in motor planning, getting ready to move after being given a visual signal. Researchers also hypothesized that both groups of children would be able to perform motor executions required of them, but the children with HFA were predicted to execute their tasks inferior to the children with AS. Findings suggested that, as researchers hypothesized, children with HFA did perform with more problems in motor planning and motor execution than children with AS (Rinehart, Bellgrove, et al.). 
Rinehart, Tonge, et al. (2006) acknowledged that motor skills are not well understood as symptoms of autism. Rinehart, Tonge, et al. explored gait function of children diagnosed with autism. Researchers used the GAITRite Walkway to collect data from the children's preferred gait (normal walk) and tandem walking (walking along a straight line of white elastic laid down the center of a mat and connecting each end of the mat while alternating feet with each foot placed heel to toe to the other). Participants included two groups: (a) one group of 11 children ( 8 males; 3 females; mean age 5 years 10 months), and (2) group two of 11 children ( 8 males; 3 females; mean age 5 years 9 months) matched by age, weight, height, sex, and IQ to group one. The Clinical Stride Analyser was used to evaluate the participants' stride. Findings suggested dysfunction of the cerebellar portion of the brain; because the children with autism demonstrated more trouble with the tandem walk, diminished ability for stride consistency, span of stride, motor coordination, and motor smoothness (Rinehart, Tonge, et al.).

Provost, Heimerl, and Lopez (2007) compared gross motor (GM) and fine motor (FM) development in 19 children with ASD, and they also compared the findings for the children with ASD with 19 developmentally delayed (DD) children without ASD. Findings showed comparable GM and FM skill development for most of the children with ASD. With ASD and DD children matched by age, sex, and IQ, researchers found comparable GM and FM development for both groups. Researchers did not find that GM development was strong in children with ASD. Clinical implications included the suggestion for therapists to begin earlier intervention in both GM and FM development (Provost, Heimerl, et al.).

Children with autism exhibited limitations in motor skill development (Dziuk et al., 2007). Dziuk et al. conducted a study of 47 children with autism (43 males; 4 females; mean age 10 years 7 months) with high functioning autism (HFA) and a control group of 47 children without autism (41 males, 6 females, mean age 10 years 6 months) to examine dyspraxia and the possibility of a connection to the children's motor skill deficiencies. Sanger et al. (2006) defined praxis, apraxia, and developmental dyspraxia: (a) Praxis is defined as a child's ability to achieve a complicated motor skill when there is no explanation for a child's inability to accomplish an expected, age-appropriate, complicated motor skill; (b) Dyspraxia refers to a motor skill that the child has never learned; (c) Apraxia transpires when a child once performed a motor skill and subsequently loses the ability to execute the skill (Sanger et al.). In the study, children with ASD performed poorer praxis than the children without autism (Dziuk et al). Findings suggested that praxis functioning in children with autism were correlated with deficiencies in the developmental areas of social, communication, and behavior; therefore, dyspraxia could be a fundamental characteristic of autism or a sign of neurological problems (Dziuk et al.).

Provost, Lopez, et al. (2007) evaluated motor delay in children (age 21-41 months) with ASD and compared results to children without ASD. The children (42 males; 14 females) were assigned to one of three groups: ASD, developmental delay, or developmental problems with no motor delay. All children had gross motor problems, 
fine motor problems, or both gross and fine motor problems. Considerably more motor development problems were documented for both the children with ASD and the children with developmental delay than those children with developmental problems with no motor delay. Provost, Lopez, et al. found all of the children with ASD had motor skill problems that included gross motor problems, fine motor problems, or both gross and fine motor skill problems.

The literature review of adaptive behaviors of children with ASD revealed studies and findings covering various components of adaptive behaviors. Parents indicated that communication limitations alerted them that their child had some kind of developmental problem (Kjelgaard \& Tager-Flusberg, 2001). Researchers studied communication abilities of children with ASD and found that one way to assist very young children (younger than four) is to have them imitate appropriate sounds and speech (Stone \& Yoder, 2001). Even when parents thought their adolescents were cured of ASD because of their growth in the areas of communication and socialization, research suggested that this was not the case (McGovern \& Sigman, 2005). Peer teaching was found to be successful in helping children with ASD in the areas of socialization and communication (Di-Salvo \& Oswald, 2002). Development of motor skills may be correlated to children's socialization and communication development because of the necessity of certain motor skills in playing games with other children (Dziuk et al., 2007). Information is scarce concerning how adaptive behaviors may be altered or even improved (McGovern \& Sigman). Current research on adaptive behaviors of children with ASD suggested a variety of results. In the current study, low or moderately low adaptive behaviors of children with ASD were expected to increase parental stress. The current study used the Vineland-II (Sparrow et al., 2005) to measure adaptive behaviors of children with autism; and data were obtained through a semi-structured interview with each participant.

\section{Family Support Networks}

Another component of the conceptual framework included in the current study was family support networks. McCubbin and Patterson (1983) defined family resources as current supports that are used or supports that are available to the family. In addition, they maintained that social support is a very important resource to families, because those families with a social support network are a stronger unit in times of a crisis (McCubbin \& Patterson). Dunst, Trivette, and Hamby (1994) identified social support as resources offered in various ways by individuals or groups for children and families that receive the support in different ways. Dunst et al. believed that support can be demonstrative, expressive, psychological, or active. Support can be offered through talking or writing that is developed to provide help that can make a difference to the receiver (Dunst et al.).

Glidden and Schoolcraft (2007) described how researchers differentiate between different types of available support: (a) informal support, (b) formal support, (c) support sources within each support network, and (d) individuals who receive support. Informal support usually consists of the family unit, extended family, close friends, and people within these groups who offer support in the forms of listening, friendship, and respite 
care, among others. Formal support networks include professionals such as doctors, psychologists, social workers, and teachers. People or organizations that supply medical, mental, emotional, informational, encouragement and other types of assistance are also part of a formal support network (Glidden \& Schoolcraft).

\section{Informal Support}

Parents of children with autism need support to assist them emotionally and physically by providing continuing support and resources (Myers, Johnson, the Council on Children with Disabilities, 2007). The primary support team includes spouses, partners, neighbors, family, and friends who offer emotional and mental assistance. Myers et al. define informal support as consisting of parents of children with autism and local organizations that give instruction, guidance, respite care, social events, and other activities.

White and Hastings (2004) recruited 33 parents (31 mothers, 2 fathers) of 21 adolescents with severe intellectual disabilities (14 with autism; 5 with cerebral palsy; 2 with Down syndrome) to examine parental views about family support networks. Parents reported informal support as being very helpful. Parents documented less informal support availability during their child's adolescent years (White \& Hastings).

Parents of children with ASD can learn to develop and expand the nonverbal and verbal behaviors (Stahmer \& Gist, 2001) and to react to their children's proper behaviors (Delaney \& Kaiser, 2001; Hancock, Kaiser, \& Delaney, 2002). Parents have perfect opportunities to offer invaluable support to their families by learning and using in-home intervention strategies to teach their children with autism (Symon, 2005). Research suggested that parents can successfully implement behavioral, social, and communication interventions for their children (Hancock et al.). Symon investigated an intervention education program where families were taught specific skills to improve their children's social communication skills. This strategy, the Pivotal Response Training technique, placed parents in both a teacher's and trainer's role. Once the parents learned the program, they were to teach someone else, the primary caregiver of the child, the technique. The parents were then expected to teach others in their communities who needed the same kind of help with their children with autism. The primary aim of this intervention was for parents to recognize how they could use the support strategy in their homes with their children. Use of this strategy was successful, and children's behaviors and their socialization improved (Symon).

Parents have preferences as to the kinds of social support that is important to them (Keller \& Honig, 2004). Keller and Honig explored the association between social support and parental stress when raising a child with autism. Seventy-five parents agreed to participate in Keller and Honig's study. Results showed there was no difference between mothers' and fathers' responses about the successfulness of social support or the kinds of resources they preferred. Researchers concluded that social support networks should (a) persuade relatives (e.g., grandparents) to offer more assistance, (b) furnish 
more support to parents of children with autism or other disabilities, (c) insist on supporting entire families, and (d) help parents learn strategies to cope with the build-up of stressors (Keller \& Honig). Bromley, Hare, Davison, and Emerson (2004) interviewed 68 mothers of children with autism to examine satisfaction with informal support. Findings suggested that when the family received low levels of informal support the child's behavior problems were higher (Bromley et al.). Families of children with autism also reported higher levels of stress when they received less informal support (Preece \& Jordan, 2007).

\section{Formal Support}

Professionals involved with children with autism and their families should refer the families to support networks, and some organization must accept the responsibility of providing support services to areas where families currently have access to few or no supports (Mandell \& Salzer, 2007). Myers et al. (2007) defined formal support as support services that are funded by the state (i.e., early intervention, special education, vocational services, residential and living services, respite care) and by the federal government (i.e., Medicaid, Supplementary Security Income benefits). There remains a discrepancy in services provided throughout a state and even in communities. In rural areas clients may have access to very few services, and they may be required to place their names on waiting lists to obtain services (Myers et al.).

Mandell and Salzer (2007) surveyed 1005 caregivers of children with autism in Pennsylvania to determine what common issues families participating in support groups had in common. They found participating caregivers to be those who had been advised by the professional who diagnosed the autism and parents of children with specific problem areas: (a) self-injury, (b) sleep, and (c) language. The results suggested the following:

- Participants desire support.

- Families want more than professional support.

- Peer support for families is important.

- Lower socioeconomic families are underrepresented.

- African American families are underrepresented.

- Support group availability should be increased (Mandell \& Salzer).

More attention needs to be channeled toward investigating parents' psychological needs because of the enormous challenges in their daily lives (Blackledge \& Hayes, 2006). Blackledge and Hayes studied the Acceptance and Commitment Therapy (ACT) with 20 parents to determine how this support might assist parents with coping and adaptation strategies as they raise their children with autism. Blackledge and Hayes declared their belief in parents' reports of extreme difficulties and challenges. The ACT support program accepted the parents' challenging reports, and accentuated the necessity 
of parents' acknowledging their surly feelings and working to overcome them by setting goals for themselves. These researchers maintained that current interventions available for families offered little difference than those from 20 years ago, because the mental and emotional needs of parents continue to be disregarded. Support and intervention programs that train parents were available; however, these programs trained parents to deal with and teach their children with autism and not how to cope with their own needs (Blackledge \& Hayes).

Parents' viewpoints about their needs and their desire to know if supports are available to meet their needs are important (Siklos \& Kerns, 2006). Siklos and Kerns performed a study in British Columbia between parents of children with autism and parents of children with Down syndrome to examine needs of parents and their feelings about supports currently available to them. Parents of children with autism conveyed more aggravation (i.e., stress, annoyance, irritation) from available social supports. Ninethree percent of parents of children with autism informed researchers they were not receiving enough money to pay for their children's treatment programs. These parents won a lawsuit that required the government to provide early intervention for their children with autism (Siklos \& Kerns). Findings in a study of symptoms of children with autism and parental stress reported no association between formal, professional support, and parental happiness (White \& Hastings, 2004).

\section{School Support}

Schools provided the largest portion of services for children with autism (Montes $\&$ Halterman, 2006). Montes and Halterman performed an analysis from the 2001 National Household Education Survey Before and After School Survey of 9583 children with parent-reported autism. They found a limited number of children with autism attending any after school program or activities. Parents reported that teachers were much better at contacting them concerning behavior problems of the children than they were in communicating with parents about poor academics, even though most of the children performed poorly (Montes \& Halterman). Gillberg (2007) reported that educational personnel find that many children with autism are bullied, and he recommended that these children receive their education in a classroom specifically designed for children with autism.

Carothers and Taylor (2004) insisted that it was imperative for schools and parents to cooperate and collaborate to reinforce appropriate adaptive functioning at the different stages of the children's development. Sivberg (2002b) stated that families' stress levels are elevated when proper special education classes and activities are not provided for the child with autism. Other researchers proposed collaboration with parents and the engagement of them as involved partners in the educational processes (Bailey, 2001; McConnell, 2001) as well as in the promotion of increasing community support programs (Hieneman \& Dunlap, 2001).

When parents are involved in the formal support processes and are informed of 
accessible services, parents report a higher degree of satisfaction with the value of the supports and education their children with ASD are receiving (Benson, Karlof, \& Siperstein, 2008; Renty \& Roeyers, 2006). Renty and Roeyers recruited 244 parents of children with ASD in Flanders, Belgium. The researchers found parents who reported dissatisfaction in the testing procedures, support and learning experiences that were offered to their children in regular classrooms and with the autism service provided for their children. However, parents were pleased with autism support and the related learning experiences provided for the parents. Consultations with parents showed that parents emphasized collaboration with professionals, stability of employees working with the children with ASD, professional dedication and interest, and professionals understanding children with ASD (Renty \& Roeyers).

\section{Unconventional Support}

Unconventional treatments are plentiful partially because there is no cure for autism (Blackwell \& Niederhauser, 2003). Professionals have expressed their uneasiness about parents becoming too dependent on support networks other than those provided by established medicine and reduce their confidence in supports, resources, and treatments that are scientifically proven (Levy, Mandell, Merhar, Ittenbach, \& Pinto-Martin, 2003). Parents must be informed about some of the offered resources being neither scientific nor beneficial (Gillberg, 2007). Research data suggested that there is no specific support or intervention that meets all the needs of parents of a child with autism (Gillberg).

Parents need to be warned about support networks that promise a miracle cure for their children with autism (Akshoomoff \& Stahmer, 2006). Desperate parents have often searched for alternative therapies that offered exceptional results, because the parents wanted to believe that their child can be cured (Blackwell \& Niederhauser, 2003). Many treatment resources that were offered do not have an evidence base; yet, these resources have been offered as supports and treatments continually. Parents must be warned to be careful of widespread media reporting and praises given to untested approaches that claim to support parents and children with ASD (Akshoomoff \& Stahmer).

Parents should ask questions before beginning any program (Blackwell \& Niederhauser, 2003). Questions that would help parents make an informed decision concerning participation in a treatment plan may include (a) What are the chances the treatment could harm the child? (b) If the treatment is unsuccessful, how will the child and the family be affected? (c) Has this program been scientifically evaluated? (d) Are there definitive evaluation measures available? (e) Does this program appropriately join together with the program the child is currently involved in? (Blackwell \& Niederhauser). Professionals and families are advised to move forward carefully when investigating treatments or approaches that offer not only support to families but a guarantee of curing children with autism (Akshoomoff \& Stahmer, 2006). 


\section{Discrepancy in Support Availability}

Researchers have confirmed parents' claims that there is a difference between available resources and supports in many parts of the country (Akshoomoff \& Stahmer, 2006). All families are not the same and all children with autism are not the same; therefore, individualization of services should be a priority. Children and families entitled to resources and supports should have accessible, appropriate, and high quality programs. Akshoomoff and Stahmer discovered that families who seek additional supports are those with sufficient personal funds to pay for privately funded therapies to strengthen the support. Higher educated parents or parents who understand their legal rights often resort to the courts to assist them in receiving proper resources and support for their children with autism and their families (Akshoomoff \& Stahmer).

Akshoomoff and Stahmer (2006) found that families often do not get the same kind or the same quality of resources or supports even when the families live in the same state or the same county within a state. They found that parents with limited skills or money are unlikely to be recipients of adequate services for their families. Resources and supports that are available to many families do not offer services to adequately attend to their needs (Symon, 2001). Mandell and Novak (2005) maintained that cultural diversities often dictate what supports and treatments parents will actually accept for their children and their families. Mandell, Listerud, Levy, and Pinto-Martin (2002) also discovered inequality of support services available for different ethnic groups. Regardless of diversities among ethnic groups, family support networks and providers have a responsibility to verify that children with ASD and their families are being given the best support available (Lessenberry \& Rehfeldt, 2004).

\section{Cost of Services}

An investigation in the United Kingdom showed the social support costs for the 6,310 children with autism and their families receiving services through the English department of social services varied (Bebbington \& Beecham, 2007). Researchers defended the variations in spending because all families do not require the same services; therefore, they offered their explanation of the cost variance. Administrators should be able to justify supports made available to families by providing sufficient answers in three primary areas:

- Meeting all social care requirements for all children with autism.

- Supplying or expanding respite care and placement services.

- Providing or improving support and resources for families providing at-home support for their children (Bebbington \& Beecham). 


\section{In-Home Training for Fathers}

Researchers found fathers to be receptive to support for in-home training to help them learn to interact successfully with their children with autism (Elder, Valcante, Won, \& Zylis, 2003). These researchers included four multicultural fathers to participate in an in-home teaching support program to instruct fathers in the procedures and techniques to promote and preserve father-child communications. Fathers showed great interest in discovering how to determine the activities their children found appealing. Another benefit for the fathers was their learning to react more effectively to their children's conduct. Researchers observed less stress in the families as fathers became more involved in the activities of the child with autism. Elder, Valcante, Won, et al. recommended that support networks cooperate with mothers' attempts to persuade fathers to participate in intervention processes and in their children's lives. The primary goal of interventions for fathers should be to support the fathers in becoming more self-assured as they interact with their children and as they learn that they can be successful caregivers (Elder, Valcante, Won, et al.).

Elder, Valcante, Yarandi, White, and Elder (2005) used an in-home training program for fathers of children with autism to improve the fathers' understanding of how these children communicate. The program provided fathers with opportunity to make a difference in their children's communication development by responding to the children's attempts to communicate. These researchers led a father training support program for 18 fathers of children with autism. Results showed that fathers successfully executed the program, and their children with autism did improve their communication abilities. Elder, Valcante, Yarandi, et al. reported significant improvements in communication between the fathers and their children with autism: (a) Fathers communicated with their children by imitating the children; and (b) Children initiated communication with their fathers. Other significant improvements were noted in the areas of fathers reacting to the children and the number of vocalizations actually made by the children. Researchers concluded that assessment of father-child communications and in-home instruction of fathers are valuable and should be continued (Elder, Valcante, Yarandi, et al.).

Literature reviewed offered perspectives in several aspects of availability and adequacy of family support networks for families of children with ASD. The literature suggested that demand for family support services continue to rise and that support services available often do not meet the needs of parents of children with ASD (Symon, 2001); therefore there is a need to increase appropriate services to this population (Hieneman \& Dunlap, 2001; Symon). To keep the best interest of the child paramount and to directly involve parents in the intervention programs for their child, schools and parents need to cooperate and collaborate (Bailey, 2001; McConnell, 2001). Research suggested that services are not always provided at the same levels for all communities, and those services that are available in some communities do not meet the needs of the families of children with ASD (Akshoomoff \& Stahmer, 2006; Mandell et al., 2002). The literature review revealed that mothers are involved in research more often than fathers. However, studies including fathers along with mothers and fathers alone confirmed that fathers will participate in research. Research data verified that fathers will accept and 
participate in formal support services that are patterned especially for their needs (Elder, Valcant, White, et al., 2005; Elder, Valcante, Won, et al., 2003).

Symon (2005) stressed the necessity of increasing and spreading resources and support networks to effectively assist with the rising needs of parents, caregivers, and children with autism. Parents and other family members should be included in the intervention support plans, because their inclusion has been noted as an important component in the development of successful programs to support the children and their families (Symon). The current study examined the relationship of family support networks with adaptive behaviors of children with ASD, parental stress, and parental coping. The FSS (Dunst et al., 1984) was administered to each participant to measure current family supports.

\section{Parental Stress}

Parental viewpoint of the crisis situation and the stressor or stressors causing the crisis are important factors of the conceptual framework of the Double ABCX Model and of the current study (McCubbin \& Patterson, 1983). The current study examined the stress levels of parents raising children with ASD. Akshoomoff and Stahmer (2006) discussed how communication problems for children with autism are complex and are often combined with other complications (i.e., fits of temper, specific clothes obsession, need for sameness, defiance, sleeping problems, phobia of crowded places). Some parents reported their inability to leave home with their children to shop or to have dinner with family or friends. Parents documented their children's behaviors were unpredictable. Difficult behaviors not only occur at home but also in public places. Therefore, parents who have been victims of their children's unacceptable behaviors did find themselves staying home more often (Akshoomoff \& Stahmer). Mothers admitted that their stress levels were increased when their child with autism embarrassed them with their unreasonable crying, giggling, or peculiar behaviors (Konstantareas \& Homatidis, 1989). Fathers claimed that their child's inability to communicate or talk at all was their greatest stressor (Konstantareas \& Homatidis). Parents have lost friends who just stopped visiting, because they could no longer tolerate the children's behaviors. There is also the possibility of the children running away, so children with autism must be supervised very closely (Akshoomoff \& Stahmer).

Besides the children's behaviors and the related stresses, parents reported that one of their first and primary problems was the great amount of effort that is sometimes required just to get a proper diagnosis of autism for their children and then to locate an intervention or treatment program that is both adequate and accessible for the children and for the families (Sivberg, 2002b). Many services the children received required payments directly from parents causing a financial burden for many families. Therefore, autism affects families not individuals (Akshoomoff \& Stahmer, 2006).

Data from studies indicated a positive connection between symptoms of autism and parental stress (Hastings \& Johnson, 2001). Researchers have found adaptive 
behaviors to be associated with parental stress (Plant \& Sanders, 2007; Szatmari, Archer, Fisman, \& Streiner, 1994; Tomanik et al., 2004). Other researchers have found no significance between adaptive behaviors and maternal stress (Bromley et al., 2004; Lecavalier, Leone, \& Wiltz, 2006). Hastings, Kovshoff, Ward, et al. (2005) found no significance between adaptive behaviors and paternal stress. Research showed that families of children with autism are exposed to stress from: (a) within the family; (b) a lack of appropriate services; (c) a lack of special education classes; and (d) a lack of knowledge among health and social services providers (Sivberg, 2002b). Studies revealed that not all family experiences with children diagnosed with autism are negative (Marcus, Kunce, \& Schopler, 2005; Olsson \& Hwang, 2002; Tobing \& Glenwick, 2002). These researchers found parents who report such satisfaction and happiness when their child successfully completed a challenging event. Parents reported that their own lives have been enriched, and they have been able to develop compassion for other people and other families (Marcus et al.; Olsson \& Hwang; Tobing \& Glenwick).

Fifty-eight parents (39 mothers; 19 fathers) participated in a study conducted by Dunn, Burbine, Bowers, and Tantleff-Dunn (2001) to examine the association between stressors, social support, locus of control, coping styles, and negative outcomes with parents of children with autism. Participants were $81 \%$ Caucasian, $8 \%$ African-American, $8 \%$ Hispanic, and the remainder was listed as other. Findings indicated that when social support decreased, parental stress levels were related to parental isolation. These researchers concluded that social support and positive coping techniques can diminish stress levels. Therefore, in times of increased stress, parents need to seek social support (Dunn et al.).

Studies presented inconsistencies about which parent experiences more stress; therefore, when parental stress is presented as a variable in a study, both mothers and fathers should be included (Baker-Ericzen, Brookman-Frazee, \& Stahmer, 2005). BakerEriczen et al. conducted a study to assess parental stress levels after their toddlers with autism attended a special school of instruction. Neither the mothers nor the fathers recognized any changes in their own stress levels. Baker-Ericzen et al. concluded: (a) that parents should participate in behavior interventions with their children, and (b) that both parents' stress levels should be evaluated when their child has autism (Baker-Ericzen et al.).

Regardless of which parent exhibited the highest level of stress, health care providers must be aware that parental stress is an important factor in the life of a child with a disability (Fombonne et al., 2001; Hastings \& Johnson, 2001; Lessenberry \& Rehfeldt, 2004; Plant \& Sanders, 2007; Tomanik et al., 2004). The child with autism depends on parents for love, support, care, and help; therefore, even though lessening parents' stress and anger may be difficult, it is necessary (Freeman \& Cronin, 2002). Many parents felt that not only have they been overlooked by professionals but they also are held responsible by many people for the inappropriate socialization, communication, and behavioral actions of their child with autism. To assist parents with their responsibilities to the child, professionals found themselves helping parents deal with their own distress and acknowledgment that their child has autism (Freeman \& Cronin). 
Hastings and Johnson (2001) explored stress in 141 biological parents (130 mothers; 11 fathers) in the United Kingdom (UK) who were members of the Parents for the Early Intervention of Autism in Children organization (at family expense) and were participating in a demanding behavioral intervention in their homes for their children with autism (mean age of children $4.98 ; 89.4 \%$ males). Researchers found their respondents to be highly educated and in most families both parents were employed outside the home and probably do not represent the majority of families with children with autism in the UK. Parents reported higher levels of stress, if the family had been involved in the program for a long time. Parents reported higher levels of stress, if the family started the intervention late in the child's life. Findings showed that adaptive coping, informal support, and trust in the benefits of the interventions were significant in lowering stress; and higher levels of autistic symptoms were significant in higher stress levels (Hastings \& Johnson).

Eighteen mother and father couples of children with autism consented to participate in a study to examine their stress levels (Hastings, 2003a). The 18 children were enrolled in special schools for children with autism and a high percentage of them did not live with their parents daily ( 8 lived at home full-time). Hastings requested parents complete self-report instruments to evaluate their stress levels. Mothers showed higher levels of anxiety. There was no evidence of a relationship between the mothers' well-being and the behavior problems of the child with autism having any affect on the fathers' stress. On the other hand, the mothers' stress level was positively correlated with the behavior problems of the child and the fathers' well-being symptoms. Hastings found a significant correlation between mothers' and fathers' stress possibly because of: (a) the children's adaptive behavior skills, (b) the demanding care schedule for the child; or (c) the little social support received by the family except by family members (Hastings). Results of research completed by Lecavalier et al. (2006) corroborated findings of Hastings that behavior problems of the child with autism are associated with stress; however, their results did not find that the child's adaptive behavior skills were significant to caregiver stress (Lecavalier et al.).

Researchers advised that parental stress may not only be caused by difficulties with the child with autism but also by the well-being of the spouse (Hastings, 2003a; Hastings, Kovshoff, Brown, et al., 2005). Hastings, Kovshoff, Brown, et al. studied parents of pre-school children diagnosed with autism concerning their stress and mental health and their description of their children. Ninety-six parents participated with 82 of the parents representing a couple (mother and father). Researchers included quantitative data about the child's behavior problems, signs of autism, and adaptive behaviors. Results indicated that the child's behavior problems have more influence on mothers than fathers. Both mothers and fathers of children with autism are affected by their spouse's stress level. Mothers and fathers reported similar stress levels (Hastings, Kovshoff, Brown, et al.).

Researchers acknowledged that the level of care involved in the daily lives of children with autism is a significant source of stress for mothers (Duarte, Bordin, Yazigi, \& Mooney, 2005). Recognition of the specific causes of maternal stress could be the first 
step in assisting mothers and indirectly helping the children. Duarte et al. enrolled 31 mothers from 3 out-patient mental health treatment centers (mean age: 32.9 years; mean education 6.6 years) of children (mean age: 6.8 years; 29 boys, 2 girls) with autism and a control group of 31 mothers with similar demographics with children without autism. Fifty-one percent of these children were identified with severe autism. The children did not speak and showed noticeable weakness in social communication. Mothering children with autism was identified as the primary cause of the mothers' stress as evidenced by: (a) very little, if any, love or friendliness conveyed by the child toward the mother, (b) the child's limited or lack of awareness of other people, and (c) an older mother caring for or mothering a young child (Duarte et al.).

Tomanik, Harris, and Hawkins (2004) conveyed results from mothers who described their greatest stressors as being specific inadequacies in adaptive behavior functioning of the child with autism: (a) short-tempered, (b) lazy, (c) unsocial, (d) agitated, or (e) disobedient. Three other areas of limitations of the child with autism that increased mother's stress included: (a) inability to talk with other people, (b) requiring assistance with dressing or other areas of self care, or (c) dependence on mothers for personal hygiene situations. Repetitive behaviors or problems with unacceptable, inappropriate language did not prove to be significant to the mothers' stress levels (Tomanik et al.).

Hastings, Kovshoff, Ward, et al. (2005) used data to focus on associations between children with autism, partners, and parents. Participants included 41 mother and father couples of 48 pre-school children with autism. Assessment of the mothers' data, showed a significant, positive correlation with the mothers' reported stress level and their children's autistic symptoms. Fathers' reports showed a positive correlation between their children's maladaptive behaviors and their own stress. However, researchers analyzed children's adaptive behaviors and parent well-being and reported no significant correlations. Researchers concluded from self-reported data that the behavior difficulties of the children with autism showed a positive presumption of mothers' stress; and the behavior difficulties of the children with autism did not show an association with fathers' stress (Hastings, Kovshoff, Ward, et al.). These results replicated findings of previous research that maternal stress levels are reportedly higher than paternal stress levels in the same families of children with autism (Hastings, 2003a; Hastings \& Brown, 2002).

Data indicated high levels of stress and aggravation of parents and primary caregivers of children with autism (Schieve, Blumberg, Rice, Visser, \& Boyle, 2007). These researchers chose children ages 4 to 17 years (78,305 children) with no missing data on autism or special health care needs from the 2003 National Survey of Children's Health in the study. Researchers interviewed either a parent or a primary caregiver of these children. Schieve et al. reported these parents or primary caregivers demonstrated higher aggravation levels than: (a) aggravation levels detected for parents of children with developmental disorders but without autism, and (b) aggravation levels detected for parents of children with no unusual health care requirements. Researchers determined that parents of children recently involved in some type of assistance program reported less aggravation. Results led researchers to conclude that exceptional types of stress and 
levels of stressors present themselves to parents and primary caregivers of children with autism; therefore, parents and caregivers could benefit from services provided in a support center that is family-focused (Schieve et al.).

An urban area of Poland was the geographical location of a study to compare the levels of stress in mothers of children with autism and the levels of stress in mothers of children with Down's syndrome (Pisula, 2007). Participants included 50 mothers (25 mothers of children with autism, and 25 mothers of children with Down's syndrome). Pisula found that mothers of children diagnosed with autism exhibited greater stress in 7 of 15 scales on an instrument. When compared to responses given by mothers of children with Down's syndrome, the mothers of children with autism: (a) rated their children as needing more assistance; (b) stressed their belief that they were not getting as much support; (c) claimed their children's physical problems were more demanding on them; (d) saw a need for more resources for the child; (e) maintained their children were weaker in the areas of personality development and learning ability; (f) insisted their families were given fewer chances at employment, education, and individual development; and (g) appeared to be more easily hurt by community viewpoints. One of the primary stressors expressed by the mothers of the children with autism was the lack of promise for their children's futures and the knowledge that there is no cure for autism. Pisula concluded that one reason mothers of children with autism are under so much stress is the lack of resources, to include special education services for the children (Pisula).

Bishop, Richler, Cain, and Lord (2007) established that African American mothers $(\mathrm{N}=110)$ of children (ages 8-10) with autism reported having less perceived negativity because their child was diagnosed with autism than White mothers even though the African American children had poorer adaptive behaviors. Trute and HiebertMurphy (2005) defined perceived negativity as those attitudes and beliefs associated with parental stress that can show a direct association with parent stress over a period of time. Blacher and McIntyre (2006) found comparable results among Latino mothers of children with autism and other developmental disabilities. The Latino mothers, like the African American mothers, reported their children had a more positive effect on their lives than the Caucasian mothers. Blacher and McIntyre suggested that cultural differences may have some bearing on parents' views about raising a child with ASD (Blacher \& McIntyre).

Although the literature reviewed suggests that parents of children with ASD experienced increased stress, there are discrepancies in findings about whether limitations in child adaptive behaviors increase parental stress (Bromley et al., 2004; Hassall et al., 2005; Lecavalier et al., 2006; Plant \& Sanders, 2007; Tomanik et al., 2004). The amount of time required to receive an ASD diagnosis and the subsequent location of appropriate intervention programming increase parental stress (Sivberg, 2002b). The daily schedule for a child with ASD is demanding, and if parents receive little support other than their family, their stress levels may increase (Duarte et al., 2005). A problem in the spouse's happiness and well-being is another source of stress for parents (Hastings, 2003a; Hastings, Kovshoff, Brown, et al., 2005). Professionals need to take into consideration the stress levels and well-being of both parents, because there is no consensus as to which 
parent is more stressed (Baker-Ericzen et al., 2005). Parents often feel that they receive no concern from professionals and that many people in their family and in the community blame them for their child's limits in adaptive behaviors (Freeman \& Cronin, 2002). Using positive coping techniques, receiving informal support, and believing in the intervention program for the child could reduce parental stress (Hastings \& Johnson, 2001). Families of children with autism experienced a higher stress level than families of children with typical development (Fombonne, Simmons, Ford, Meltzer, \& Goodman, 2001), and families of children with other disabilities (Fombonne et al.). In the current study, the relationship between adaptive behaviors of children with ASD, family support networks, parental stress, and parental coping were examined. Parents' stress was assessed by administering the PSI-SF (Abidin, 1995).

\section{Parental Coping}

Parental coping is the fourth component of the conceptual framework of this study. When family support networks, parents' views of the families' circumstances, and adaptive functioning are combined within families, the families' coping strategies become the channels which help families bring stability to their family units (McCubbin \& Patterson, 1983). Hastings, Kovshoff, Brown, et al. (2005) and Pakenham et al. (2005) maintain the need for research that concentrates on parental coping and parental stress in homes where a child has been diagnosed with autism. A literature review of current research suggests how parents strive to cope as they raise their children with autism.

Parental coping with autism is complex, because children with autism have problems with communication and socialization (Gupta \& Singhal, 2005). Parents are often deprived of opportunities to enjoy the pleasures of parenting a child, because children with autism frequently have difficulty in demonstrating love or fondness toward others (Gupta \& Singhal). Tunali and Power (2002) agreed and added that one of life's greatest tests is when people find themselves in situations with which they have no control. When parents hear the diagnosis of autism, they come into one of these complex situations they cannot control; therefore, coping becomes a demand (Hastings, Kovshoff, Brown, et al., 2005). This literature review offered data exploring current research on coping when both mothers and fathers were included in the results.

Dunn et al. (2001) recruited 58 participants (39 mothers and 19 fathers), parents of children with autism, from southeastern Florida to study the association between stressors, support, locus of control, eight coping styles, and negative outcomes for these parents. They determined that parents need additional support during elevated stressful periods. Coping and particular coping styles were found to be important in reducing stressful times for parents. Researchers concluded that when parents used escapeavoidance as a coping technique to reduce stress (i.e., expecting a miracle, using drugs or food, and staying away from people), they only intensified their despair, misery, loneliness, and problems with their spouse. Therefore, parents should be discouraged from using this coping technique (Dunn et al.). 
Parents of children with autism need practical, ongoing support (Sivberg, 2002a). Sivberg (2002a) took his study to the southern area of Sweden where he investigated the association between parenting techniques and how parents coped with problems they encountered while raising a child with autism. He recruited 66 parents of children with autism and a control group of 66 parents of children without autism. Sivberg (2002a) concluded that parents of children with autism do not receive daily support to help them cope. In a resulting analysis of data, Sivberg (2002b) found the families of children with autism to exhibit a greater level of strain than the control group families. He also revealed that parents of children with autism used the distancing and escaping coping technique more often than the use of self-control or support networks for assistance. He concluded that parents need help in learning and using positive coping strategies (Sivberg, 2002b). Hastings, Allen, McDermott, and Still (2002) suggested a positive outlook in parents of children with a disability could have an influence on the supports received by the family.

Mothers of children with autism who declared a high level of satisfaction with their lives possessed definite coping strategies (Tunali \& Power, 2002). Tunali and Power gave 58 mothers ( 29 with and 29 without children of autism) an opportunity to explain their coping strategies that helped them find satisfaction in their daily lives. Mothers shared the following positive ways of coping: (a) They placed less weight on career and more importance on being a full-time homemaker; however, some of them did work. (b) Most of their free time was with extended family members, and they reported as much satisfaction with free time as mothers without children with autism. (c) They did not worry about what other people thought about their children's behaviors. (d) When they talked about marriage, they spoke of parental responsibilities; and they recognized their spouse as being their greatest supporter. (e) The mothers admitted their children's behaviors were confusing and difficult to understand. (f) They ranked higher in their patience with uncertainness than the mothers who did not have children with autism (Tunali \& Power).

Gray (2003) found many differences in the expectations of mothers and fathers and variations in coping strategies of both parents. Mothers who worked outside the home often missed work because of problems related to their children's autism. Many working mothers had to accept part-time jobs. Mothers who desired to hold positions outside the home resented not being able to accept employment. Gray maintained that mothers were expected to accept responsibility for their children's behaviors not only from non-family members but also from their husbands. On the other hand, fathers of children with autism claim that even though they realize the children's behaviors cause problems in the home, the fathers did not attribute any distress to their children's behavior. Fathers disclosed that their biggest coping dilemmas come from dealing with their wives' stresses that were caused by the children's behaviors. Fathers described their normal coping strategy as being their ability to work outside the home, thereby fulfilling their responsibility to their children with autism. Many fathers expressed that they possess the ability to restrain or conceal their emotions; however, fathers did admit that this strategy often led them to lose their temper (Gray). Based on his research, David Gray (1994) suggested that the two most important resources for parents coping with children with autism were support from family members and professional resources. 
Positive reframing, using a positive thought or action to take the place of negative situations, earned praise as being a successful coping strategy for parents under extreme burdens and anxieties raising a child with autism (Hastings, Kovshoff, Brown, et al., 2005). Researchers conducted a study in the United Kingdom that included two sets of participants: (a) parents of preschool children with autism (89 parents: 48 mothers and 41 fathers), and (b) parents of children with autism enrolled in school (46 parents: 26 mothers and 20 fathers). Parents completed questionnaires revealing their coping techniques. Mothers and fathers using active avoidance as a coping strategy were more stressed and unhappy. Positive thinking and positive coping resulted in less sadness and feelings of hopelessness for both mothers and fathers. Religion, combined with denial, worsened parents' well-being; it did not prove to be a positive coping strategy in this study. Mothers used problem-focused and emotion-focused coping more often than fathers. Researchers could not determine that the child's age caused parents to cope differently (Hastings, Kovshoff, Brown, et al.).

Luther, Canham, and Cureton (2005) found most studies about coping techniques reported parents of children with autism used social support as their coping strategy and did not provide much information about the parental coping techniques. Therefore, Luther et al. studied the coping strategies of 18 parents of children with autism (ages 513). Parents responded to letters sent home by the children's special education teachers in northern California. Participants completed questionnaires and mailed them to researchers. Researchers determined three primary coping strategies among participants: (a) reframing, (b) social support, and (c) spiritual support (Luther et al.).

Available research about the ability of a family to cope when a child has been diagnosed with autism and the parental changes in coping techniques as the child matures remains limited (Gray, 2006). Gray conducted a qualitative, longitudinal study in Brisbane, Australia, to address his interest and concerns. The study included 28 parents (19 mothers and 9 fathers) of 20 children with autism who had also participated in a study performed approximately 15 years earlier. Findings showed that parents had changed their coping strategies from the time of the original research. Instead of relying on family support networks, family members, social activities, and service providers, many parents reported their dependence on religion and emotion-based techniques. Gray's follow-up study found that none of the children were attending the special autism treatment center, and none of those who had graduated from high school were employed full-time.

Researchers stressed the need for services especially intended to improve marital and family performance for families of a child with autism (Higgins, Bailey, \& Pearce, 2005). Higgins et al. surveyed parents and primary caregivers of children with autism to study stress, coping strategies, and the effect on the family. Participants included 52 primary caregivers of 58 children with ASD from a rural area of Victoria, Australia. Parents and primary caregivers reported: (a) less marital contentment, (b) less adaptability within the family, and (c) less harmony within the family. Even though family problems were rated high, researchers found no evidence that parents or primary caregivers suffered from a lower sense of worth (Higgins et al.). In 1989, Konstantareas and Homatidis established that mothers of children with autism desired extra assistance 
from their spouses. Mothers maintained that even though they felt close to their husbands, they did not feel that their husbands helped them enough with the children, disciplined the children, or volunteered to help with housework (Konstantareas \& Homatidis). Data reported by Higgins et al. suggest that coping within the home remains a problem for parents of children with autism.

Asian American parents of children with autism seek support from friends, other families who faced similar problems, agencies, programs, and groups to help them cope (Twoy, Connolly, \& Novak, 2007). Researchers used data collected from 55 parents with a child diagnosed with autism aged 12 years and under to determine: (a) the level of family adaptation, (b) any difference based on family demographics, and (c) how long it took for parents to receive a diagnosis of autism from the time they first suspected the disorder. Results showed that fathers scoring slightly higher than mothers in coping. Data showed Asian Americans with a higher coping score for reframing. Non-Englishspeaking participants scored higher on placing importance on spiritual support. English speaking participants scored higher in passive appraisals. The time from parents' suspicions to diagnosis of autism was 6 months or greater (Twoy et al.).

The literature review reveals differing coping strategies are used by parents of children with autism. Parents who receive a diagnosis of autism for their child find themselves faced with a challenging situation they cannot control (Hastings, Kovshoff, Brown et al., 2005). Coping techniques used by parents can help reduce the resulting stress they encountered (Dunn et al., 2004) and help the parents effectively deal with problems directly related to raising a child with autism (Sivberg, 2002a). Research suggests that parents need assistance in not only learning but also using positive coping techniques (Sivberg, 2002b).

Mothers and fathers coped differently (Gray, 2003). Therefore, mothers and fathers must be taught additional, positive coping techniques that correspond with their preferred coping patterns. Gray (2006) found that family coping patterns change as the age of the child with autism changes. Coping strategies that worked during one phase of the family's life did not meet the needs of the family during another time phase. A child with autism has difficulty in the areas of communication and socialization; so, parents may find that coping is a very difficult, ongoing process for them. The current study examined the relationship among adaptive functioning of the child with autism, family support networks, parental stress, and parental coping. The CHIP (McCubbin et al., 1981) was administered to each participant to measure coping patterns.

\section{Summary}

This chapter presented a literature review of peer-reviewed journal articles and textbooks covering the years 2001-2008 exploring research in four areas: (a) adaptive behaviors of children with ASD; (b) support networks used by families of children with ASD; (c) parental stress associated with raising a child with ASD; and (d) parental coping techniques used when raising a child with ASD. Limitations of adaptive behaviors in the 
areas of daily living skills, communication, socialization, and motor skills are present in children with ASD (Dyches et al., 2004). Data provide evidence of limitations and describe various methods that have been used and examined to help children with ASD improve their adaptive behaviors. Mastering adaptive behaviors during childhood gives hope that the child may have the opportunity to become an independent adult without the need for constant supervision (Carothers \& Taylor, 2004). Both informal and formal family supports and services are needed to assist parents in relieving stressors that may be present in their homes. Research suggested that professionals can effectively support parents by helping them learn to use positive coping techniques to deal with their daily stress.

Current research reviewed does not show that parents and primary caregivers of children with ASD are less stressed today or have better, more efficient ways of coping than they did seven years ago. Therefore, professionals should not assume that because there is a longer list of family support networks available and additional web-sites published on the Internet that parents and primary caregivers are no longer feeling desperate for help. Researchers continue to report that:

- Children with ASD have adaptive behavior problems.

- Parents are stressed.

- Coping techniques for parents need to be strengthened.

- Support networks in many geographical areas remain out of reach for parents and families in need.

- Many parents do not take advantage of family support networks that are available to them.

The current study examined parents' and primary caregivers' views of their children's adaptive behaviors; use of available family support networks; current stress levels; and choices of coping techniques used by parents and primary caregivers to bring stability to each family. 


\section{CHAPTER 3. METHODOLOGY}

The purpose of this study was to examine the relationships among the adaptive behaviors of children with ASD, family support networks, parental stress, and parental coping. This chapter explains the research design and procedures followed in this study.

\section{Research Design}

A descriptive, correlational, cross-sectional study was designed to acquire data on adaptive behaviors of children with autism, family support networks, parental stress, and parental coping. This design was chosen for this study to examine relationships among the variables using a one time interview. Polit and Beck (2008) described a descriptive, correlational design as a study design that should be used to explain variable relationships. The current study was conducted to examine relationships among variables. After extensive literature review, no study was located that described the relationships of these variables obtained during a one time interview with parents of children with autism.

\section{Sample}

The current study included a purposive sample of 75 parents that included 73 biological parents (50 mothers; 23 fathers), 1 grandmother, and 1 stepfather of children diagnosed with autism. Participants were recruited through parent support group coordinators in Mobile, Baldwin, and Houston counties in the state of Alabama; the Autism Society of Alabama's Community Forum; the Mobile County Public School System; Spanish Fort Public School; a developmental pediatrician in Mobile, Alabama; and the Director of the Autism Society of Mississippi. Recruitment for the study began in October 2007 and ended in March 2008, when the last parent showed interest in participating in the study.

Inclusion criteria for study participants were: (a) parent/primary caregiver of a child diagnosed with autism, (b) resident of Alabama, Florida, or Mississippi, (c) ability to speak English, (d) parent/primary caregiver of a child with autism who is 21 years old or younger, and (e) ability to comprehend concepts of the current study and provide verbal consent to participate.

\section{Instrumentation}

Data were collected using instruments that required participants to answer questions with pen/pencil and semi-structured interview. The primary investigator assisted participants as necessary. The self-administered instruments included the (a) Demographic Form (see Appendix A), (b) CHIP (McCubbin et al., 1981; see Appendix B), (c) FSS (Dunst et al., 1984; see Appendix C), (d) PSI-SF (Abidin, 1995). The 
Vineland-II (Sparrow et al., 2005) was administered by semi-structured interview.

\section{Demographic Form}

A Demographic Form was developed to obtain demographic data and information about the participant and the child diagnosed with autism. Specific information obtained included: (a) participant's relationship to child; (b) participant's education, age, race, and residence; (c) number, ages, and genders of children in participant's family; (d) age, gender, and health status of the child with autism; and (e) participant's attendance at a parent support group for children diagnosed with autism. The length of time required to complete the Demographic Form was five minutes.

\section{Coping Health Inventory for Parents}

The CHIP (McCubbin et al., 1981) was used to measure the participant's views of coping with life when a family member includes a child diagnosed with a critical and/or chronic illness (McCubbin, Thompson, \& McCubbin, 2001). Permission was requested to use the CHIP (McCubbin et al., 1981), a copyrighted instrument (see the permission-touse letter in Appendix D). The CHIP was self-administered, included 45 items, and consisted of three subscales:

(1) Coping Pattern I: Family Integration, Cooperation, and an Optimistic Definition of the Situation (McCubbin et al., 2001, p. 432);

(2) Coping Pattern II: Maintaining Social Support, Self Esteem and Psychological Stability (McCubbin et al., 2001, p. 432); and

(3) Coping Pattern III: Understanding the Health Care Situation Through Communication with Other Parents and Consultation with the Health Care Team (McCubbin et al., 2001, p. 433).

Each participant ranked the helpfulness of specific coping behaviors using a 4point scale (3=Extremely Helpful, 2=Moderately Helpful, 1= Minimally Helpful, or $0=$ Not Helpful). If the participant did not use a specific behavior as a coping technique, the participant was asked to choose from two answers: (a) Chose Not To; or (b) Not Possible (McCubbin et al., 2001). The higher the participant's scores for each coping behavior, the more these coping behaviors were used by parents of children with autism.

Coping Pattern I measured behaviors in 19 items and concentrated on family adjustment, teamwork, and a positive meaning of the situation (McCubbin et al., 2001). According to McCubbin et al., Coping Pattern I has a reliability coefficient (Cronbach's alpha) of .79. The CHIP items that measured this subscale include: 1, 3, 6, 8, 11, 13, 16, $18,21,23,26,28,31,36,38,41,43,44$, and 45. The participant's scores on each item were added to generate a total subscale score (McCubbin et al.). The possible range of scores was $0-57$. In this study, internal consistency reliability (Cronbach's alpha) for the subscale was .76 and the split-half reliability coefficient was .76. 
Coping Pattern II measured behaviors using 18 items that focused on continuing to seek and use available social support, self-respect, and emotional strength (McCubbin et al., 2001). McCubbin et al. described the reliability coefficient (Cronbach's alpha) for Coping Pattern II as .79. The CHIP items that measured this subscale included: 2, 4, 7, 9, $12,14,17,19,22,24,27,29,32,33,34,37,39$, and 42. The scores for each item were summed to produce a total subscale score for each participant (McCubbin et al.). The possible range of scores was $0-54$. In this study, internal consistency reliability (Cronbach's alpha) for this subscale was .74 and the split-half reliability coefficient was .73 .

Coping Pattern III included eight items that measured behaviors which aimed at insight into the health care position by talking with other parents and health care professionals (McCubbin et al., 2001). McCubbin et al. reported the reliability coefficient (Cronbach's alpha) for Coping Pattern III as .71. The CHIP items that measured this subscale included: $5,10,15,20,25,30,35$, and 40 . The participants' responses for each item were summed to generate a total subscale score (McCubbin et al.). The possible range of scores was 0-24. In this study, internal consistency reliability (Cronbach's alpha) for this subscale was .70 and the split-half reliability coefficient was .64.

McCubbin et al. (2001) described validity evaluations using the CHIP subscales with a sample of families raising children diagnosed with cerebral palsy. The results documented that the utilization of all three coping patterns was greatest among mothers and fathers living in families with higher conflict (McCubbin et al., 2001). McCubbin et al. (1983) used the CHIP to measure parental coping with children diagnosed with cystic fibrosis (CF). The construct validity of CHIP was evaluated utilizing the Family Environment Scale [FES] (Moos \& Moos, 1976) and height/weight and pulmonary function indexes of the child with CF (McCubbin et al., 1983). The purpose of the FES development was to examine specific features of a family which included social and environment (Moos \& Moos, 1976).

The results of the study conducted by McCubbin et al. (1983) documented a positive relationship between Coping Patterns I and III with FES family cohesiveness $(\mathrm{r}=.21, \mathrm{p}<.01 ; \mathrm{r}=.19, \mathrm{p}<.05)$, and a positive relationship between Coping Pattern II with FES family expressiveness $(\mathrm{r}=.19, \mathrm{p}<.05)$ when used by the mother (McCubbin et al.).

McCubbin et al. (2001) described responses given by fathers in the study and the Coping Pattern I subscale documented a positive relationship with FES family cohesiveness $(\mathrm{r}=.36, \mathrm{p}=<.01)$ and a negative relationship with FES family conflict $(\mathrm{r}=-.21, \mathrm{p}<.05)$. Also, fathers' responses for Coping Pattern I subscale had a positive relationship with FES family organization $(\mathrm{r}=.32, \mathrm{p}<.01)$. Fathers' responses for Coping Pattern II subscale were positively associated with FES family organization $(\mathrm{r}=.22$, $\mathrm{p}<.05)$ and FES family control $(\mathrm{r}=.19, \mathrm{p}<.05)$ (McCubbin et al., 1983). No test-retest reliability was reported (McCubbin et al., 2001).

Researchers used the CHIP to measure coping strategies of parents with children 
diagnosed with ASD. Higgins et al. (2005) used an adapted version of the CHIP to survey the coping strategies of 53 primary caregivers of children with ASD. Researchers examined relationships among the following variables: characteristics of child with ASD, family well-being, and coping techniques. Higgins et al. found coping strategies to be non-significant predictors of happiness in marriage, family unity, family ability to adapt, and self-worth ( $p>.05)$. Tobing and Glenwick (2006) measured coping patterns of mothers with children diagnosed with PDD. Results documented a non-significant, negative relationship ( $p>.05$ ) between coping strategies and psychological distress of mothers (Tobing \& Glenwick). Additional studies have used the CHIP to measure coping patterns of parents. Little (2002) assessed parents' coping pattern when their child has Asperger syndrome. Jones and Passey (2004) evaluated coping strategies of primary caregivers of children who were developmentally disabled and exhibited difficulties with behaviors (Jones \& Passey).

The CHIP was chosen to examine parental coping, a variable in this research study. The instrument was developed as a self report questionnaire especially for identifying strategies parents of children with a chronic illness or a disability found useful for coping (McCubbin et al., 2001). Questionnaire items identified strategies participants found useful in assisting them with coping with the pressures of life, managing the family unit (McCubbin et al.) and raising a child diagnosed with ASD. Since the CHIP has been used in various published studies of children with developmental disabilities, including ASD, current study results can be compared with previous research. The current study used the total score obtained from each of the three coping patterns. The length of time required to complete the CHIP for the current study was 15 minutes.

\section{Family Support Scale}

The FSS (Dunst et al., 1984) was used to measure parents' views of the support their family received while raising a child with ASD (Dunst et al., 1994). The FSS, a self report instrument, included 18 items, with two additional write-in items for the participants to rate their supports on a 5 -point Likert scale $(0=$ not available, $1=$ not at all helpful, 2=sometimes helpful, 3=generally helpful, 4=very helpful, and 5=extremely helpful). Participants' responses were summed to generate a total score. The possible range of scores for the FSS was 0-90. The higher the participant's scores for each item, the more these supports were helpful in dealing with the experiences related to raising children with autism. The supports measured on the FSS were: (a) informal kinship; (b) spouse/partner support; (c) social organizations; (d) formal kinship; and (e) professional services (Dunst et al., 1994).

According to Dunst, Trivette, and Jenkins (2003), FSS reliability and validity were explored with a study which included 139 parents of preschool children at risk for an intellectual and/or developmental disorder. The average correlation coefficient alpha among the 18 items was .77. Dunst et al. used the Spearman-Brown formula to determine the corrected length of the split-half reliability of .75. The test-retest reliability for the average correlation for the 18 scale items was $.75(\mathrm{SD}=.17, \mathrm{p}<.001)$ and for the total score of the scale $.91(\mathrm{p}<.001)$. A month elapsed between test-retest reliability 
measurements. A test-retest reliability spaced out by 18 months for the 18 items was .41 $(\mathrm{SD}=.18, \mathrm{p}<.05)$ and for the total score $.47(\mathrm{p}<.01)$. The criterion-related validity has been determined by various studies recognizing the association between the scale total score, scores of the subscales, and effects on the parent, family, and parent-child (Dunst, 1985).

Dunst et al. (2003) described a positive association between the total score of the FSS to outcomes for the parent and the family: (a) personal well being (average $r=.28$, $\mathrm{p}<.01$ ); (b) family unit integrity (average $\mathrm{r}=.18, \mathrm{p}<.01$ ); (c) parent views about their child's behavior (average $\mathrm{r}=.19, \mathrm{p}<.05$ ); and (d) parent-child play (average $\mathrm{r}=.40$, $\mathrm{p}<.001$ ). For the current study, the internal consistency reliability (Cronbach's alpha) for the FSS was .72 and the split-half reliability coefficient was .53.

Benson (2006) reported good internal consistency of the FSS in a study of informal and formal supports for families of children with autism. The internal consistency reliability (Cronbach's alpha) was .73 for informal support and .70 for formal support. Benson referred to the findings as a modest correlation $(\mathrm{r}=.22, \mathrm{p}<.05)$ between informal and formal support, implying that the two types of family support are associated but also different. Boyd (2002) examined research covering 20 years (1979-1999) regarding mothers of children with autism and the use of social support to diminish their stress levels. The most consistently used instrument to measure family support was the FSS (Boyd). Researchers used the FSS to measure family support in various other studies of children with developmental disabilities: Chinese mothers of children with an intellectual disability (Mak \& Ho, 2007), caregivers of children with developmental disabilities and behavior problems (Jones \& Passey, 2004), caregivers of children with disabilities who live in urban and rural locations (Darling \& Gallagher, 2004), mothers of children with an intellectual disability (Hassall et al., 2005), and mothers of children with disabilities (Reyes-Blanes, 2001), parents of preschool children with developmental disabilities (Oelofsen \& Richardson, 2006), parents of adolescents with severe intellectual disabilities (White \& Hastings, 2004), and parents of children with autism (Hastings, 2003b).

The FSS was chosen for this study because it measured the participants' views of family supports received when raising a child with a disability (Dunst et al., 1994). The current study examined the association among adaptive behaviors of children with autism, family support networks, parental stress, and parental coping. The FSS provided data compatible with the purpose and aims of the current study in the area of family support networks. The FSS was originally designed to be used as a component for studying social support effect on: (a) preschool children with disabilities and their families; and (b) preschool children at-risk for intellectual or developmental disabilities (Dunst, Trivette, \& Cross, 1988). The current study utilized the FSS total score. The length of time to complete the FSS for the current study was 10 minutes. 


\section{Parenting Stress Index-Short Form}

The PSI-SF (Abidin, 1995), a self-report instrument, was used to measure the stress in parent-child relationships and evaluate parenting or child behavior difficulty. The PSI-SF is a derivative of the PSI (Abidin). The PSI-SF includes 36 items from the PSI. The PSI-SF produced a total score from three subscales: (a) Difficult Child (DC); (b) Parent-Child Dysfunctional Interaction (P-CDI); and (c) Parental Distress [PD] (Abidin). The subscales DC, P-CDI, and PD were added to obtain the Total Stress score. Total Stress raw scores above 90 indicated parental stress considered to be significant clinically (Abidin). Abidin described the Total Stress score as measuring no more than the stresses a person endures with the responsibilities and position of being a parent. The Total Stress score indicated stress within the following: (a) parental stress, (b) stresses in a parent child relationship, and (c) stress caused by child's behaviors (Abidin).

According to Abidin (1995), the PSI-SF test-retest reliability was examined during routine one year well child appointments at a pediatrician's office in Virginia over a six-month interval with a sample of 530 mothers. The test-retest reliability for this sample of mothers was .84 for Total Stress, .85 for PD, .68 for P-CDI, and .78 for DC. The development of the PSI-SF was completed using the original 530 mothers and an additional 270 mothers recruited from the same pediatric clinic. The coefficient alpha for internal reliability was analyzed using data from all 800 mothers. The coefficient alpha for Total Stress was .91; PD was .87; P-CDI was .80; and DC was .85 (Abidin). Roggman, Moe, Hart, and Forthun (1994) conducted a study which included a sample of 103 parents with children enrolled in Head Start. The following PSI-SF alpha reliabilities were reported: (a) PD .79, (b) P-CDI .80, (c) DC .78, and (d) Total Stress .90. For the current study, the PSI-SF Total Stress internal consistency reliability coefficient (Cronbach's alpha) was .93 and the split-half reliability was .84.

Currently, the PSI-SF does not have self-supporting research corroborating its validity (Abidin, 1995). Abidin contends that since the PSI-SF is a derivative of the original PSI, it in all likelihood shares the validity of the PSI. The PSI was validated with a study conducted with parents of children with autism and children with externalizing behaviors (Donenberg \& Baker, 1993). The purpose of the study was to examine preschool children diagnosed with autism or children exhibiting externalizing behaviors and the impact of family operations (Donenberg \& Baker). The PSI-SF and the original PSI correlations were applied using a sample of 530 participants who participated in the normative PSI sample. The correlation between the PSI Total Stress and the Total Stress for PSI-SF was .94, which is similar to the test-retest reliability of .95 for PSI, examined for a 2 week interval (Abidin).

The PSI-SF (Abidin, 1995) has been used to measure stress in mothers of children with PDD, especially autism (Tomanik et al., 2004), parents of girls with Rett syndrome (Perry, Sarlo-McGarvey, \& Factor, 1992), parents of Chinese children with sleep problems diagnosed with PDD (Doo \& Wing, 2006), mothers of children with autism located in Hong Kong (Mak, Ho, \& Law, 2007), parents of children with developmental disabilities (Oelofsen \& Richardson; Woolfson \& Grant, 2006), and parents of school-age 
children with global developmental delay or developmental language impairment (Webster, Majnener, Platt, \& Shevell, 2008). The PSI (Abidin, 1995) has been used to measure stress in mothers of children with autism and children with PDD-NOS (Tobing \& Glenwick, 2002), parents of children with conduct disorder, children with autism, and children with Down syndrome (Noh, Dumas, Wolf, \& Fisman, 1989).

The PSI-SF was used for the current study to assess parental and primary caregiver stress and determined parental and primary caregivers' views of child behavior problems when the child has autism (Abidin, 1995). The Total Stress score of the parent and primary caregivers were used in this study. The average length of time required to complete the PSI-SF for the current study was 15 minutes.

\section{Vineland Adaptive Behavior Scales, Second Edition}

The Vineland-II (Sparrow et al., 2005) was used to measure the adaptive behaviors of the child with autism. This instrument was administered during a semistructured interview with each parent and primary caregiver. The Vineland-II measured adaptive and maladaptive behaviors from birth to 21 years in the following domains: (a) Communication (Receptive, Expressive, and Written), (b) Daily Living Skills (Personal, Domestic, and Community), (c) Socialization (Interpersonal Relationships, Play and Leisure Time, and Coping Skills), (d) Motor Skills (Gross and Fine), (e) Maladaptive Behavior Index (Internalizing, Externalizing, and Other), and (f) Maladaptive Critical Items (Sparrow et al., p. 3).

Parents and primary caregivers were asked to respond to statements describing the behaviors of the child with autism by answering either (a) usually, (b) sometimes or partially, (c) never, or (d) don't know. For children ages birth through 6 years, 11 months, and 30 days, the Adaptive Behavior Composite score contains four domains: (a) Communication, (b) Daily Living Skills, (c) Socialization, and (d) Motor Skills. For children equal to or older than age 7, the Adaptive Behavior Composite score contains three domains which include: (a) Communication, (b) Daily Living Skills, and (c) Socialization (Sparrow et al., 2005). The Vineland-II ASSIST Software Scoring and Reporting System Version 1.1 (Pearson Assessments, 2007) was used for scoring each survey form answered by the participants. A $90 \%$ confidence interval was selected for scoring the data, as Sparrow et al. suggested. The standard score ranges for each adaptive level were:

(1) High: 130 and above

(2) Moderately High: 115-129

(3) Adequate: 86-114

(4) Moderately Low: 71-85

(5) Low: 70 and below (Sparrow et al., p. 65).

According to Sparrow et al. (2005), the Vineland-II mean split-half reliability coefficients for the Domains in Communication, Daily Living Skills, Socialization, and Motor Skills Domains for children age birth-5 are: (a) Communication .92, with 
subdomains ranging from .80 to .93; (b) Daily Living Skills .89, with subdomains ranging from .77 to .83; (c) Socialization .93 , with subdomains ranging from .83 to .87; and (d) Motor Skills .90, with subdomains at .85 (Sparrow et al.). For a child age 6-11, the split-half reliability coefficients for the Domains are: (a) Communication .93, with subdomains ranging from .76 to .88; (b) Daily Living Skills .91, with subdomains ranging from .73 to .85; (c) Socialization .93, with subdomains ranging from .77 to .88; and (d) Motor Skills .87, with subdomains at .78 and .82 (Sparrow et al.). The internalconsistency reliability of the domains is mainly in the high $.80 \mathrm{~s}$ to.90s (Sparrow et al.). The Adaptive Behavior Composite score reliability for internal-consistency consists of the following for the different age groups: (a) birth-5 is .97, (b) 6-11 is .97, (c) 12-18 is .95 , and (d) 19-51 is .93 (Sparrow et al.). In the current study, the internal consistency reliability coefficient (Cronbach's alpha) of Communication, Daily Living Skills, Socialization, and Motor Skills Domains was .89, and the split-half reliability was .92.

Sparrow et al. (2005) described the test-retest reliability of the Vineland-II. A study was conducted with 414 participants from the sample of 3,695 recruited to evaluate the standardization of the Vineland-II (Sparrow et al.). These participants' (aged birth-90) data originally were evaluated using the Vineland-II Survey Interview Form or Parent/Caregiver Rating Form. These 414 participants completed another Vineland-II Survey Interview Form or Parent/Caregiver Rating Form for the test-retest reliability. The investigators blended the data from both documents (Sparrow et al.). The test-retest time frame was 13 to 34 days. The same individual interviewed the participants both times. Sparrow et al. explains that most subdomain retest reliability coefficients are greater than .85 . For age group 14-21, the mean subdomain reliability was .85 or greater. The reliability mean for each domain varied from .88 to .92 , with the exception of ages 14-21, where the reliability mean was .76 (Sparrow et al.). The reliabilities for the Adaptive Behavior Composite scores were greater than .90 for every age, with the exception of adolescence with a reliability of .83 (Sparrow et al.).

Sparrow et al. (2005) described the validity of using the Vineland-II in a study with 77 persons who met the DSM-IV-TR (2000) criteria for the diagnosis of autistic disorder. The participants were split into groups: (a) autism-nonverbal and (b) autismverbal. The autism-verbal group maintained an Adaptive Behavior Composite mean score of 65.7 with Socialization domain resulting in the lowest score (Sparrow et al.). The mean Adaptive Behavior Composite score for the autism-nonverbal group was 51. These findings uphold the criteria for an autism diagnosis according to the DSM-IV-TR (Sparrow et al.).

The Vineland-II's (Sparrow et al., 2005) predecessor, the VABS (Sparrow, Balla, \& Cicchetti, 1984) has been extensively used to measure adaptive behaviors of children. The VABS (Sparrow et al., 1984) has been used in studies of children with ASD (Bishop et al., 2007; Gilotty et al., 2002; Kenworthy et al., 2005), autism (Cederlund, Hagberg, Billstedt, Gillberg, \& Gillberg, 2008; Gabriels, Hill, Pierce, Rogers, \& Wehner, 2001; Gillham, Carter, Volkmar, \& Sparrow, 2000; Paul et al., 2004; Stone, Ousley, Hepburn, Hogan, \& Brown, 1999; Tomanik, Pearson, Loveland, Lane, \& Shaw, 2007), and autism and moderate to severe developmental delay (Fenton et al., 2003). The VABS (Sparrow 
et al., 1984) has also been used to measure adaptive behavior in studies of children with PDD-NOS (Gabriels et al.; Gillham et al.; Paul et al.), AS (Cederlund et al), a developmental disorder of children who have not been diagnosed with autism or PDD (Gillham et al.), and mild intellectual disabilities and children with moderate intellectual disabilities with and without autism (de Bildt et al., 2005).

The Vineland-II was used for the current study to assess the adaptive behaviors of the child diagnosed with autism (Sparrow et al., 2005). The study measured the Adaptive Behavior Composite score of the child with autism. The semi-structured interview with the parents and primary caregivers in the current study took approximately 20-40 minutes, depending on the child's chronological age and the child's developmental stage (Sparrow et al.).

\section{Procedure}

The Institutional Review Board at The University of Tennessee Health Science Center approved the current study (Appendix E). The method of identifying and recruiting participants was with an advertisement (Appendix F). To obtain the sample for this study, the Mobile County, Alabama, parent support group coordinator mailed advertisements to parents with children diagnosed with autism and sent reminder emails to the parents. This coordinator also distributed advertisements at the Autism Society of Alabama's Community Forum held in Mobile, Alabama. The Baldwin County, Alabama, parent support group coordinator mailed advertisements to parents with children diagnosed with autism and emailed these parents. The Houston County, Alabama, parent support group coordinator advertised the study at their meetings. The Director of the Autism Society of Mississippi emailed every parent with a child diagnosed with autism on the organization's address list. The developmental pediatrician associated with the University of South Alabama mailed advertisements to parents of children he diagnosed with autism and follows in his clinic. The Executive Director of Special Programs for the Mobile County Public School System sent advertisements to every teacher with a child in their class identified with autism. Teachers were asked to send advertisements home to parents. Spanish Fort Public School in Baldwin County sent advertisements home with every child identified with autism.

When parents or primary caregivers called to show interest in participating in the study, the primary investigator followed the same procedure with each potential participant. The investigator requested the name, phone number, and mailing address of the potential participant. In addition, parents and primary caregivers were asked the age of their child with autism. A location, date, and time of the meeting for data collection or telephone interview were established with parents and primary caregivers who met the criteria for inclusion in the study. If a meeting for data collection was planned, the participant chose a convenient location. If the parent or primary caregiver chose to be interviewed via telephone, a date and time convenient for the participant was established.

Upon arrival to the interview the primary investigator: (a) introduced herself to 
the participant, (b) provided explicit explanation of research study, (c) read the consent statement approved by the Institutional Review Board (see Appendix G), and (d) obtained verbal informed consent from each participant. Instruments were administered in the following order: (a) Demographic Form, (b) CHIP (McCubbin et al., 1981), (c) FSS (Dunst et al., 1984), (d) PSI-SF (Abidin, 1995), and the final instrument administered by semi-structured interview was the Vineland-II (Sparrow et al., 2005). All instruments were assigned a code number to maintain confidentiality of the participants' identity. After the interview, an incentive in the amount of $\$ 30.00$ was mailed to the participants' address within five days.

\section{Data Analysis}

Statistical analyses were performed on 75 participants' scores for the following instruments administered by self-administration and semi-structured interview: (a) Demographic Form, (b) CHIP (McCubbin et al., 1981), (c) FSS (Dunst et al. 1984), (d) PSI-SF (Abidin, 1995), and (e) Vineland-II (Sparrow et al., 2005). These data were analyzed using Statistical Package for the Social Sciences (SPSS) Version 16.0. SPSS was used to describe the sample and answer the research questions. A 5\% risk of committing a Type I error was accepted (Ott \& Longnecker, 2001).

\section{Sample Characteristics}

Participants that met the inclusion criteria and verbally consented to participate in a meeting for data collection interview or a telephone interview were enrolled in the study. Forty-nine participants personally met with the researcher for data collection and 26 chose to participate by telephone interview. Before the research questions were answered, demographic data on participants and the child with autism were analyzed through the use of descriptive statistics. Variable distributions included mean, standard deviation, and frequency tables. Demographic data are presented for the entire sample, mothers, fathers, and other in Table 3-1. Most of the participants were mothers $(66.7 \%)$, Caucasian (84\%), had at least one year of college or graduated from a university $(68 \%)$, and lived in Mobile County, Alabama (68\%). The mean age of the participants was $40 \pm 9.0$ years; participants' ages ranged from 24 to 68 . Twenty-two couples participated in the study. A total of 53 families were represented in this study. A majority of participants reported they did not attend a support group for parents of children with autism $(53.3 \%)$.

Data are presented on the ages of all children in the families represented in this study (Table 3-2). These data included children with and without autism. Hockenberry and Wilson (2007) described the age limits for each stage of growth and development as the following: (a) infancy, birth to 12 months; (b) toddler, 12 months to 36 months; (c) preschooler, 3 to 5 years; and (d) school-age child, 6 to 12 years. Adolescence was separated into three distinct phases: (a) early, 11 to 14 years; (b) middle, 15 to 17 years; and (c) late, 18 to 20 years (Hockenberry \& Wilson). The mean number of children in the 
Table 3-1. Demographic Characteristics of Participants

\begin{tabular}{|c|c|c|c|c|}
\hline Characteristics & $\begin{array}{l}\text { Sample } \\
\text { N }(\%) \\
75(100)\end{array}$ & $\begin{array}{l}\text { Mother } \\
\mathrm{n} \quad(\%) \\
50(66.7)\end{array}$ & $\begin{array}{l}\text { Father } \\
\mathrm{n} \quad(\%) \\
23(30.7)\end{array}$ & $\begin{array}{l}\text { Other } \\
\text { n } \quad(\%) \\
2(2.7)\end{array}$ \\
\hline \multicolumn{5}{|l|}{ Ethnicity } \\
\hline Caucasian & $63(84)$ & $42(84)$ & $20(87)$ & $1(50)$ \\
\hline African American & $9(12)$ & $6(12)$ & $2(8.7)$ & $1(50)$ \\
\hline Hispanic & $2(2.7)$ & $1(2)$ & $1(4.3)$ & 0 \\
\hline American Indian & $1(1.3)$ & $1(2)$ & & \\
\hline \multicolumn{5}{|l|}{ Highest Grade Completed } \\
\hline $10^{\text {th }}$ or $11^{\text {th }}$ Grade & $5(6.7)$ & $2(4)$ & $3(13)$ & 0 \\
\hline High School Graduate & $14(18.7)$ & $10(20)$ & $4(17.4)$ & 0 \\
\hline Partial College & $25(33.3)$ & $17(34)$ & $6(26.1)$ & $2(100)$ \\
\hline University Graduate & $26(34.7)$ & $18(36)$ & $8(34.8)$ & 0 \\
\hline Graduate Degree & $5(6.7)$ & $3(6)$ & $2(8.7)$ & 0 \\
\hline \multicolumn{5}{|l|}{ Residence } \\
\hline Alabama & $69(92)$ & $45(90)$ & $22(95.7)$ & $2(100)$ \\
\hline Mobile County & $51(68)$ & $33(66)$ & $16(69.6)$ & $2(100)$ \\
\hline Baldwin County & $11(14.7)$ & $8(16)$ & $3(13)$ & 0 \\
\hline Houston County & $5(6.7)$ & $3(6)$ & $2(8.7)$ & 0 \\
\hline Tuscaloosa County & $2(2.7)$ & $1(2)$ & $1(4.3)$ & 0 \\
\hline Florida & $1(1.3)$ & $1(2)$ & 0 & 0 \\
\hline Okaloosa County & $1(1.3)$ & $1(2)$ & 0 & 0 \\
\hline Mississippi & $5(6.7)$ & $4(8)$ & $1(4.3)$ & 0 \\
\hline Harrison County & $2(2.7)$ & $1(2)$ & $1(4.3)$ & 0 \\
\hline DeSoto County & $1(1.3)$ & $1(2)$ & 0 & 0 \\
\hline Lafayette County & $1(1.3)$ & $1(2)$ & 0 & 0 \\
\hline Lowndes County & $1(1.3)$ & $1(2)$ & 0 & 0 \\
\hline
\end{tabular}


Table 3-2. Children With and Without Autism Spectrum Disorder by Age Groups

\begin{tabular}{lllll}
\hline Age Groups & $\begin{array}{l}\text { Sample } \\
\mathrm{N}(\%) \\
\mathrm{N}=141\end{array}$ & $\begin{array}{l}\text { Mother } \\
\mathrm{n}(\%) \\
\mathrm{n}=91\end{array}$ & $\begin{array}{l}\text { Father } \\
\mathrm{n}(\%) \\
\mathrm{n}=46\end{array}$ & $\begin{array}{l}\text { Other } \\
\mathrm{n}(\%) \\
\mathrm{n}=4\end{array}$ \\
& $16(11.3)$ & $10(11)$ & $5(10.9)$ & $1(25)$ \\
0-3 Years & $35(24.8)$ & $20(22)$ & $15(32.6)$ & 0 \\
3-5 Years & $50(35.5)$ & $32(35.2)$ & $16(34.7)$ & $2(50)$ \\
6-12 Years & $17(12.1)$ & $11(12.1)$ & $5(10.9)$ & $1(25)$ \\
11-14 Years & $16(11.3)$ & $11(12.1)$ & $5(10.9)$ & 0 \\
15-17 Years & $7(5.0)$ & $7(7.6)$ & 0 & 0 \\
$18-20$ Years & & &
\end{tabular}


families in the current study was $2.0 \pm 1$; the number of children in these families ranged from 1 to 6 . Of the 141 children in the families of the current study, 50 (35.5\%) were school-age children (ages 6-12) and 35 (24.8\%) were toddlers (ages 3-5).

\section{Children with Autism Characteristics}

The characteristics of participants' children with autism are presented in Table 3-3. Children with autism ranged in age from 2 to 20 years. A majority of children with autism were male, first-born, and reported to be in very good (56\%) or good health $(14.7 \%)$. Over one fourth of participants reported the child with autism was in poor health.

\section{Specific Aim One}

Specific Aim One was to examine parental views of adaptive behaviors of children with autism, family support networks, parental stress, and parental coping.

The following research questions related to Aim One:

- Research Question 1a - In families of children with autism, how do parents view the adaptive behaviors of their child with autism, the support for their family, parental stress, and their patterns of coping?

- Research Question $1 b$-What do parents report as the autism-related resources used and needs for themselves, their children with autism, and their family?

The statistical technique univariate descriptive analysis was used to identify the distribution of the data from the participants' scores on the adaptive behaviors of their children with autism, family support, parental stress, and parental coping patterns. The data distributions were documented with mean, range, and standard deviation (SD). The participants' attendance at parent support group meetings was reported using percentages.

\section{Specific Aim Two}

Specific Aim Two was to gain an understanding of the relationships among the adaptive behaviors of children with autism, family support networks, parental stress, and parental coping.

The following research questions are related to Aim Two:

- Research Question 2a-What are the relationships among adaptive behaviors of children with autism, family support, parental stress, and patterns of coping? 
Table 3-3. Demographic Characteristics of Participants' Children with Autism Spectrum Disorder

\begin{tabular}{|c|c|c|c|c|}
\hline Characteristics & $\begin{array}{l}\text { Sample } \\
\mathrm{N}(\%) \\
\mathrm{N}=75\end{array}$ & $\begin{array}{l}\text { Mother } \\
n(\%) \\
n=50\end{array}$ & $\begin{array}{l}\text { Father } \\
n(\%) \\
n=23\end{array}$ & $\begin{array}{l}\text { Other } \\
n(\%) \\
n=2\end{array}$ \\
\hline \multicolumn{5}{|l|}{ Gender of Child } \\
\hline Male & $62(82.7)$ & $42(84)$ & $19(82.6)$ & $1(50)$ \\
\hline Female & $13(17.3)$ & $8(16)$ & $4(17.4)$ & $1(50)$ \\
\hline Age in years $($ mean \pm sd $)$ & $8 \pm 4$ & $9.04 \pm 4.55$ & $7.10 \pm 3.42$ & $6.56 \pm .77$ \\
\hline \multicolumn{5}{|l|}{ Birth Order of Child } \\
\hline First-born & $40(53.3)$ & $26(52)$ & $14(60.9)$ & 0 \\
\hline Second-born & $18(24)$ & $12(24)$ & $6(26.1)$ & 0 \\
\hline Third-born & $12(16)$ & $9(18)$ & $2(8.7)$ & $1(50)$ \\
\hline Fourth-born & $3(4)$ & $2(4)$ & $1(4.3)$ & 0 \\
\hline Other & $2(2.7)$ & $1(2)$ & 0 & $1(50)$ \\
\hline \multicolumn{5}{|l|}{ Health of Child } \\
\hline Very Good & $42(56)$ & $27(54)$ & $14(60.9)$ & $1(50)$ \\
\hline Good & $11(14.7)$ & $10(20)$ & $1(4.3)$ & 0 \\
\hline Fair & $1(1.3)$ & $1(2)$ & 0 & 0 \\
\hline Poor & $21(28)$ & $12(24)$ & $8(34.8)$ & $1(50)$ \\
\hline
\end{tabular}


- Research Question $2 b$ - Which predictor, adaptive behaviors of children with autism or family support, better predicts the criterion parental coping?

Statistical procedures were conducted to identify the correlation between the variables. The procedures used to determine the relationships were the Pearson productmoment correlation coefficients.

Following the identification of relationships between the predictor and criterion variables, multiple regression analysis was conducted to determine which variables predicted the criterion, parental coping patterns. 


\section{CHAPTER 4. RESULTS}

The purpose of this study was to examine the adaptive behaviors of children with ASD, family support networks, parental stress, and parental coping and the relationships among these variables. This descriptive, correlational, cross-sectional study examined two specific aims.

\section{Specific Aim One}

Specific Aim One was to examine the parental views of adaptive behaviors of children with autism, family support networks, parental stress, and parent patterns of coping.

\section{Research Question 1a and Findings}

In families of children with autism, how do parents view the adaptive behaviors of their child with autism, the support for their family, parental stress, and their patterns of coping?

Findings: Adaptive Behaviors of Children with Autism

The adaptive behaviors of the children with autism were measured using the Vineland-II (Sparrow et al., 2005) during a semi-structured interview with each participant in the current study. Domain means and standard deviations are presented in Table 4-1. The mean scores for the Communication, Daily Living Skills, and Socialization domains were less than 70 and represented low adaptive behavior levels of functioning. The mean score for the Motor Skills domain was between 61 and 85 and signified a moderately low adaptive level for the children with autism in this sample. The mean adaptive behavior composite score of 63.47 represented a low adaptive level of overall functioning among the children. The Socialization domain was the weakest area of adaptive functioning for this group of children as evidenced by the mean score of 62.93. The strongest area of adaptive behavior level of functioning for the children was the Motor Skills domain, with a mean score of 78.05.

\section{Findings: Family Support Networks}

The parents' views of the family support networks were measured using the FSS [Dunst et al., 1984] (Table 4-2). This mean total scale score represents parents' views of support from family support networks in raising the child with autism as being sometimes helpful. The mean total score for the FSS (Dunst et al.) was 44.35; the mean item score was 2.46 (44.35 divided by 18 equals 2.46). The range of FSS total scores for this sample was 12-74. The lowest score of 12 signified that supports, if available, were not helpful; and the highest score of 74 denoted that parents viewed available supports as being very 
Table 4-1. Vineland-II Domain and Adaptive Behavior Composite Behavior Scores for Sample, Mothers, Fathers, and Others

\begin{tabular}{|c|c|c|c|c|}
\hline $\begin{array}{l}\text { Domains } \\
\text { Mean } \pm \text { SD }\end{array}$ & $\begin{array}{l}\text { Sample } \\
\mathrm{N}=75\end{array}$ & $\begin{array}{l}\text { Mother } \\
n=50\end{array}$ & $\begin{array}{l}\text { Father } \\
n=23\end{array}$ & $\begin{array}{l}\text { Other } \\
\mathrm{n}=2\end{array}$ \\
\hline Communication & $65.51 \pm 15.56$ & $64.68 \pm 15.35$ & $68.13 \pm 15.97$ & $56.00 \pm 19.8$ \\
\hline Daily Living Skills & $64.95 \pm 13.24$ & $63.70 \pm 13.44$ & $68.04 \pm 13.08$ & $60.50 \pm 3.54$ \\
\hline Socialization & $62.93 \pm 12.23$ & $61.94 \pm 12.13$ & $65.30 \pm 12.92$ & $60.50 \pm 2.12$ \\
\hline Motor Skills & $78.05 \pm 17.05$ & $77.78 \pm 15.56$ & $79.48 \pm 20.67$ & $68.50 \pm 2.12$ \\
\hline $\begin{array}{l}\text { Adaptive Behavior } \\
\text { Composite Score }\end{array}$ & $63.47 \pm 13.06$ & $62.40 \pm 12.87$ & $66.13 \pm 13.81$ & $59.50 \pm 7.78$ \\
\hline
\end{tabular}


Table 4-2. Family Support Scale Subscale Item Scores for the Sample, Mothers, Fathers, and Others

\begin{tabular}{lllll} 
Levels of Support & Sample & Mother & Father \\
Mean \pm SD & $\mathrm{N}=75$ & $\mathrm{n}=50$ & $\begin{array}{l}\text { Other } \\
\mathrm{n}=23\end{array}$ & \\
\hline
\end{tabular}

Informal Kinship (Factor I)

$\begin{array}{lllll}\text { Friends } & 2.72 \pm 1.43 & 2.94 \pm 1.43 & 2.17 \pm 1.34 & 3.50 \pm 0.71\end{array}$

Spouse's/Partner's

$\begin{array}{lllll}\text { Friends } & 1.85 \pm 1.58 & 1.70 \pm 1.69 & 2.22 \pm 1.35 & 1.50 \pm 0.71 \\ \text { Own Children } & 2.91 \pm 1.96 & 3.06 \pm 1.92 & 2.57 \pm 2.09 & 3.00 \pm 1.41 \\ \text { Other Parents } & 1.89 \pm 1.59 & 1.92 \pm 1.71 & 1.87 \pm 1.39 & 1.50 \pm 0.71 \\ \text { Church } & 2.81 \pm 1.79 & 2.70 \pm 1.87 & 3.09 \pm 1.54 & 2.50 \pm 3.54\end{array}$

Spouse/Partner Support (Factor II)

$\begin{array}{lllll}\begin{array}{l}\text { Spouse/Partner } \\ \text { Spouse's/Partner's }\end{array} & 4.32 \pm 1.53 & 4.06 \pm 1.77 & 4.96 \pm 0.21 & 3.50 \pm 2.12 \\ \begin{array}{l}\text { Parents } \\ \begin{array}{l}\text { Spouse's/Partner's } \\ \text { Relatives/Kin }\end{array}\end{array} & 2.60 \pm 1.97 & 2.24 \pm 2.07 & 3.39 \pm 1.59 & 2.50 \pm 0.71 \\ & 2.08 \pm 1.62 & 1.72 \pm 1.59 & 2.83 \pm 1.50 & 2.50 \pm 0.71\end{array}$

Social Organizations (Factor III)

$\begin{array}{lllll}\text { Social Groups/Clubs } & 0.93 \pm 1.25 & 0.96 \pm 1.29 & 0.83 \pm 1.11 & 1.50 \pm 2.12 \\ \text { Parents Groups } & 1.77 \pm 1.76 & 2.18 \pm 1.88 & 1.04 \pm 1.15 & 0 \\ \text { School/Day Care } & 3.27 \pm 1.72 & 3.10 \pm 1.81 & 3.52 \pm 1.53 & 4.50 \pm 0.71 \\ \text { Co-Workers } & 1.35 \pm 1.51 & 1.18 \pm 1.55 & 1.61 \pm 1.44 & 2.50 \pm 0.71\end{array}$

Formal Kinship (Factor IV)

$\begin{array}{lllll}\text { Relatives/Kin } & 2.36 \pm 1.65 & 2.42 \pm 1.67 & 2.26 \pm 1.60 & 2.00 \pm 2.83 \\ \text { Own Parents } & 3.05 \pm 2.00 & 3.10 \pm 2.09 & 2.91 \pm 1.88 & 3.50 \pm 2.12\end{array}$

Professional Services (Factor V)

Early Intervention

$\begin{array}{lllll}\text { Programs } & 2.25 \pm 2.11 & 2.10 \pm 2.12 & 2.39 \pm 2.11 & 4.50 \pm 0.71\end{array}$

Professional Helpers $3.55 \pm 1.69 \quad 3.52 \pm 1.76 \quad 3.65 \pm 1.50 \quad 3.00 \pm 2.83$

Family/Child's

$\begin{array}{lllll}\text { Physician } & 3.07 \pm 1.61 & 2.76 \pm 1.61 & 3.74 \pm 1.36 & 3.00 \pm 2.83\end{array}$

Professional Agencies 1.56 $\pm 1.73 \quad 1.40 \pm 1.75 \quad 1.78 \pm 1.59 \quad 3.00 \pm 2.83$ 
helpful. Parents' responses indicated their belief that their spouse or partner provided the most support, with a mean score and standard deviation of $4.32 \pm 1.53$. Professional helpers, school or day care, family or child's physician, and the participants' own parents were rated generally to very helpful, as evidenced by their mean scores ranging between 3.0 and 4.0. Other parents, their spouse or partner's friends, parent groups, professional agencies, and coworkers were rated by the participants as not at all to sometimes helpful, as evidenced by their mean scores ranging between 1.0 and 2.0. The parents viewed social groups or social clubs least helpful, with a mean score and standard deviation of $.93 \pm 1.25$.

The mean and the standard deviation for items included within each of the FSS (Dunst et al., 1984) factors are presented in Table 4-2. Parents reported Spouse or Partner Support (Factor II) as the most helpful. Factor II contains scale items representing the spouse or partner, spouse or partner's parents, and spouse or partner's relatives or kin. The Factor II total score mean (9.00) divided by number of Factor II items (3) yields a mean item score (3.0), which reflects that supports represented by Factor II were viewed as generally helpful. Factor II contained the FSS item with the highest mean of all scale items. This item, spouse or partner, with a mean of 4.32, showed that this group of parents viewed their spouse or partner as the most helpful.

Formal Kinship (Factor IV) was the second most helpful resource for parents. Factor IV includes the scale items relatives or kin and own parents. The Factor IV total score mean (5.41) divided by the number of Factor IV items (2) yields a mean item score (2.70), which reflects that supports represented by Factor IV were viewed as generally helpful. Parents viewed their own parents as generally helpful and other relatives or kin as sometimes helpful.

Professional Services (Factor V) was the third most helpful resource for parents. Factor V represents early intervention programs, professional helpers, family or child's physician, and professional agencies. The Factor V total score mean (10.43) divided by the number of Factor $\mathrm{V}$ items (4) yields a mean item score (2.61), which shows that supports represented by Factor V were viewed as sometimes to generally helpful. Parents viewed professional helpers as generally to very helpful.

Informal Kinship (Factor I) was the fourth most helpful resource for parents. Factor I items included friends, spouse or partner's friends, own children, other parents, and church. Factor I total mean score (12.19) divided by the number of Factor I items (5) yields a mean item score (2.44), which suggested that parents viewed informal kinship as sometimes to generally helpful. Parents viewed their own children and the church as the most helpful resources within Factor I and friends as the least helpful.

Social Organizations (Factor III) was the least helpful resource for parents. Factor III scale items included social groups or clubs, parents groups, school or day care, and co-workers. Factor III total mean score (7.32) divided by the number of Factor III items (4) yields a mean item score (1.83), which indicates that parents generally viewed Factor III as sometimes helpful. Parents viewed school or day care as generally helpful 
and social groups/clubs as not at all helpful.

\section{Findings: Parental Stress}

Parents' views of stress were measured using the PSI-SF [Abidin, 1995] (Table 4-3). The range of the parents' Total Stress Score was 41 ( ${ }^{\text {rd }}$ percentile) -149 (above the $99^{\text {th }}$ percentile). The mean for the participants' Total Stress Score was 99.87, with a range 41-149, and is above the $95^{\text {th }}$ percentile, which is considered significant clinically according to Abidin. The mean scores for the Parental Distress (PD), Parent-Child Dysfunctional Interaction (P-CDI), and Difficult Child (DC) subscales were at the $80^{\text {th }}$ percentile, above the $90^{\text {th }}$ percentile, and at the $95^{\text {th }}$ percentile, respectively. The ranges were as follows: PD 14-58, P-CDI 12-48, and DC 14-58. The percentage of the participants, mothers, fathers, and other with Total Stress scores at or above the $90^{\text {th }}$ percentile was $62.7,66,52.2$, and 100 , respectively.

\section{Findings: Parental Coping}

Parents reported on coping strategies they used and ranked the helpfulness of each (Table 4-4). These coping strategies were measured using the CHIP (McCubbin et al., 1981). The mean score for Coping Pattern I showed that parents found that coping by using family adjustment, teamwork, and a positive meaning of the situation (McCubbin et al., 2001) was moderately helpful. The mean total score for Coping Pattern I was 42.71; the mean item score for Coping Pattern I was 2.25 (42.71 divided by 19 equals 2.25). A 2.25 on the CHIP (McCubbin et al., 1981) represents moderately helpful coping behaviors. Parents' total scores for Coping Pattern I ranged from 26-57, representing minimally helpful to extremely helpful coping behaviors.

Parents' scores suggested that Coping Pattern II behaviors, which included continuing to seek and use available social support, self-respect, and emotional strength (McCubbin et al., 2001), were minimally helpful. The mean total score for Coping Pattern II was 30.76; the mean item score for Coping Pattern II was 1.71 (30.76 divided by 18 equals 1.71 ). This score of 1.71 on the CHIP (McCubbin et al.) represents minimally helpful coping behaviors. Participants' total scores for Coping Pattern II ranged from 10-51, denoting minimally helpful to moderately helpful coping strategies.

Participants' responses suggested that Coping Pattern III behaviors that consist of insight into the health care position by talking with other parents and health care professionals (McCubbin et al., 2001) were moderately helpful. The mean total score for Coping Pattern III was 17.6; the mean item score for Coping Pattern III was 2.2 (17.6 divided by 8 equals 2.2). A 2.2 on the CHIP (McCubbin et al.) represents moderately helpful coping behaviors. The total scores for Coping Pattern II ranged from 7-24, denoting minimally helpful to extremely helpful behaviors for parental coping strategies used when a child has autism.

Parents' total coping score on the CHIP (McCubbin et al., 1981) suggested that participants were using coping behaviors that were moderately helpful. The mean score 
Table 4-3. Parenting Stress Index-Short Form Scale and Total Scores for the Sample, Mothers, Fathers, and Others

\begin{tabular}{lllll}
\hline $\begin{array}{l}\text { Subscales } \\
\text { Mean } \pm \text { SD }\end{array}$ & $\begin{array}{l}\text { Sample } \\
\mathrm{N}=75\end{array}$ & $\begin{array}{l}\text { Mother } \\
\mathrm{n}=50\end{array}$ & $\begin{array}{l}\text { Father } \\
\mathrm{n}=23\end{array}$ & $\begin{array}{l}\text { Other } \\
\mathrm{n}=2\end{array}$ \\
\hline $\begin{array}{l}\text { Parental Distress } \\
\text { Parent-Child Dysfunctional }\end{array}$ & $30.99 \pm 8.79$ & $31.52 \pm 9.21$ & $29.91 \pm 8.09$ & $30.00 \pm 8.49$ \\
$\begin{array}{l}\text { Interaction } \\
\text { Difficult Child }\end{array}$ & $29.61 \pm 8.01$ & $30.90 \pm 8.07$ & $26.17 \pm 7.02$ & $37.00 \pm 1.41$ \\
\hline Total Stress Score & $39.00 \pm 9.51$ & $40.02 \pm 8.97$ & $36.09 \pm 10.31$ & $47.00 \pm 5.66$ \\
\hline
\end{tabular}

Table 4-4. Parental Coping Patterns as Measured by the Coping Health Inventory for Parents

\begin{tabular}{lllll}
\hline $\begin{array}{l}\text { Subscales } \\
\text { Mean } \pm \text { SD }\end{array}$ & $\begin{array}{l}\text { Sample } \\
\mathrm{N}=75\end{array}$ & $\begin{array}{l}\text { Mother } \\
\mathrm{n}=50\end{array}$ & $\begin{array}{l}\text { Father } \\
\mathrm{n}=23\end{array}$ & $\begin{array}{l}\text { Other } \\
\mathrm{n}=2\end{array}$ \\
\hline Coping Pattern I & $42.71 \pm 7.65$ & $42.62 \pm 7.91$ & $42.78 \pm 7.06$ & $44.00 \pm 12.73$ \\
Coping Pattern II & $30.76 \pm 8.5$ & $32.74 \pm 7.23$ & $25.70 \pm 8.48$ & $39.50 \pm 16.26$ \\
Coping Pattern III & $17.6 \pm 4.3$ & $18.76 \pm 3.87$ & $15.09 \pm 4.06$ & $17.50 \pm 7.78$ \\
\hline Coping (Total Score) & $91.07 \pm 16.70$ & $94.12 \pm 16.05$ & $83.57 \pm 14.63$ & $101.00 \pm 36.77$ \\
\hline
\end{tabular}


for Total Coping Behaviors was 91.07; therefore, when divided by 45, the total CHIP (McCubbin et al.) items, equals 2.02, which represents moderately helpful coping behaviors. The scores for the Total Coping Behaviors ranged from 58-127, denoting minimally helpful to moderately helpful behaviors for strategies used by parents when a child has autism.

\section{Research Question 1b and Findings}

What do parents report as the autism-related resources used and needs for themselves, their children with autism, and their family?

Professional Services (Factor V) and Social Organizations (Factor III) were measured using the FSS (Dunst et al., 1984). The third most beneficial support for parents was Professional Services (Factor V), with a total mean and standard deviation of $10.43 \pm 4.45$ and a mean item score of 2.6. Participants viewed early intervention programs, professional helpers, family/child's physician, and professional agencies as sometimes to generally helpful. Professional helpers were viewed as the most helpful in this factor. Participants viewed Social Organizations (Factor III) that included social groups or clubs, parents' groups, school or day care, and co-workers as the least helpful factor. The mean item score for Factor III was 1.83. The scale item social groups/clubs was not at all helpful to parents. The mean for this item was 0.93 , the lowest mean of all items on the FSS.

Coping Pattern III included coping behaviors of gaining insight into the health care position by talking with other parents and health care professionals (McCubbin et al., 2001). Participants reported these coping behaviors were moderately helpful.

Participants responded to the question, "Are you currently attending a support group?" Findings from the current study suggested that $46.7 \%$ of participating parents of children with autism have or are presently involved in family support groups.

\section{Specific Aim Two}

Specific Aim Two was to examine the relationships among the adaptive behaviors of children with autism, family support networks, parental stress, and parent patterns of coping.

\section{Research Question 2a and Findings}

What are the relationships among adaptive behaviors of children with autism, family support, parental stress, and parental coping?

The relationships among the adaptive behaviors of children with autism, family 
support, parental stress, and patterns of coping were examined using Pearson product moment correlations (Table 4-5). To decrease the chance of making a Type I error, the Bonferroni adjustment was used to calculate a corrected significance level of $\alpha=.003$. Adaptive behaviors of children with autism were negatively correlated with parental Coping Pattern II ( $\mathrm{r}=-.358, \mathrm{p}=.002)$. According to Green and Salkind (2003), since $\mathrm{r}=-.358$ low adaptive behavior scores on the Vineland-II had a tendency to be correlated with increased parental Coping Pattern II scores, and high adaptive behaviors of the child with autism had a tendency to be associated with decreased parental Coping Pattern II behaviors. Family support was positively correlated with parental Coping Pattern I $(\mathrm{r}=.427, \mathrm{p}=.000)$. Coping patterns I, II, and III positively correlated, as expected.

Additional analyses were conducted to examine the adaptive behaviors of children with autism, family support, maternal stress and patterns of coping (Table 4-6) and adaptive behaviors of children with autism, family support, paternal stress and patterns of coping (Table 4-7). Maternal stress was negatively correlated with family support and a weak correlation was documented $(\mathrm{r}=-.297, .036)$. Maternal coping pattern I was positively associated with family support $(\mathrm{r}=.412, .003)$. However, maternal coping patterns I and II were negatively associated with maternal stress and weak associations were reported $(-.344, .014)$ and $(-.301, .034)$, respectively. All maternal coping patterns were positively correlated. Paternal stress was negatively and strongly correlated with the adaptive behaviors of the child with autism $(-.573, .004)$. Like maternal stress, paternal stress was negatively and strongly correlated with paternal coping pattern II $(-.572, .004)$. The only paternal coping patterns positively associated were coping patterns I and II and a strong correlation was documented $(.658, .001)$, respectively.

\section{Research Question 2b and Findings}

Which of the predictors, adaptive behaviors of children with autism or family support, better predict the criterion parental coping?

Multiple regression analyses were performed for the outcome variables Coping Patterns I, II, and III obtained from the CHIP (McCubbin et al., 1981). According to Burns and Grove (2005), multicollinearity should be considered when multiple regression analyses include strongly correlated predictor variables. The multiple regression analyses included 73 participants who were biological parents of children with autism and excluded grandmother and stepfather, who participated in the study.

In Model 1 (Table 4-8) adaptive behaviors of the child with autism obtained from the Vineland-II (Sparrow et al., 2005), FSS (Dunst et al., 1984) total score, PSI-SF (Abidin, 1995) total stress score, Coping Pattern II, and Coping Pattern III were entered as the predictor variables for Coping Pattern I. The sample results documented a significant positive relationship between family support networks and parental Coping Pattern I ( $\mathrm{p}=.002$ ) which focused on family adjustment, teamwork, and a positive meaning of the situation (McCubbin et al., 2001). There was not much difference 
Table 4-5. Correlations Among Adaptive Behaviors of Children with Autism, Their Family Support Networks, and Parental Stress and Coping: Pearson Correlation, p-value

\begin{tabular}{lccccc}
\hline Variables & FSS & PSI-SF & CPI & CPII & CPIII \\
\hline Vineland-II & $-.015, .898$ & $-.301, .009^{* *}$ & $-.108, .358$ & $-.358, .002^{* * *}$ & $-.227, .050$ \\
FSS & & $-.252, .029^{*}$ & $.427, .000^{* * *}$ & $.102, .385$ & $.095, .416$ \\
PSI-SF & & & $-.223, .055$ & $.018, .881$ & $.155, .185$ \\
CPI & & & $.537, .000^{* * *}$ & $.395, .000^{* * *}$ \\
CPII & & & & $.463, .000^{* * *}$ \\
\hline
\end{tabular}

Vineland-II=Vineland Adaptive Behavior Scales, Second Edition; FSS=Family Support Scale; PSI-SF=Parenting Stress Index-Short Form; CPI=Coping Pattern I of the Coping Health Inventory for Parents; CPII=Coping Pattern II of the Coping Health Inventory for Parents; CPIII $=$ Coping Pattern III of the Coping Health Inventory for Parents; ${ }^{*} \mathrm{p}<.05$; $* * \mathrm{p}<.01 ; * * \mathrm{p}<.003$ (Bonferonni correction); $\mathrm{N}=75$ 
Table 4-6. Correlations Among Adaptive Behaviors of Children with Autism, Their Family Support Networks, and Maternal Stress and Coping: Pearson Correlation, p-value

\begin{tabular}{lccccc}
\hline Variables & FSS & PSI-SF & CPI & CPII & CPIII \\
\hline Vineland-II & $.031, .831$ & $-.138, .338$ & $-.016, .914$ & $-.188, .191$ & $-.084, .562$ \\
FSS & $-.297, .036^{*}$ & $.412, .003^{* *}$ & $.153, .289$ & $.121, .402$ \\
PSI-SF & & $-.344, .014^{*}$ & $-.301, .034^{*}$ & $-.085, .559$ \\
CPI & & & $.538, .000^{* * *}$ & $.585, .000 * * *$ \\
CPII & & & & $.544, .000 * * *$ \\
\hline
\end{tabular}

Vineland-II=Vineland Adaptive Behavior Scales, Second Edition; FSS=Family Support Scale; PSI-SF=Parenting Stress Index-Short Form; CPI=Coping Pattern I of the Coping Health Inventory for Parents; CPII=Coping Pattern II of the Coping Health Inventory for Parents; CPIII $=$ Coping Pattern III of the Coping Health Inventory for Parents; ${ }^{*} \mathrm{p}<.05$; $* * \mathrm{p}<.01 ; * * * \mathrm{p}<.003$ (Bonferonni correction); $\mathrm{n}=50$ 
Table 4-7. Correlations Among Adaptive Behaviors of Children with Autism, Their Family Support Networks, and Paternal Stress and Coping: Pearson Correlation, p-value

\begin{tabular}{lccccc}
\hline Variables & FSS & PSI-SF & CPI & CPII & CPIII \\
\hline Vineland-II & $-.136, .537$ & $-.573, .004^{* *}$ & $-.287, .184$ & $-.572, .004^{* *}$ & $-.375, .078$ \\
FSS & & $-.137, .532$ & $.404, .056$ & $.073, .741$ & $.153, .487$ \\
PSI-SF & & $.004, .985$ & $.263, .224$ & $.405, .055$ \\
CPI & & & $.658, .001^{* * *}$ & $-.007, .974$ \\
CPII & & & & $-.036, .870$ \\
\hline
\end{tabular}

Vineland-II=Vineland Adaptive Behavior Scales, Second Edition; FSS=Family Support Scale; PSI-SF=Parenting Stress Index-Short Form; CPI=Coping Pattern I of the Coping Health Inventory for Parents; CPII=Coping Pattern II of the Coping Health Inventory for Parents; CPIII=Coping Pattern III of the Coping Health Inventory for Parents; ${ }^{*}<<.05$; $* * \mathrm{p}<.01 ; * * * \mathrm{p}<.003$ (Bonferonni correction); $\mathrm{n}=23$ 
Table 4-8. Multiple Regression Analyses Results Predicting Parental Coping Patterns by Adaptive Behaviors of Children with Autism, Family Support Networks, Parental Stress and Other Parental Coping Behaviors $(\mathrm{n}=73$ )

\begin{tabular}{llll} 
Models & $\beta$ & Standard error & $\mathrm{p}$-value \\
\hline Coping Pattern I & & & \\
Maternal Intercept & 12.746 & 1.657 & \\
Paternal Intercept & 16.639 & 7.698 & .022 \\
Parent & -3.893 & 1.657 & .034 \\
Vineland-II & .041 & .057 & .022 \\
FSS & .175 & .054 & .471 \\
PSI-SF & -.040 & .032 & .002 \\
Coping Pattern II & .466 & .099 & .222 \\
Coping Pattern III & .457 & .182 & .000 \\
$\mathrm{R}^{2}=.504$ & Adjusted $\mathrm{R}^{2}=.459$ & $\mathrm{~F}=11.187$ & .015 \\
& & & $\mathrm{p}=.000$
\end{tabular}

Coping Pattern II

$\begin{array}{llll}\text { Maternal Intercept } & 23.822 & 1.703 & .001 \\ \text { Paternal Intercept } & 17.911 & 8.263 & .034 \\ \text { Parent } & 5.911 & 1.703 & .001 \\ \text { Vineland-II } & -.167 & .058 & .005 \\ \text { FSS } & -.082 & .062 & .193 \\ \text { PSI-SF } & -.032 & .035 & .352 \\ \text { Coping Pattern I } & .538 & .114 & .000 \\ \text { Coping Pattern III } & .173 & .203 & .397 \\ \mathrm{R}^{2}=.517 & \text { Adjusted } \mathrm{R}^{2}=.473 & \mathrm{~F}=11.765 & \mathrm{p}=.000\end{array}$

Coping Pattern III

$\begin{array}{llll}\text { Maternal Intercept } & 7.012 & 1.055 & .008 \\ \text { Paternal Intercept } & 4.104 & 5.120 & .426 \\ \text { Parent } & 2.908 & 1.055 & .008 \\ \text { Vineland-II } & -.019 & .037 & .609 \\ \text { FSS } & .000 & .038 & .996 \\ \text { PSI-SF } & .027 & .021 & .203 \\ \text { Coping Pattern I } & .191 & .076 & .015 \\ \text { Coping Pattern II } & .063 & .074 & .397 \\ \mathrm{R}^{2}=.342 & \text { Adjusted } \mathrm{R}^{2}=.283 & \mathrm{~F}=5.727 & \mathrm{p}=.000\end{array}$

Coping Pattern I, Coping Pattern II, and Coping Pattern III-Coping Health Inventory for Parents; Vineland-II=Adaptive Behavior Scales, Second Edition; FSS=Family Support Scale; PSI-SF=Parenting Stress Index-Short Form 
between mothers and fathers in the diagram of this relationship between family support networks and Coping Pattern I (Figure 4-1). Additionally, a significant positive relationship existed between Coping Pattern II which focused on continuing to seek and use available social support, self-respect, and emotional strength (McCubbin et al., 2001) and Coping Pattern $\mathrm{I}(\mathrm{p}=.000)$. The $\mathrm{R}^{2}=.504$, Adjusted $\mathrm{R}^{2}=.459$, and $\mathrm{F}$ value $=11.187$.

In Model 2 (Table 4-8) the adaptive behaviors of the child with autism, family support networks, parental stress, parental Coping Pattern I, and parental Coping Pattern III were entered as the predictor variables for Coping Pattern II. A significant negative relationship existed between the adaptive behaviors of the child with autism and Coping Pattern II ( $\mathrm{p}=.005)$. The diagram presented an inverse relationship between the adaptive behaviors of the child with autism and parental Coping Pattern II (Figure 4-2).

Additionally, parental Coping Pattern I was positively associated with parental Coping Pattern II ( $\mathrm{p}=.000$ ). Additionally, the $\mathrm{R}^{2}=.517$, Adjusted $\mathrm{R}^{2}=.473$, and $\mathrm{F}$ value $=11.765$, the highest of all three models in the multiple regression analyses.

In Model 3 (Table 4-8), the adaptive behaviors of the child with autism, family support networks, parental stress, parental Coping Pattern I, and parental Coping Pattern II were entered as predictor variables for Coping Pattern III. The maternal intercept was the only significance between the two $(\mathrm{p}=.008)$. The only significant relationship was positive between parental Coping Pattern I and parental Coping Pattern III $(\mathrm{p}=.015)$. The $\mathrm{R}^{2}=.342$, Adjusted $\mathrm{R}^{2}=.283$, and $\mathrm{F}$ value $=5.727$. 


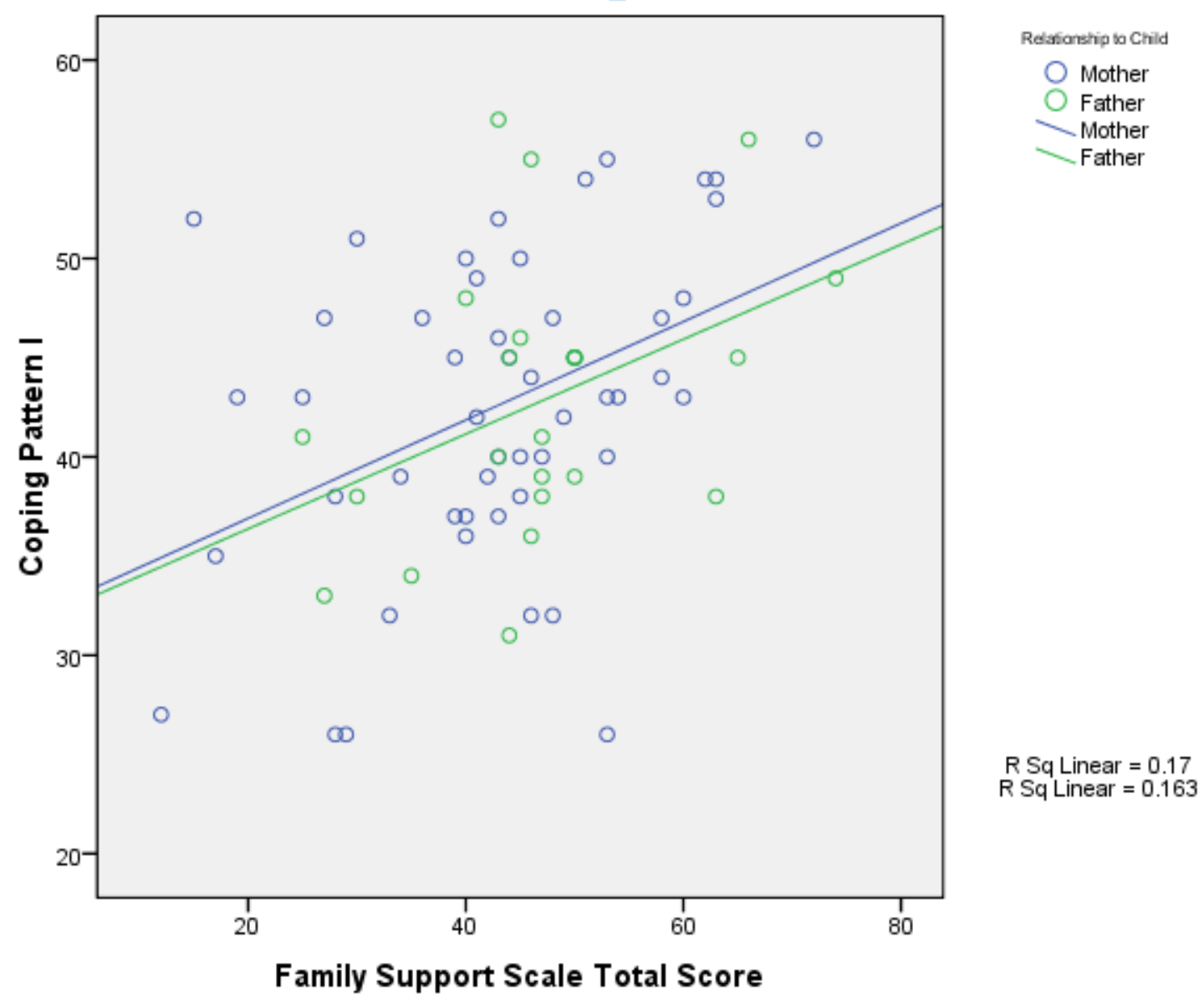

Figure 4-1. Scatter Diagram of Family Support Networks and Parental Coping Pattern I 


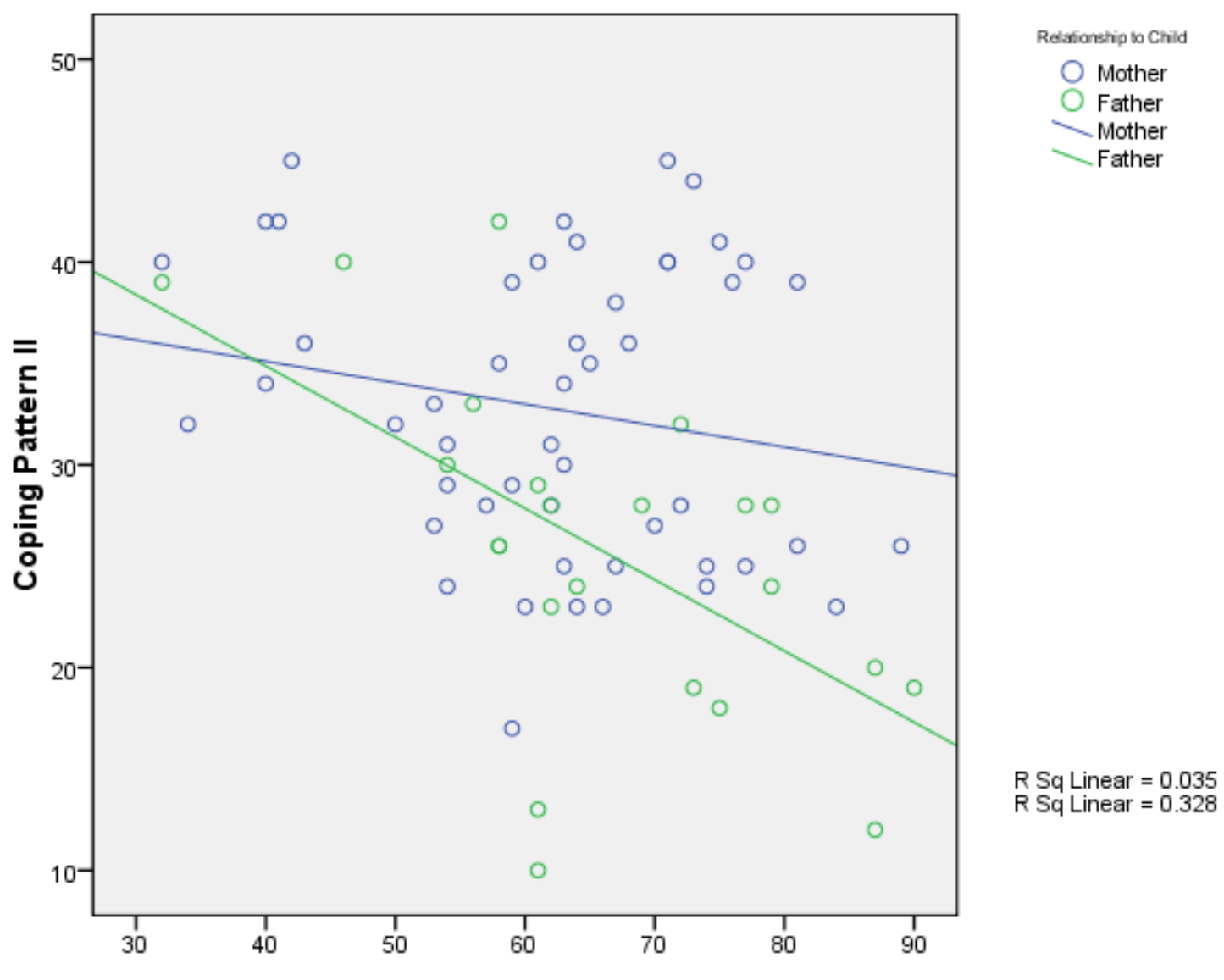

VABS-II Adaptive Behavior Composite Standard Score

Figure 4-2. Scatter Diagram of Adaptive Behaviors of Child with Autism and Parental Coping Pattern II 


\section{CHAPTER 5. DISCUSSION}

This study examined the adaptive behaviors of children with ASD, family support networks, parental stress, parental coping, and relationships among these variables. A discussion of the study findings and an evaluation of these findings in relation to the published research are included in this chapter. The limitations, strengths, practice and theoretical implications, recommendations for future research, and summary are presented.

\section{Demographics}

Seventy-five parents, including one grandmother and one step-father, participated in the current study as primary caregivers; seventy-three of these participants were biological parents ( $\mathrm{N}=50$ Mothers; $\mathrm{N}=23$ Fathers). The higher percentage of female participants in this study is similar to findings in previous research involving parents of children with autism (Dunn et al., 2001; Gray, 2006; Hastings, Kovshoff, Brown, et al., 2005; Hastings \& Johnson, 2001). That a majority of participants were well-educated and Caucasian also corresponded with educational levels and ethnicity rates of participants in previous research (Benson, 2006; Hastings, 2003; Lecavalier et al., 2006; Tomanik et al, 2004). The mean age of participants in this study was 40 , and most participants resided in Mobile County, Alabama (68\%). The ethnicity of Mobile County residents is $62.1 \%$ Caucasian, 34.5\% African American, 0.6\% American Indian, and 1.5\% Latino or Hispanic (U.S. Census Bureau, 2008). Based on data from 14 states and reported by the ADDM Network, Rice (2007) reported a trend toward increased prevalence of ASD in non-Hispanic Caucasian children compared to non-Hispanic African-American children. There was also a trend toward lower prevalence of ASD in Hispanic children compared to non-Hispanic Caucasian and non-Hispanic African-American children (Rice).

The majority of participants in the current study were parents of male children $(82.7 \%)$ diagnosed with autism. The CDC (2007) reported that autism appears four times higher in males than in females. Many studies in the literature review related to the current study included samples representing parents of males four times more often than parents of females (Duarte et al., 2005; Dziuk et al., 2007; McGovern \& Sigman, 2005; Rinehart, Bellgrove, et al., 2006). Other studies reviewed included at least considerably more parents of males than females (Elder, Valcante, Yarandi, et al., 2005; Keller \& Honig, 2004; Montes \& Halterman, 2006; Provost, Lopez, et al., 2007; Rinehart, Tonge, et al., 2006; Stone \& Yoder, 2001). Fombonne (2003) speculated that perhaps more parents of girls were from minority ethnic groups, and these parents might not believe that support groups would be able to help them in their unique situations. 


\section{Specific Aim One}

Specific Aim One was to examine parental views of adaptive behaviors of children with autism, family support networks, parental stress, and parental coping.

The related Research Questions were: (a) In families of children with autism, how do parents view the adaptive behaviors of their child with autism, the support for their family, parental stress, and their patterns of coping? (b) What do parents report as the autism-related resources used and needs for themselves, their children with autism, and their family?

The findings were as follows:

\section{Adaptive Behaviors of Children with Autism}

The adaptive functioning levels of the children with autism were established through the scoring of parents' responses on the Vineland-II (Sparrow et al., 2005). A low adaptive functioning level has been set as a score at or below 70, and a score of 7185 indicates a moderately low adaptive behavior level. Adaptive functioning is important to the ability of the children with autism to function successfully and independently, adaptive behaviors are important to individuals with autism (Liss et al., 2001). Parents in the current study reported that the children with autism functioned at a low adaptive level in Socialization, Communication, and Daily Living Skills; the children functioned at a moderately low adaptive level in Motor Skills. This finding is consistent with findings reported by Butter et al. (2007) and Tomanik et al. (2007).

In the current study, domain scores for Socialization, Communication, Daily Living Skills, and Motor Skills on the Vineland-II were used to calculate a low adaptive functioning composite score $(\mathrm{M}=63.47)$ for the children with autism. Parents designated Socialization as the lowest adaptive functioning level, and Motor Skills was chosen by parents as the highest adaptive functioning level for the children with autism. Socialization skills have been found to be poor for children with autism in previous research (Anderson et al., 2004; Heimann et al., 2006; Kamps et al., 2002; OwenDeSchryver et al., 2008; Pisula, 2007; Tomanik et al., 2004). Anderson et al. maintained that the limitations in socialization cause the children difficulties in relating to peers and to adults; therefore, the children need professional not paraprofessional teaching in the schools. Supervised, free-play time shared by young children with autism and typically developing children would help children with autism learn required motor skills to play age-appropriate games with peers and practice socialization skills simultaneously (Provost, Lopez, et al., 2007).

Findings in the current study suggested low adaptive functioning levels in the areas of Communication and Daily Living skills for children with autism. These findings are consistent with findings in previous research (Carothers \& Taylor, 2004; Sigman \& McGovern, 2005; Tomanik et al., 2004). Sigman and McGovern maintained the necessity of early intervention in communication for children with autism, because children with 
autism make their greatest language improvements from preschool to middle school years. Carothers and Taylor maintained that Daily Living Skills are complicated for children with autism; therefore; parents, educators, and other professionals should collaborate to provide appropriate, ongoing instruction for the children. Tomanik et al. discovered that interventions to reduce maladaptive behaviors could also improve adaptive behaviors for children with autism; because the more maladaptive behaviors the child presented, the lower the adaptive functioning.

Findings in this study are similar to findings in previous research that Motor Skills for children with autism under the age of 7 years are observed to be at a moderately low adaptive functioning level. Research suggested that even high-functioning children with autism had greater difficulty planning a motor movement, executing the motor movement (Rinehart, Bellgrove, et al., 2006), and completing the motor movement than children without autism of the same age (Dziuk et al., 2007). Children with autism present observable differences in coordination, stride, and smoothness in walking (Rinehart, Tonge, et al., 2006).

In the current study, mothers and fathers reported similarities and differences in their views of their children's adaptive behaviors. Mothers and fathers in the current study agreed that their children with autism had low adaptive functioning in three domains of the Vineland-II, and they ranked them in the following order from lowest to highest: Socialization, Daily Living Skills, and Communication. Parents viewed Motor Skills for children under the age of 7 as moderately low with the fathers scoring the children slightly higher than the mothers. Differences in maternal and paternal views about the adaptive behavior functioning levels for their children with autism were not significant. Scores in the current study reflect the findings of Pisula (2007), which suggested that mothers of children with autism find that their children with autism had a greater limitation in the area of Socialization. Findings of the current study are inconsistent with those of Tomanik et al. (2007) where participants reported Daily Living Skills as the lowest functioning level for children with autism.

\section{Family Support Networks}

Parents in the current study reported their views about support they received from

family support networks within the last three to six months by completing the FSS (Dunst et al., 1984). Parents reported supports in the following order from most helpful to least helpful: spouse or partner support, formal kinship, professional services, informal kinship, and social organizations. Scale items within each chosen area provided additional information concerning parents' views of supports received.

Spouse or partner was designated by parents as their most helpful source of family support. Scale items included in the spouse or partner factor of the FSS are spouse or partner, spouse's or partner's parents, and spouse or partner's relatives or kin (Dunst et al., 1984). This finding is consistent with previous research of Tunali and Power (2002).

Parents of this study reported formal kinship as their second most helpful family 
support. Three scale items are listed for formal kinship on the FSS: relatives, kin, and own parents (Dunst et al., 1984). Participants chose their own parents as most helpful. This finding is consistent with previous research (Hastings, 2003a; Keller \& Honig, 2004; White \& Hastings, 2004). Participants reported to Hastings that relatives or kin were important sources of support for their families of children with autism. Parents maintained that informal support that included their immediate and extended family was very helpful until their child reached adolescence, and then the support received from family members became limited (White \& Hastings). When parents received less family support, their stress levels were high (Preece \& Jordan, 2007). Therefore, relatives, especially grandparents, should be encouraged to offer more support for parents of children with autism (Keller \& Honig).

Professional services were viewed as parents' third most helpful resource. Scale items on the FSS listed under professional services included early intervention programs, professional helpers, family or child's physician, and professional agencies (Dunst et al., 1984). Parents designated professional helpers as offering the most family support, and professional agencies were reported as the least helpful. White and Hastings (2004) found no association between professional support and parental well-being. Parents have reported that professional collaboration and consultation about autism within the school system were very helpful (Renty \& Roeyers, 2006).

Informal kinship was viewed by parents in the current study as their fourth most helpful family supports. Informal kinship consists of friends, spouse or partner's friends, own children, other parents, and church on the FSS (Dunst et al., 1984). Parents chose their own children as their greatest source of support from this group, church ranked second, and spouse's or partner's friends were ranked last from this group. Findings are consistent with previous research that place school and church low on respondents' lists of helpful family supports (Gray, 2006; Hastings, Kovshoff, Brown, et al., 2005; Luther et al., 2005; Renty \& Roeyers, 2006; Twoy et al., 2007). Hastings, Kovshoff, Brown et al. reported that when parents of children with autism combined their denial of their child's autism diagnosis with religion, the parents' sense of well-being deteriorated. These findings are also consistent with research conducted by Weiss (2002) where parents reported that even though it was not always available, receiving support from good friends enhanced their self-esteem and lowered their anxiety.

Parents in this study viewed social organizations as providing their families with the least amount of support. Scale items included within the social organizations are social groups or social clubs, parents' groups, school or day care centers, and co-workers on the FSS (Dunst et al., 1984). Parents selected school or day care centers as their most helpful support from these scale items, and social groups or social clubs as their least helpful source of support. Findings of this study are consistent with previous research (Benson et al., 2008; Montes \& Halterman, 2006; Pisula, 2007; Sivberg, 2002b). Parents reported dissatisfaction and increased stress because schools were not providing appropriate special education classes for their children with autism (Pisula; Renty \& Roeyers, 2006; Sivberg); however, parents reported satisfaction with the support the children receive at school (Benson et al.) and the autism-related services that were 
provided for parents (Renty \& Roeyers). Parents expressed their concern that teachers were quicker to report their child's behavior problems than their academic problems (Montes \& Halterman).

Six scale items on the FSS were ranked by parents in the current study as being not at all helpful. These items included other parents, spouse's friends or partner's friends, parent groups, professional agencies, co-workers, social groups or social clubs. Social groups or social clubs received the lowest score on the FSS. These findings are consistent with previous research. Blackledge and Salzer (2007) stated that often parents do not attend support groups, because the interventions provided for parents are outdated and ineffective. Mandell and Salzer (2007) determined that many of the parents who attend support groups have common concerns about their children with autism: selfinjury, sleep problems, and language limitations.

Parents in the current study suggested a tendency toward favoring one-on-one support resources. In each of the five factors of the FSS, parents preferred scale items that could be supportive as a one-on-one support resource: spouse or partner, professional helpers, school or day care, family's or child's physician, and own parents. Findings of this study could reflect parents' preferences to use sources of support that would keep them away from social situations. Sivberg (2002b) reported that parents might lean toward detaching themselves from others and seek no social support. Parents are unlikely to attend group meetings if they believe the services have nothing to offer them (Symon, 2005). This finding is consistent with additional research (Elder, Valcante, Won, et al., 2003; Elder, Valcante, Yarandi, et al., 2005; Hancock et al., 2002; Symon, 2005). Elder, Valcante, Won, et al. and Elder, Valcante, Yarandi, et al. found fathers willing to participate with in-home, intervention training to help them understand procedures they might use to assist their children with autism.

Mothers and fathers in the current study expressed similarities and differences in their views about family support resources. Mothers and fathers agreed that their spouses or partners had been their greatest source of support, and they agreed that social groups or social clubs provided the least amount of support. The greatest differences of viewpoints were found on four scale items on the FSS. Mothers differed with fathers on parents' groups; mothers reported them more supportive than the fathers did. Fathers viewed spouse or partner's parents, spouse or partner's relatives, and family or child's physician as being more supportive than the mothers did.

\section{Parental Stress}

Parents in the current study reported high stress levels. Parents' responses showed a broad range of stress levels from the $3^{\text {rd }}$ percentile to above the $99^{\text {th }}$ percentile on the PSI-SF (Abidin, 1995). Parents scored at either a high normal or a high level of stress of each of the three subscales of the PSI-SF: Parental Distress (PD); Parent-Child Dysfunctional Interaction (P-CDI), and Difficult Child (DC). The Total Stress Score on the PSI-SF for parents was in the $96^{\text {th }}$ percentile. The Total Stress Score suggests the level of stress experienced in the role as a parent, and Abidin warned researchers not to 
infer any other meaning into the score. A percentile score above the $90^{\text {th }}$ percentile is high, and a Total Stress Score in the $96^{\text {th }}$ percentile on the PSI-SF indicated that parents are encountering a significant level of parental stress (Abidin).

On two of the three subscales (P-CDI and DC) of the PSI-SF, parents scored at the $95^{\text {th }}$ percentile, a high stress level. The high stress level on the P-CDI indicated that the parent and child relationship was at risk or that the relationship had never been created (Abidin, 1995). The parent might be disappointed in the child, and communications between parent and child are not strengthening the parenting role. The child might represent a depressing component in the parent's life where the parent often feels insulted and mistreated by the child (Abidin). Hamlyn-Wright, Draghi-Lorenz, and Ellis (2007) found that parents of children with ASD showed high levels of despair, concern, and uneasiness.

Parents in the current study reported difficulties in managing the children's behaviors. The high stress level reported on DC subscale score $\left(95^{\text {th }}\right.$ percentile) of the PSI-SF suggested that parents may be encountering difficulties in establishing boundaries and persuading the child to work together with them (Abidin, 1995). Professional counsel and advice could prove beneficial to the parents with a DC score above the $90^{\text {th }}$ percentile (Abidin). Parents scored their lowest stress level $\left(80^{\text {th }}\right.$ percentile) on the PD subscale, which is a high, normal stress level on the PSI-SF. The PD subscale established that parents are concerned and stressed as parents of a child with autism (Abidin).

The PSI-SF results showed similarities in stress levels for mothers and fathers in the current study on the DC scores and the Total Stress Scores. Although the mothers' mean subscale scores and mean Total Stress Score rated consistently higher than the fathers' scores, Abidin used percentile conversions to interpret stress scores. The DC scores and the Total Stress Scores were at or above a significant stress level $\left(90^{\text {th }}\right.$ percentile) for mothers and fathers. These findings suggest that there is no significant difference between the stress levels of fathers and mothers in the current study.

Parents' greatest percentile difference in stress score was on the P-CDI subscale (Mothers $=96^{\text {th }}$ percentile; Fathers $=85^{\text {th }}$ percentile). Regardless of the 11 percentile difference, both percentiles are above the $80^{\text {th }}$ percentile and are considered high stress scores on this subscale of the PSI-SF (Abidin, 1995). Instructions given by Abidin suggested that because the mothers' score was above the $90^{\text {th }}$ percentile, a closer examination of all subscale scores is advisable to look for possible abuse risks to the children. Because all three subscales for mothers are not above the $90^{\text {th }}$ percentile $\left(\mathrm{PD}=81^{\text {st }}\right.$ percentile; $\mathrm{P}-\mathrm{CDI}=96^{\text {th }}$ percentile; $\mathrm{DC}=96^{\text {th }}$ percentile $)$, the P-CDI subscale score of $96^{\text {th }}$ percentile is not considered a reliable indicator of potential abuse risk problems for the child because of the mothers' high stress level (Abidin).

\section{Parental Coping}

The Total Coping Score on the CHIP (McCubbin et al., 1981) for parents in this study suggested that parents viewed their current coping behaviors as moderately helpful. 
This finding is consistent with previous research that reported parents do not always have access to daily support to assist them in coping with the experiences of raising a child with autism (Sivberg, 2002b). Therefore, more accessible support offering appropriate assistance needs to be available to help parents cope (Dunn et al., 2001). Parents need opportunities to learn new coping strategies, because coping strategies that proved to be helpful during one time period might not work for each stressful period (Gray, 2006).

Parents' responses on the CHIP in the current study suggested that parents viewed Coping Pattern I on the CHIP represented by family adjustment, teamwork, and a positive, confident meaning and clarification of the situation (McCubbin et al., 2001) as being their most helpful coping strategies. This finding is consistent with previous research (Bishop et al., 2007; Blacher \& McIntyre, 2006; Delaney \& Kaiser, 2001; Elder, Valcante, Won, et al., 2003; Higgins et al., 2005; Marcus et al., 2005; Olsson \& Hwang, 2002; Symon, 2005; Tobing \& Glenwick, 2002; Tunali \& Power, 2002; White \& Hastings, 2004). Parents reported the helpfulness of family support (White \& Hastings). Mothers of children with autism believed that being a stay-at-home-mom and spending most of their free time with family helped them cope better (Tunali \& Power). Parents stressed a desire to learn intervention strategies, especially those that could learn in their own homes (Elder, Valcante, Won, et al.; Symon). Learning to react only to the positive behaviors of the child with autism increased optimism within the family unit (Delaney \& Kaiser), because all experiences with the child are not negative (Marcus et al.). African American mothers found less negativity related to raising children with autism than White mothers (Bishop et al.), and Latino mothers reported many positive experiences in their lives associated with their children with autism (Blacher \& McIntyre). Many parents believe they have become better people and their lives have improved because of the experiences they have been given with their children with autism (Olsson \& Hwang).

Coping behaviors viewed as the second most helpful for parents in the current study were found in Coping Pattern III of the CHIP and represent meeting with other parents or talking with the professionals that were involved in their children's lives. Coping Pattern III of the CHIP included insight into the health care position by talking with other parents and health care professionals (McCubbin et al., 2001). This finding is consistent with previous research (Mandell \& Salzer, 2007; Sivberg, 2002b). Parents have reported increased stress because service providers and health care providers do not have answers to their questions or ways to fulfill the needs of their families (Sivberg). The majority of parents of children with autism who do communicate with other parents were found to be parents of children with specific problems in the areas of self-injury, sleep problems, and language limitations (Mandell \& Salzer). The finding of the current study is consistent with results found by White and Hastings (2004) that there was no association between professional support and parental well-being.

Parents' responses on the CHIP in the current study suggested they did not place much emphasis on coping by using Coping Pattern II behaviors on the CHIP and represent parents continuing to seek and use available social support, self-respect and confidence, and emotional strength (McCubbin et al., 2001), and this coping pattern scored as minimally helpful on the CHIP. This finding is consistent with previous 
research (Blackledge \& Hayes, 2006; Gupta \& Singhal, 2005; Mandell et al, 2002; Siklos $\&$ Kerns, 2006). Self-confidence in parents often suffers when their children with autism do not learn easily; parents sometimes respond by isolating the family and refusing to seek social support (Gupta \& Singhal). Parents who have reached out to social support frequently become annoyed with the social supports that are available (Siklos \& Kerns). Mandell et al. found that parent reports are true; social support is not provided for all families in all communities on the same level. Programs are being developed on the foundation that parents know what they are talking about concerning their children with autism and the effects on their families, and that today's families require a different kind of social support system than those developed for families twenty years ago (Blackledge \& Hayes).

Mothers and fathers in the current study reported similarities and differences in their coping behaviors. Mothers and fathers chose the same pattern of coping behaviors in the same order on the CHIP. They chose Coping Pattern I that included family adjustment, teamwork, and a positive, confident meaning and clarification of the situation (McCubbin et al., 2001) as the coping behaviors they considered the most helpful. Second, parents chose Coping Pattern III that included insight into the health care position by talking with other parents and health care professionals (McCubbin et al.). Lastly, parents chose Coping Pattern II that included continuing to seek and use available social support, self-respect and emotional strength (McCubbin et al.) as their coping behaviors. The similarity between coping behaviors of mothers and fathers of children with autism is consistent with previous research that found no differences in the kinds of supports chosen by mothers and fathers or their views about the effectiveness of the supports (Keller \& Honig, 2004). This finding is inconsistent with previous research that found fathers scoring higher than mothers in coping (Twoy et al., 2007).

The finding of the current study that mothers and fathers use similar coping behaviors does not agree with Gray (2003). Gray conducted a qualitative study and discovered that mothers and fathers of children with autism use different coping behaviors. Fathers reported repressing their thoughts and feelings that often results in anger. Mothers often have no problem expressing their emotions. Mothers resorted to anger, sadness, or crying to cope with stresses. Mothers also reported talking and sharing their feelings with best friends or close family members (Gray).

\section{Specific Aim Two}

Examine the relationships among the adaptive behaviors of children with autism, family support networks, parental stress, and parent patterns of coping.

The related Research Questions were: (a) What are the relationships among adaptive behaviors of children with autism, family support, parental stress, and patterns of coping? (b) Which predictor, adaptive behaviors of children with autism or family support, better predict the criterion parental coping? 
Findings of the current study suggested a relationship between adaptive behaviors of children with autism and parental stress. Paternal and maternal reports suggested a difference regarding adaptive behaviors of children with autism and stress levels for fathers and mothers. In the current study, paternal reports were significant regarding increased parental stress and the relationship with low adaptive behaviors of children with autism. This finding is consistent with previous research (Plant \& Sanders, 2007; Tomanik et al., 2004). This finding is inconsistent with previous research of Hastings, Kovshoff, Ward, et al. (2005) that suggested no association between paternal stress and adaptive behaviors of children with autism.

Maternal reports in the current study did not suggest a relationship between parental stress and adaptive behaviors of children with autism. This finding is consistent with the literature (Bromley et al., 2004; Hastings, Kovshoff, Ward, et al., 2005; Lecavalier et al., 2006). The finding is inconsistent with findings of Tomanik et al. (2004) that reported a correlation between low adaptive behaviors of children with autism and increased maternal stress.

Parents who reported that few family supports were available to them or that the supports available were not useful also reported higher stress levels in this study. This finding is consistent with the literature (Dunn et al., 2001; Hastings, 2003b; Hastings \& Johnson, 2001; Preece \& Jordan, 2007; Schieve et al., 2007). Dunn et al. reported increased parental stress with decreased social support. Hastings suggested that family support had an effect on parental stress. Hastings and Johnson reported parents of children with autism receiving informal support endure less parental stress. Schieve et al. documented that parents of children with autism involved with a support program reported minimal aggravation.

Parents in the current study reported an association among all three patterns of coping examined in the CHIP. Maternal and paternal reports differed with regard to the association of coping patterns. Maternal reports in the current study reported a positive association among all three coping patterns. Paternal reports documented a positive association between Coping Pattern I and Coping Pattern III only. Findings for paternal reports suggested that adaptive behaviors of the child with autism predicted parental Coping Pattern II behaviors on the CHIP that according to McCubbin et al.(2001) include using available social support, self-respect, and emotional strength. Findings are consistent with previous research findings of Gray (2003) and Hastings, Kovshoff, Brown, et al. (2005). Gray suggested that fathers expected mothers to be in charge of the behaviors of the child with autism. Gray also maintained that fathers considered working out of the house as one of their coping strategies, and they were, at the same time, fulfilling their responsibility of preparing for the future of the child with autism. Hastings, Kovshoff, Brown, et al. documented mothers or fathers coping by staying away from the home reported increased stress and sadness.

In the current study, no definitive determination could be made as to which predictor variable, adaptive behaviors of the child with autism or family support, better predicted parental coping patterns. The difference in the proportion of variance was only .013 between the models including Coping Pattern I and Coping Pattern II as dependent 
variables. Adaptive behaviors of the child with autism predicted Coping Pattern II behaviors which according to McCubbin et al. (2001) included using available social support, self-respect, and emotional strength. This finding is consistent with previous research (Hastings 2003b; Hastings et al., 2002; Tobing \& Glenwick, 2006). In the current study, family support predicted Coping Pattern I behaviors which according to McCubbin et al. included family adjustment, teamwork, and a positive meaning of the situation. Hastings et al. documented a positive attitude in parents of children with a disability might be associated with the family supports. Tobing and Glenwick reported a positive association between social support satisfaction and total coping score.

\section{Limitations and Strengths}

This research study contained limitations and strengths. Limitations of the study included the generalizability of the findings and the sample. All participants lived in Alabama, Mississippi, and Florida. In addition, parents in this study were mostly Caucasian mothers who had either graduated from college or had attended at least one year. Care should be used when generalizing the findings to parents of children with autism residing in other geographic areas. A threat to the internal validity of this study was temporal ambiguity. It is difficult to discern which variable precedes the other in the associated variables (Polit \& Beck, 2008). Random sampling was not the method used for this study; therefore, heterogeneity was used to control for various characteristics (i.e., participant's age, age of child with autism, and participant's education) to decrease bias (Burns \& Grove, 2005).

Another limitation of the current study is the sampling method and sample size. The sample in this descriptive, correlational study included a purposive sample. Polit and Beck (2008) stated that when non-probability sampling is used there is the possibility of not supplying a representative sample. However, most nursing research does use nonprobability sampling (Burns \& Grove, 2005; Polit \& Beck). The current study had a sample size of 75 which almost met the necessary size to achieve .80 power and medium effect size (Cohen, 1992). Cohen suggested a sample of 76 to accomplish such power. It is likely with a larger sample, a more complete understanding of these variables and relationships between the variables would have been documented. When a study has a small sample size or a low statistical power, a Type II error is possible (Burns \& Grove). Burns and Grove described a Type II error as a conclusion of samples without significant variation when a difference exists.

An additional limitation of this study is no report confirming a diagnosis of autism. The parent's report claiming their child had been diagnosed with an autism spectrum disorder was accepted. Even though no report from a healthcare provider was acquired, the children's adaptive functioning was low and consistent with adaptive skills observed in children with autism (Akshoomoff \& Stahmer, 2006; Kjelgaard \& TagerFlusberg, 2001). Using the Vineland-II to measure the child's adaptive functioning strengthened this study. According to Sparrow et al. (2005), the results of the Vineland-II supported the DSM-IV-TR (APA, 2000) criteria of a child diagnosed with autism. 
Self-report was used as the method to obtain data for this study. Currently, most research for ASD depends upon parent reports (Klinger \& Renner, 2000). Self-report was used because obtaining the information for this study would have been hard to attain using any other method (Polit \& Beck, 2008). Therefore, in the current study, self-report data supplied by interviews with parents of the children with autism was a strong aspect of the research method. Parents are educators to everyone regarding their child's characteristics and diagnosis of autism (Sheehan, 2004).

Polit and Beck (2008) discussed strengths and weaknesses of self-report instruments. They maintained that correlation designs have strength and are vital to nursing due to the need for specific areas to be investigated. Correlational designs have power in answering realistic research questions (Polit \& Beck). Self-report instruments used in the current study consisted of closed-ended questions with answer choices that required the participant to choose the one that correctly or most closely described the participant's answer. Polit and Beck discussed some of the strengths of closed-ended questions: (a) Closed-ended questions are easy for the participant and the researcher, (b) Because the answer choices are already listed, the participant can finish the instrument in less time, (c) Closed-ended questions are good for participants who have difficulty writing responses, and (d) Some questions are less offensive when they are presented in this manner (Polit and Beck).

Polit and Beck (2008) discussed weaknesses of self-report instruments and closed-ended questions: (a) Researchers may have failed to include all pertinent responses, (b) When participants do not have an appropriate response they want to use, they may choose an answer that does not accurately express their attitude or feelings, (c) If the research is exploring a new area, closed-ended questions could result in bias findings, (d) They do not allow for elaboration by those participants who might desire to say more, and (e) They require participants to choose from certain listed answers (Polit and Beck).

\section{Practice Implications}

Findings of the current study provide practice implications for healthcare providers, therapists, and other professionals involved in the lives of children with autism and their families. Professionals working together with a family need to be aware of the family's involvement in community supports so they do not become involved in so many autism-related support groups, resources, and interventions that they become stressed trying to maintain an over-booked schedule (Perry, 2004). The primary goal is to involve, educate, and comfort parents and families instead of causing additional problems (Perry). Appointment scheduling is important to the family, because both parents need to be involved in the early intervention plan to practice strategies to decrease parental stress and strengthen communication skills socially and between parents and the child (McConachie \& Diggle, 2006). 
Perry (2004) stressed that clinicians, therapists, and other professionals have the perfect opportunities to persuade parents to reach out to a social support network when they feel alone. Joining other parents who may be experiencing similar situations in their lives provides parents with a situation that professionals will not be able to give to them unless they are parents of children with autism (Perry). Research conducted by Mandell and Salzer (2007) led them to speculate on the reason that support group participants are most likely to be well-educated and Caucasian. They deduced that possibly people with these characteristics found comfort in discussing confidential family experiences with other people. Whereas, parents of children with autism who were less educated, lowincome, inner-city, or rural parents would be uncomfortable discussing their family business in a support group (Mandell \& Salzer). Therefore, evaluation of parents' stress levels and preferred coping strategies by professionals are advised before appropriate support resources can be determined (Perry).

Nurses are vital to the care of a child diagnosed with autism and their family. Nurses are present in various health care and education settings where they could be engaged with families of children with ASD (Pinto-Martin et al., 2005). It is essential that nurses attend activities which will enhance their knowledge and skills in caring for people with intellectual and developmental disabilities (Graff et al., 2007). Nurses serve as a valuable support to parents; therefore, involving nurses in the course of diagnosis and early intervention is important (Cade \& Tidwell, 2001).

\section{Theoretical Implications}

Theoretical implications confirm the use of the Double ABCX Model (McCubbin \& Patterson, 1983) of family behavior for future studies of behaviors of children with autism, family support networks, parental stress, and parental coping. In the current study, the "aA" Factor, Family Demands: Pile-up (McCubbin \& Patterson) was represented by the adaptive behaviors of children with autism. The daily repetition of adaptive behavior dysfunction would cause a build-up of stressors as indicated by the "aA" Factor of the Double ABCX Model (McCubbin \& Patterson). The current study used the "bB" Factor, Family Adaptive Resources (McCubbin \& Patterson), as the family support networks variable. The "cC" Factor, Family Definition and Meaning (McCubbin \& Patterson), examined parental stress as expressed by the Double ABCX Model (McCubbin \& Patterson). Coping used by parents was recognized by McCubbin and Patterson as the supports, views, and behaviors used to respond and interact while trying to maintain or accomplish balance within the family. The current study placed emphasis on the parental coping and the association among the variables (i.e., family support networks and adaptive behaviors of the child with autism). Factors of the Double ABCX Model allowed the researcher to examine the variables and to discover how they were associated. 


\section{Recommendations for Future Research}

There are implications for further research based on the results of the current study. The coping behaviors parents reported suggested that the more that parents attempted to maintain social support, self-esteem, and psychological stability (Coping Pattern II), the lower the adaptive behaviors of their child with autism. Future research utilizing qualitative research methodology could be conducted to acquire more information regarding the coping strategies parents use, parental stress levels, and the child's adaptive behaviors. This study could examine family adaptation balancing (xX Factor) of the Double ABCX Model (McCubbin \& Patterson, 1983) in parents of children with autism. Results could be used to guide professionals in planning education for parents on specific coping behaviors that would be useful for them as parents of a child with autism.

A focus group with parents of children with autism could assist in identifying specific supports and resources to strengthen certain coping behaviors in parents when a child is diagnosed with autism. Studies could examine parents' understanding of accessible resources in their community and which resources parents are currently using. Information supplied by parents would assist in identifying needed changes in community supports. Findings of previous research support this finding. Additional research could investigate the effects of positive experiences on parents' emotions (Hastings et al., 2002). A positive point of view while parenting a child with a disability could impact the support families seek and receive (Hastings et al.).

Future research could compare adaptive and maladaptive behaviors of children with autism and the differences when little or no family supports are available. The information obtained from these reports could contribute to determining the available and needed supports and resources for families of children with autism with maladaptive behaviors or low adaptive behaviors. Certain characteristics related to a child's disability are significant connections with the stress of the parent (Hastings \& Johnson, 2001; Plant $\&$ Sanders, 2007). These characteristics are specific to the intensity of the behavioral problems of the child (Hastings \& Johnson; Lecavalier et al., 2006). There is an indication of a relationship between the difficult behaviors of a child with autism and parental stress (Plant \& Sanders; Tomanik et al., 2004). Tomanik et al. reported that a child's maladaptive behavior and a child's adaptive behavior are both significant to a mother's stress level. Maladaptive behaviors are associated with low adaptive behaviors in children diagnosed with autism (Tomanik et al.).

Future research should not only include parents of children with autism but also siblings of the children. Results of studies should supply information on all members of the family of a child diagnosed with autism. These results could contribute to expanding the family supports to offer family intervention (Hastings, Kovshoff, Ward, et al., 2005). 


\section{Summary}

By providing parents the opportunity to participate in this study, insight into the mothers' and fathers' views about the adaptive behaviors of their children with autism, family support networks, parental stress, and parental coping were documented. Analysis of data provides professionals and researchers with valuable information from parents, the people who know the most about their own lives and the lives of their children. Their data bring new challenges and thoughts about how the children with autism and their families can be assisted. Families who are struggling to cope with the added stresses in their lives need help.

By using parents' information and respecting their perspectives, professionals can make informed decisions and more appropriate recommendations to parents of children with autism. Current study findings suggested that children with autism have limitations in adaptive functioning; therefore, early diagnosis and intensive intervention are vital to the successful development of the children. Regardless of the number of family support networks that are currently available, findings suggested that parents remain stressed at a very high level; and that many parents find family support networks not at all helpful or only minimally helpful.

Findings of the current study accentuate the importance of helping parents learn and apply appropriate, positive coping techniques that have been effectively used by parents of children with autism to diminish stress in both mothers and fathers. Viewpoints of participants in the current study can be used to update policymakers, health care providers, therapists, and other professionals directly involved with families of children with autism. With a more realistic understanding of the challenges faced by parents of children with autism, efforts can be made to recommend appropriate support and resources for the children with autism, their parents, and their families. Therefore, professionals with knowledge about successful coping strategies need to be given access to families having difficulties coping in order to teach the family members new, appropriate, positive coping strategies. Findings from the current study suggest that efforts could be made to supply accessible, useful family support networks to lower parental stress. Findings also suggest the need to teach parents positive coping strategies in order to help themselves, their children with autism, and their families. 


\section{LIST OF REFERENCES}

Abidin, R. R. (1995) Parenting Stress Index ( $3^{\text {rd }}$ ed.). Lutz, FL: Psychological Assessment Resources, Inc.

Akshoomoff, N. A., \& Stahmer, A. (2006). Early intervention programs and policies for children with autistic spectrum disorders. In H. E. Fitzgerald, B. M. Lester, \& B. Zuckerman (Eds.), The Crisis in Youth Mental Health: Critical Issues and Effective Programs: Childhood Disorders (Vol. 1, pp. 109-131). Westport, CT: Praeger. Accessed on April 4, 2008, from http://www.casrc.org/People/Internal Investigators/AkshoomoffStahmer fin.pdf

American Psychiatric Association. (2000). Diagnostic and statistical manual of mental disorders: DSM-IV-TR ( ${ }^{\text {th }}$ ed.). Washington, DC: American Psychiatric Association.

Anderson, A., Moore, D. W., Godfrey, R., \& Fletcher-Flinn, C. M. (2004). Social skills assessment of children with autism in free-play situations. Autism, 8(4), 369-385.

Ashley-Koch, E., Wolpert, C. M., Menold, M. M., Zaeem, L., Basu, S., Donnelly, S. L., et al. (1999) Genetic studies of autistic disorder and chromosome 7. Genomics, 61(3), 227-236.

Autism NSW. (2004). Autism - How to help and understand your child. Accessed January 30, 2006, from http://www.health.nsw.gov.au/health-public-affairs/mhes/publications/6965.html

Bailey, D. B., Jr. (2001). Evaluating parent involvement and family support in early intervention and preschool programs. Journal of Early Intervention, 24(1), 1-14.

Bailey, A., Le Couteur, A., Gottesman, I., Bolton, P., Simonoff, E., Yuzda, E. et al. (1995). Autism as a strongly genetic disorder: Evidence from a British twin study. Psychological Medicine, 25(1), 63-77.

Baker-Ericzen, M. J., Brookman-Frazee, L., \& Stahmer, A. (2005). Stress levels and adaptability in parents of toddlers with and without autism spectrum disorders. Research \& Practice for Persons with Severe Disabilities, 30(4), 194-204.

Baron-Cohen, S. (2004). Autism: research into causes and prevention. Pediatric Rehabilitation, 7(2), 73-78.

Benson, P., Karlof, K. L., \& Siperstein, G. N. (2008). Maternal involvement in the education of young children with autism spectrum disorders. Autism, 12(1), 4763. 
Benson, P. R. (2006). The impact of child symptom severity on depressed mood among parents of children with ASD: The mediating role of stress proliferation. Journal of Autism and Developmental Disorders, 36(5), 685-695.

Bebbington, A., \& Beecham, J. (2007). Social services support and expenditure for children with autism. Autism, 11(1), 43-61.

Bishop, S. L., Richler, J., Cain, A. C., \& Lord, C. (2007). Predictors of perceived negative impact in mothers of children with autism spectrum disorder. American Journal on Mental Retardation, 112(6), 450-461.

Blacher, J., \& McIntyre, L. L. (2006). Syndrome specificity and behavioural disorders in young adults with intellectual disability: Cultural differences in family impact. Journal of Intellectual Disability Research, 50(3), 184-198.

Blackledge, J. T., \& Hayes, S. C. (2006). Using acceptance and commitment training in the support of parents of children diagnosed with autism. Child \& Family Behavior Therapy, 28(1), 1-18. Accessed May 2, 2008, from http://www.haworthpress.com/web/CFBT

Blackwell, J., \& Niederhauser, C. (2003). Diagnose and manage autistic children. Nurse Practitioner 28(6), 36-43.

Boyd, B. A. (2002). Examining the relationship between stress and lack of social support in mothers of children with autism. Focus on Autism and Other Developmental Disabilities, 17(4), 208-215.

Bromley, J., Hare, D. J., Davison, K., \& Emerson, E. (2004). Mothers supporting children with autistic spectrum disorders-Social support, mental health status and satisfaction with services. Autism, 8(4), 409-423.

Bryson, S. E., Rogers, S . J., \& Fombonne, E. (2003). Autism spectrum disorders: early detection, intervention, education, and psychopharmacological management. The Canadian Journal of Psychiatry, 48(8), 506-516.

Burns, N., \& Grove, S. K. (2005). The practice of nursing research: Conduct, critique, and utilization. ( $5^{\text {th }}$ ed.). St. Louis, MO: Elsevier.

Butter, E. M., Aman, M. G., Arnold, L. E., Hall, K., Mulick, J. A., Holloway, J., et al. (2007). Parent training for children with pervasive developmental disorders: A multi-site disability trial. Behavioral Interventions, 22(3), 179-199. 
Buxbaum, J. D., Silverman, J. M., Smith, C. J., Kilifarski, M., Reichert, J., Hollander, E. et al. (2001). Evidence for a susceptibility gene for autism on chromosome 2 and for genetic heterogeneity. American Journal of Human Genetics, 68(6), 1514-1520.

Cade, M., \& Tidwell, S. (2001). Autism and the school nurse. Journal of School Health 71(3), 96-100.

Carothers, D. E., \& Taylor, R. L. (2004). How teachers and parents can work together to teach daily living skills to children with autism. Focus on Autism and Other Developmental Disabilities, 19(2), 102-104.

Cederlund, M., Hagberg, B., Billstedt, E., Gillberg, I. C., \& Gillberg, C. (2008). Asperger syndrome and autism: A comparative longitudinal follow-up study more than 5 years after original diagnosis. Journal of Autism and Developmental Disorders, 38(1), 72-85.

Centers for Disease Control and Prevention. (2006). Autism spectrum disorders among children. Accessed May 7, 2008, from http://www.cdc.gov/ncbddd/dd/documents/autism_factsheet020306.pdf

Centers for Disease Control and Prevention. (2007). Autism spectrum disorders overview. Accessed May 7, 2008, from http://www.cdc.gov/ncbddd/autism/overview.htm

Charman, T., Cass, H., Owen, L., Wigram, T., Slonims, V., Weeks, L., et al. (2002). Regression in individuals with Rett syndrome. Brain \& Development, 24(5), 281 283.

Chess, S. (1997). Follow-up report on autism in congenital rubella. Journal of Autism \& Developmental Disorders, 7(1), 69-81.

Cohen, J. (1992). A power primer. Psychological Bulletin, 112(1), 155-159.

Croen, L. A., Najjar, D. V., Ray, G. T., Lotspeich, L., \& Bernal, P. (2006). A comparison of health care utilization and costs of children with and without autism spectrum disorders in a large group - model health plan. Pediatrics, 118(4), e1203-e1211.

Dales, L., Hammer, S. J., \& Smith, N. J. (2001). Time trends in autism and in MMR immunization coverage in California. JAMA, 285(9), 1183-1185.

Darling, S. M., \& Gallagher, P. A. (2004). Needs of and supports for African American and European American caregivers of young children with special needs in urban and rural settings. Topics in Early Childhood Special Education, 24(2), 98-109. 
de Bildt, A., Serra, M., Luteijn, E., Kraijer, D., Sytema, S., \& Minderaa, R. (2005). Social skills in children with intellectual disabilities with and without autism. Journal of Intellectual Disability Research, 49(Pt. 5), 317-328.

Delaney, E. M., \& Kaiser, A. P. (2001). The effects of teaching parents blended communication and behavior support strategies. Behavioral Disorders, 26(2), 93116.

Desorgher, S., \& Desorgher, M. (2000). Autism - dietary treatment options. Positive Health, 57, 37-40.

DiSalvo, C. A., \& Oswald, D. P. (2002). Peer-mediated interventions to increase the social interaction of children with autism: Consideration of peer expectancies. Focus on Autism and Other Developmental Disabilities, 17(4), 198-207.

Donenberg, G., \& Baker, B. L. (1993). The impact of young children with externalizing behaviors on their families. Journal of Abnormal Child Psychology, 21(2), 179198.

Doo, S., \& Wing, Y. K. (2006). Sleep problems of children with pervasive developmental disorders: Correlation with parental stress. Developmental Medicine \& Child Neurology, 48(8), 650-655.

Duarte, C. S., Bordin, I. A., Yazigi, L., \& Mooney, J. (2005). Factors associated with stress in mothers of children with autism. Autism, 9(4), 416-427.

Dunn, M. E., Burbine, T., Bowers, C. A., \& Tantleff-Dunn, S. (2001). Moderators of stress in parents of children with autism. Community Mental Health Journal, 37(1), 39-52.

Dunst, C. J. (1985). Rethinking early intervention. Analysis and Intervention in Developmental Disabilities, 5(1-2), 165-201.

Dunst, C. J., Jenkins, V., \& Trivette, C. (1984). Family Support Scale: Reliability and validity. Journal of Individual, Family, and Community Wellness, 1(4), 45-52.

Dunst, C. J., Trivette, C. M., \& Cross, A. H. (1988). Social support networks of families with handicapped children. In S. E. Keefe (Ed.). Appalachian mental health (pp. 101-121). Lexington: University of Kentucky Press.

Dunst, C. J., Trivette, C. M., \& Hamby, D. W. (1994). Measuring social support in families with young children with disabilities. In C. J. Dunst, C. M. Trivette, \& A. G. Deal (Eds.), Supporting \& strengthening families: Methods, strategies and practice (Vol. 1, pp. 152-159). Cambridge, MA: Brookline Books. 
Dunst, C. J., Trivette, C. M., \& Jenkins, V. (2003). Family support scale. In C. Dunst, C. Trivette, \& A. Deal (Eds.), Enabling \& empowering families: Principles \& guidelines for practice (pp. 155-157). Newton, MA: Brookline Books.

Dyches, T. T., Wilder, L. K., Sudweeks, R. R., Obiakor, F. E., \& Algozzine, B. (2004). Multicultural issues in autism. Journal of Autism \& Developmental Disorders, $34(2), 211-221$.

Dziuk, M. A., Gidley Larson, J. C., Apostu, A., Mahone, E. M., Denckla, M. B., \& Mostofsky, S. H. (2007). Dyspraxia in autism: Association with motor, social, and communicative deficits. Developmental Medicine \& Child Neurology, 49(10), 734-739.

Eikeseth, S., Smith, T., Jahr, E., \& Eldevik, S. (2002). Intensive behavioral treatment at school for 4-7-year-old children with autism. Behavior Modification, 26(1), 4968.

Einspieler, C., Kerr, A. M., \& Prechtl, H. F. R. (2005). Abnormal general movements in girls with Rett disorder: The first four months of life. Brain \& Development, 27(Suppl. 1), S8-S13.

Elder, J. H., Valcante, G., Won, D., \& Zylis, R. (2003). Effects of in-home training for culturally diverse fathers of children with autism. Issues in Mental Health Nursing, 24(3), 273-295.

Elder, J. H., Valcante, G., Yarandi, H., White, D., Elder, T. H. (2005). Evaluating inhome training for fathers of children with autism using single-subject experimentation and group analysis methods. Nursing Research, 54(1), 22-32.

Escalona, A., Field, T., Nadel, J., \& Lundy, B. (2002). Brief report: Imitation effects on children with autism. Journal of Autism \& Developmental Disorders, 32(2), 141144.

Fawcett, J. (2005). Contemporary nursing knowledge: Analysis and evaluation of nursing models and theories ( $2^{\text {nd }}$ ed.). Philadelphia: F. A. Davis Company.

Fenton, G., D’Ardia, C., Valente, D., DelVecchio, I., Fabrizi, A., \& Bernabei, P. (2003). Vineland adaptive behavior profiles in children with autism and moderate to severe developmental delay. Autism: The International Journal of Research and Practice, 7(3), 269-287.

Field, T., Field, T., Sanders, C., \& Nadel, J. (2001). Children with autism display more social behaviors after repeated imitation sessions. Autism, 5(3), 317-323. 
Folkman, S., Lazarus, R. S., Gruen, R. J., \& DeLongis, A. (1986). Appraisal, coping, health status, and psychological symptoms. Journal of Personality and Social Psychology, 50(3), 571-579.

Fombonne, E. (2003). Epidemiological surveys of autism and other pervasive developmental disorders: An update. Journal of Autism and Developmental Disorders, 33(4), 365-382.

Fombonne, E., Simmons, H., Ford, T., Meltzer, H., \& Goodman, R. (2001). Prevalence of pervasive developmental disorders in the British nationwide survey of child mental health. Journal of the Academy of Child and Adolescent Psychiatry, 40(7), 820-827.

Freeman, B. J., \& Cronin, P. (2002). Diagnosing autism spectrum disorder in young children: An update. Infants \& Young Children, 14(3), 1-10.

Frith, U. (1996). Asperger and his syndrome. In U. Frith (Ed.), Autism and Asperger syndrome (pp. 1-36). United Kingdom: Cambridge University Press.

Gabriels, R. L., Hill, D. E., Pierce, R. A., Rogers, S. J., Wehner, B. (2001). Predictors of treatment outcome in young children with autism: A retrospective study. Autism, 5(4), 407-429.

Gillberg, C. (2007). The Autism Spectrum. In J. W. Jacobson, J. A. Mulick, \& J. Rojahn (Eds.). Handbook of Intellectual and Developmental Disabilities (pp. 41-60). New York: Springer Publishing Co.

Gillham, J. E., Carter, A. S., Volkmar, F. R., \& Sparrow, S. S. (2000). Toward a developmental operational definition of autism. Journal of Autism and Developmental Disorders, 30(4), 269-278.

Gilotty, L., Kenworthy, L., Sirian, L., Black, D. O., \& Wagner, A. E. (2002). Adaptive skills and executive function in autism spectrum disorders. Child Neuropsychology, 8(4), 241-248.

Glaze, D. G. (2004). Rett syndrome: Of girls and mice-lessons for regression in autism. Mental Retardation and Developmental Disabilities Research Reviews, 10(2), 154-158.

Glidden, L. M., \& Schoolcraft, S. A. (2007). Family assessment and social support. In J. W. Jacobson, J. A. Mulick, \& J. Rojahn (Eds.). Handbook of Intellectual and Developmental Disabilities (pp. 391-422). New York: Springer Publishing Co.

Gomez, C. R., \& Baird, S. (2005). Identifying early indicators for autism in selfregulation difficulties. Focus on Autism and Other Developmental Disabilities, 20(2), 106-116. 
GovTrack.us.S.843-109 ${ }^{\text {th }}$ Congress. (2006): Combating Autism Act of 2006, GovTrack.us (database of federal legislation). Accessed May 8, 2008, from http://www.govtrack.us/congress/bill.xpd?bill=s109-843\&page-command=print

Graff, J. C., Barks, L., Nehring, W., Schlaier, J., Tupper, L., \& Moore, M. K. (2007). Nursing support and nurse staffing: Guidelines to improve the health of people with intellectual and developmental disabilities. International Journal of Nursing in Intellectual \& Developmental Disabilities, 3(1), 1-7. Accessed May 8, 2008, from http://journal.hsmc.org/ijnidd

Gray, D. E. (1994). Coping with autism: Stresses and strategies. Sociology of Health \& Illness, 16(3), 275-300.

Gray, D. E. (2003). Gender and coping: The parents of children with high functioning autism. Social Science and Medicine, 56(3), 631-642.

Gray, D. E. (2006). Coping over time: the parents of children with autism. Journal of Intellectual Disability Research, 50(12), 970-976.

Green, S. B., \& Salkind, N. J. (2003). Using SPSS for windows and macintosh: Analyzing and understanding data $\left(3^{\text {rd }}\right.$ ed.). Upper Saddle River, NJ: Prentice Hall.

Gupta, A., \& Singhal, N. (2005). Psychological support for families of children with autism. Asia Pacific Disability Rehabilitation Journal, 16(2), 62-83. Accessed May 8,2008 , from http://www.aifo.it/english/resources/online/apdrj/apdri205/autism.pdf

Hamlyn-Wright, S., Draghi-Lorenz, R., \& Ellis, J. (2007). Locus of control fails to mediate between stress and anxiety and depression in parents of children with a developmental disorder. Autism, 11(6), 489-501.

Hancock, T. B., Kaiser, A. P., \& Delaney, E. M. (2002). Teaching parents of preschools at high risk: Strategies to support language and positive behavior. Topics in Early Childhood Special Education, 22(4), 191-212.

Hastings, R. P. (2003a). Child behavior problems and partner mental health as correlates of stress in mothers and fathers of children with autism. Journal of Intellectual Disability Research: Special Issue on Family Research, 47(4-5), 231-237.

Hastings, R. P. (2003b). Behavioral adjustment of siblings of children with autism engaged in applied behavior analysis early intervention programs: The moderating role of social support. Journal of Autism and Developmental Disorders, 33(2), 141-150. 
Hastings, R. P., Allen, R., McDermott, K., \& Still, D. (2002). Factors related to positive perceptions in mothers of children with intellectual disabilities. Journal of Applied Research in Intellectual Disabilities, 15(3), 269-275.

Hastings, R. P., \& Brown, T. (2002) Behavior problems of autistic children, parental selfefficacy and mental health. American Journal on Mental Retardation, 107(3), $222-232$.

Hastings, R. P., \& Johnson, E. (2001) Stress in UK families conducting intensive homebased behavioral intervention for their young child with autism. Journal of Autism and Developmental Disorders, 31(3), 327-336.

Hastings, R. P., Kovshoff, H., Brown, T., Ward, N. J., Espinosa, F. D., \& Remington, B. 2005). Coping strategies in mothers and fathers of preschool and school-age Children with autism. Autism, 9(4), 377-391.

Hastings, R. P., Kovshoff, H., Ward, N. J., Espinosa, F. d., Brown, T., \& Remington, B. 2005). Systems analysis of stress and positive perceptions in mothers and fathers of pre-school children with autism. Journal of Autism and Developmental Disorders, 35(5), 635-644.

Heimann, M., Laberg, K. E., \& Nordøen, B. (2006). Imitative interaction increases social interest and elicited imitation in non-verbal children with autism. Infant and Child Development, 15(3), 297-309.

Hieneman, M., \& Dunlap, G. (2001). Factors affecting the outcomes of community-based behavioral support: II. Factor category importance. Journal of Positive Behavior Interventions, 3(2), 67-74.

Higgins, D. J., Bailey, S. R., \& Pearce, J. C. (2005). Factors associated with functioning style and coping strategies of families with a child with an autism spectrum disorder. Autism, 9(2), 125-137.

Hockenberry, M. J., \& Wilson, D. (2007). Wong's nursing care of infants and children $\left(8^{\text {th }}\right.$ ed. $)$. St. Louis, MO: Mosby.

Howard , J. S., Sparkman, C. R., Cohen, H. G., Green, G., \& Stanislaw, H. (2005). A comparison of intensive behavior analytic and eclectic treatments for young children with autism. Research in Developmental Disabilities, 26(4), 359-383.

Jones, J., \& Passey, J. (2004). Family adaptation, coping, and resources: Parents of children with developmental disabilities and behaviour problems. Journal on Developmental Disabilities, 11(1), 31-46. 
Kamps, D., Royer, J., Dugan, E., Kravits, T., Gonzalez-Lopez, A., Garcia, J., et al. (2002). Peer training to facilitate social interaction for elementary students with autism and their peers. Exceptional Children, 68(2), 173-187.

Kanner, L. (1973). The birth of infantile autism. Journal of Autism \& Developmental Disorders, 3(2), 93-95.

Keller, D., \& Honig, A. S. (2004). Maternal and paternal stress in families with schoolaged children with disabilities. American Journal of Orthopsychiatry, 74(3), 337348.

Kenworthy, L.E., Black, D. O., Wallace, G. L., Ahluvalia, T., Wagner, A. E., \& Sirian, L. M. (2005). Disorganization: The forgotten executive dysfunction in highfunctioning autism (HFA) spectrum disorders. Developmental Neuropsychology, 28(3), 809-827.

Keen, D., Brannigan, K. L., \& Cuskelly, M. (2007). Toilet training for children with autism: The effects of video modeling. Journal of Development and Physical Disabilities 19(4), 291-303.

Kerr, A. M., \& Prescott, R. J. (2005). Predictive value of the early clinical signs in Rett disorder. Brain \& Development, 27(Suppl 1), S20-S24.

Kjelgaard, M. M., \& Tager-Flusberg, H. (2001). An investigation of language impairment in autism: Implication for genetic subgroups. Language and Cognitive Processes, 16(2-3), 287-308.

Klin, A., Volkmar, F., \& Sparrow, S. (1992). Autistic social dysfunction: Some limitations of the Theory of Mind hypothesis. Journal of Child Psychology and Psychiatry, 33(5), 861-876.

Klinger, L. G., \& Renner P. (2000). Performance-based measures in autism: Implications for diagnosis, early detection, and identification of cognitive profiles. Journal of Clinical Child Psychology, 29(4), 479-492.

Konstantareas, M. M., \& Homatidis, S. (1989). Assessing child symptom severity and stress in parents of autistic children. Journal of Child Psychology and Psychiatry, 30(3), 459-470.

Krausz, M., \& Meszaros, J. (2005). The retrospective experiences of a mother of a child with autism. The International Journal of Special Education, 20(2), 36-46.

Lecavalier, L., Leone, S., \& Wiltz, J. (2006). The impact of behaviour problems on caregiver stress in young people with autism spectrum disorders. Journal of Intellectual Disability Research, 50(3), 172-183. 
Lessenberry, B. M., \& Rehfeldt, R. A. (2004). Evaluating stress levels of parents of children with disabilities. Exceptional Children, 70(2), 231-244.

Levy, S., Mandell, D., Merhar, S., Ittenbach, R., \& Pinto-Martin, J. (2003). Use of complementary and alternative medicine among children recently diagnosed with autistic spectrum disorder. Journal of Developmental and Behavioral Pediatrics, 24(6), 418-423.

Liss, M., Harel, B., Fein, D., Allen, D., Dunn, M., Feinstien, C., Morris, R., Waterhouse, L., \& Rapin, I. (2001). Predictors and correlates of adaptive functioning in children with developmental disorders. Journal of Autism \& Developmental Disorders, 31( 2), 219-230.

Little, L. (2002). Differences in stress and coping for mothers and fathers of children with Asperger's syndrome and nonverbal learning disorders. Pediatrics Nursing, 28(6), 565-570.

Li-Tsang, C. W., Yau, M. K., \& Yuen, H. K. (2001). Success in parenting children with developmental disabilities: Some characteristics, attitudes and adaptive coping skills. The British Journal of Developmental Disabilities, 47(2), 61-71.

Luther, E. H., Canham, D. L., \& Cureton, V. Y. (2005). Coping and social support for parents of children with autism. The Journal of School Nursing, 21(1), 40-47.

Mak, W. W. S., Ho, A. H. Y., Law, R. W. (2007). Sense of coherence, parenting attitudes and stress among mothers of children with autism in Hong Kong. Journal of Applied Research in Intellectual Disabilities, 20(2), 157-167.

Mak, W. W. S., \& Ho, G. S. M. (2007). Caregiving perceptions of Chinese mothers of children with intellectual disability in Hong Kong. Journal of Applied Research in Intellectual Disabilities, 20(2), 145-156.

Mandell, D. S., Listerud, J., Levy, S. E., \& Pinto-Martin, J. A. (2002). Race differences in the age at diagnosis among Medicare-eligible children with autism. Journal of the American Academy of Child and Adolescent Psychiatry, 41(12), 1447-1453.

Mandell, D. S., \& Novak, M. (2005). The role of culture in families' treatment decisions for children with autism spectrum disorders. Mental Retardation and Developmental Disabilities Research Reviews, 11(2), 110-115.

Mandell, D. S., \& Salzer, M. S. (2007). Who joins support groups among parents of children with autism? Autism, 11(2), 111-122. 
Marcus, L. M., Kunce, L. J., \& Schopler, E. (2005). Working with families. In F. R. Volkmar, R. Paul, A. Klin, \& D. Cohen (Eds.), Handbook of autism and pervasive developmental disorders ( $3^{\text {rd }}$ ed.): Assessment, interventions, and policies, (Vol. 2, pp. 1055-1086). Hoboken, NJ: John Wiley \& Sons, Inc.

Matson, J. L., \& Boisjoli, J. A. (2007). Differential diagnosis of PDD-NOS in children. Research in Autism Spectrum Disorders, 1(1), 75-84.

McConachie, H., \& Diggle, T. (2006). Parent implemented early intervention for young children with autism spectrum disorder: A systematic review. Journal of Evaluation in Clinical Practice, 13(1), 120-129.

McConnell, S. (2001). Parent involvement and family support: Where do we want to go, and how will we know we are headed there? Journal of Early Intervention, 24(1), $15-18$.

McCubbin, H. I., McCubbin, M. A., Nevin, R., \& Cauble, E. (1981). Coping-Health Inventory for Parents (CHIP). In H. I. McCubbin, A. I. Thompson, \& M. A. McCubbin (Eds.). Family assessment: Resiliency, coping, and adaptationInventories for research and practice. (pp. 407-453). Madison, WI: University of Wisconsin System.

McCubbin, H. I., McCubbin, M. A., Patterson, J. M., Cauble, A. E., Wilson, L. R., \& Warwick, W. (1983). CHIP-Coping health inventory for parents: An assessment of parental coping patterns in the care of the chronically ill child. Journal of Marriage and the Family, 45(2), 359-370.

McCubbin, H. I., \& Patterson, J. M. (1983). The family stress process: The Double ABCX model of adjustment and adaptation. In H. I. McCubbin, M B. Sussman, \& J. M.Patterson (Eds.). Social stress and the family: Advances and developments in family stress theory and research. (pp. 7-38). New York: The Haworth Press.

McCubbin, H. I., Thompson, A. I., \& McCubbin, M. A. (2001). Family measures: Stress, coping, and resiliency. Inventories for research and practice. Honolulu, HI: Kamehameha Schools.

McGovern, C. W., \& Sigman, M. (2005). Continuity and change from early childhood to adolescence in autism. Journal of Child Psychology and Psychiatry, 46(4), 401408.

McGuinness, T. A. (2007). Update on autistic spectrum disorders. Journal of Psychosocial Nursing, 45(4), 1-5.

Montes, G., \& Halterman, J. S. (2006). Characteristics of school-age children with autism. Developmental and Behavioral Pediatrics, 27(5), 379-385. 
Montes, G., \& Halterman, J. S. (2008). Association of childhood autism spectrum disorders and loss of family income. Pediatrics, 121(4), e821-e826.

Moos, R. H., \& Moos, B. S. (1976). A typology of family social environments. Family Process, 15(4), 357-371.

Myers, S. M., Johnson, C. P., \& the Council on Children with Disabilities. (2007). Management of children with autism spectrum disorders. Pediatrics, 120(5), 1162-1182.

National Institute of Child Health and Human Development. (2007). Autism spectrum disorders (ASDs) last updated 09/06/2007. Accessed April 30, 2008, from http://www.nichd.nih.gov

National Institute of Mental Health. (2008a). Interagency autism coordinating committee (IACC). Accessed May 1, 2008, from http://www.nimh.nih.gov/research-funding/scientific-meetings/ recurring-meetings/iacc/index.shtml

National Institute of Mental Health. (2008b). Autism activities at NIH. Last reviewed 04/03/2008. Accessed May 1, 2008, from http://www.nimh.nih.gov/research-funding/scientific-meetings/ recurring-meetings/iacc/nih-initiatives/index.shtml

National Institute of Neurological Disorders and Stroke. (2008). NINDS autism information page last updated 04/11/2008. Accessed May 1, 2008, from http://www.ninds.nih.gov/disorders/autism/autism,htm

National Research Council. (2001). Educating children with autism. Committee on education intervention for children with autism. Division of behavioral and social sciences and education. Washington, DC: National Academy Press.

Newschaffer, C. J., Fallin, D., \& Lee, N. L. (2002). Heritable and nonheritable risk factors for autism spectrum disorders. Epidemiologic Reviews, 24(2), 137-153.

Noh, S., Dumas, J. E., Wolf, L. C., \& Fisman, S. (1989). Delineating sources of stress in parents of exceptional children. Family Relations, 38(4), 456-461.

Nomura, Y. (2005). Early behavior characteristics and sleep disturbance in Rett syndrome. Brain \& Development, 27(Suppl. 1), S35-S42.

Oelofsen, N., \& Richardson, P. (2006). Sense of coherence and parenting stress in mothers and fathers of preschool children with developmental disabilities. Journal of Intellectual and Developmental Disability, 31(1), 1-12. 
OLPA-Bill Tracking. (2006). Senate Bills S. 843-The Combating Autism Act (December 2006). Accessed May 8, 2008, from http://olpa.od.nih.gov/tracking/109/senate bills/session1/s- 843.asp

Olsson, M. B., \& Hwang, C. P. (2002). Sense of coherence in parents of children with different developmental disabilities. Journal of Intellectual Disability Research, 46(Pt. 7), 548- 559.

Ott, R. L., \& Longnecker, M. (2001). An introduction to statistical methods and data analysis $\left(5^{\text {th }}\right.$ ed.). Pacific Grove, CA: Duxsbury.

Owen-DeSchryver, J. S., Carr, E. G., Cale, S. I., Blakeley-Smith, A. (2008). Promoting social interaction between students with autism spectrum disorders and their peers in inclusive school settings, Focus on Autism and Other Developmental Disabilities, 23(1), 15-28.

Pakenham, K. I., Samios, C., \& Sofronoff, K. (2005). Adjustment in mothers of children with Asperger syndrome: An application of the double ABCX Model of family adjustment. Autism, 9(2), 191-212.

Paul, R., Miles, S., Cicchetti, D., Sparrow, S., Klin, A., Volkmar, F., et al. (2004). Adaptive behavior in autism and pervasive developmental disorder-not otherwise specified: Microanalysis of scores on the Vineland adaptive behavior scales. Journal of Autism and Developmental Disorders, 34(2), 223-228.

Pearson Assessments. (2007). Vineland-II ASSIST Scoring and Reporting System (Version 1.1) [Computer software]. Minneapolis, MN: NCS Pearson, Inc.

Perry, A. (2004). A model of stress in families of children with developmental disabilities: Clinical and research applications. Journal on Developmental Disabilities, 11(1), 1-16. Accessed May 28, 2008, from www.oadd.org/publications/journal/issues/vol11no1/download/perry.pdf

Perry, A., Sarlo-McGarvey, N., \& Factor, D. C. (1992). Stress and family functioning in parents of girls with Rett syndrome. Journal of Autism and Developmental Disorders, 22(2), 235-248.

Pinto-Martin, J. A., Dunkle, M., Earls, M., Fliedner, D., \& Landes, C. (2005). Developmental stages of developmental screening: Steps to implementation of a successful program. American Journal of Public Health, 95(11), 1928-1932.

Pinto-Martin, J. A., Sauders, M. C., Giarelli, E., \& Levy, S. E. (2005). The role of nurses in screening for autistic spectrum disorder in pediatric primary care. Journal of Pediatric Nursing, 20(3), 163-169. 
Pisula, E. (2007). A comparative study of stress profiles in mothers of children with autism and those of children with Down's syndrome. Journal of Applied Research in Intellectual Disabilities, 20(3), 274-278.

Plant, K. M., \& Sanders, M. R. (2007). Predictors of care-giver stress in families of preschool-aged children with developmental disabilities. Journal of Intellectual Disability Research, 51(2), 109-124.

Polit, D. F., \& Beck, C. T. (2008). Nursing research: Generating and assessing evidence for nursing practice ( $8^{\text {th }}$ ed.). New York: Lippincott, Williams, \& Wilkins.

Preece, D. \& Jordan, R. (2007). Short breaks services for children with autistic spectrum disorders: Factors associated with service use and non-use. Journal of Autism and Developmental Disorders, 37(2), 374-385.

Provost, B., Heimerl, S., \& Lopez, B. R. (2007). Levels of gross and fine motor development in young children with autism spectrum disorder. Physical \& Occupational Therapy in Pediatrics, 27(3), 21-36.

Provost, B., Lopez, B. R., \& Heimerl, S. (2007). A comparison of motor delays in your children: Autism spectrum disorder, developmental delay, and developmental concerns. Journal of Autism and Developmental Disorders, 37(2), 321-328.

Quinn, L., \& Gordon, J. (2003). Functional Outcomes Documentation for Rehabilitation. St. Louis, MO: Elsevier Science.

Rector, C. (2005). Research in Community Health Nursing. In J. A. Allender \& B. W. Spradley (Eds.). Community health nursing: Promoting and protecting the public health (pp. 329-346). Hagerstown, MD: Lippincott Williams \& Wilkins.

Renty, J., \& Roeyers, H. (2006). Satisfaction with formal support and education for children with autism spectrum disorder: The voices of the parents. Child: Care, Health, \& Development, 32(3), 371-385.

Reyes-Blanes, M. E. (2001). Puerto Rican mothers of young children with disabilities: A comparison of perceived support systems. International Journal of Sociology and Social Policy, 21(3), 1-11.

Rice, C. (2007, February 9). Prevalence of autism spectrum disorders - autism and developmental monitoring network, 14 sites, United States, 2002. Morbidity and Mortality Weekly Report, Centers for Disease Control and Prevention, 56(SS01), 12-28. Accessed September 29, 2008, from http://www.cdc.gov/mmwr/preview/mmwrhtml/ss5601a2.htm 
Rinehart, N. J., Bellgrove, M. A., Tonge, B. J., Brereton, A. V., Howells-Rankin, D., \& Bradshaw, J. L. (2006). An examination of movement kinematics in young people with high-functioning autism and asperger's disorder: Further evidence for a motor planning deficit. Journal of Autism and Developmental Disorders, 36(6), 757-767.

Rinehart, N. J., Tonge, B. J., Iansek, R., McGinley, J., Brereton, A. V., Enticott, P. G., et al. (2006). Gait function in newly diagnosed children with autism: Cerebellar and basal ganglia related motor disorder. Developmental Medicine \& Child Neurology, 48(10), 819-824.

Risch, N., Spiker, D., Lotspeich, L., Nouri, N., Hinda, D.,Hallmayer, J., et al. (1999). A genomic screen of autism: Evidence for a multilocus etiology. American Journal of Human Genetics, 65(2), 493-507.

Rivers, J. W. (2003). Sibling relationships when child has autism: marital stress and support coping. Journal of Autism and Developmental Disabilities, 33(4), 383394.

Rodier, P. M., \& Hyman, S. L. (1998). Early environmental factors in autism. Mental Retardation and Developmental Disabilities Research Reviews, 4(2), 121-128.

Rodrigue, J., Morgan, S., \& Geffken, G. (1991). A comparative evaluation of adaptive behavior in children and adolescents with autism, Down syndrome, and normal development. Journal of Autism and Developmental Disorders, 21(2), 187-196.

Roggman, L. A., Moe, S. T., Hart, A. D., \& Forthun, L. F. (1994). Family leisure and social support: Relations with parenting stress and psychological well-being in Head Start parents. Early Childhood Research Quarterly, 9(3-4), 463-480.

Sand, N., Silverstein, M., Glascoe, F. P., Gupta, V. B., Tonnioges, T. P., \& O'Connor, K. G. (2005). Pediatricians' reported practices regarding developmental screening: Do guidelines work? Do they help? Pediatrics, 116(1), 174-179.

Sanger, T. D., Chen, D., Delgado, M. R., Gaebler-Spira, D., Hallett, M., Mink, J. W., et al. (2006). Definition and classification of negative motor signs in childhood. Pediatrics, 118(5), 2159-2167.

Schieve, L. A., Blumberg, S. J., Rice, C., Visser, S. N., \& Boyle, C. (2007). The relationship between autism and parenting stress, Pediatrics, 119(Suppl. Feb.), S114-S121.

Segawa, M. (2005). Early motor disturbances in Rett syndrome and its pathophysiological importance. Brain \& Development, 27(Suppl. 1), S54-S58. 
Sevin, B. M., Knight, C. L., \& Braud, S. A. (2007). Autism and pervasive developmental disorders. In J. L. Matson (Ed.), Handbook of assessment in persons with intellectual disability: A volume in international review of research in mental retardation (Vol. 34, pp. 163-196). Boston: Elsevier, Inc.

Shao, Y., Raiford, K. L., Wolpert, M., Cope, H. A., Ravan, S. A., Ashley-Koch, A. A. et al. (2002). Phenotypic heterogeneity provides increased support for linkage on chromosome 2 in autistic disorder. American Journal of Human Genetics, 70(4), 1058-1061.

Sheehan, M. (2004). Autism. In P. J. Allen \& J. A. Vessey (Eds.). Primary care of the child with a chronic condition ( $4^{\text {th }}$ ed.). (pp. 217-238). St. Louis, MO: Mosby.

Sigman, M., \& McGovern, C. W. (2005) Improvement in cognitive and language skills from preschool to adolescence in autism. Journal of Autism \& Developmental Disorders, 35(1), 15-23.

Siklos, S., \& Kerns, K. A. (2006). Assessing need for social support in parents of children with autism and Down Syndrome. Journal of Autism \& Developmental Disorders, 36(7), 921-933.

Sivberg, B. (2002a). Coping strategies and parental attitudes: A comparison of parents with children with autistic spectrum disorders and parents with non-autistic children. International Journal of Circumpolar Health, 61(Suppl. 2), 36-50.

Sivberg, B. (2002b). Family systems and coping behaviors: A comparison between parents of children with autism spectrum disorders and parents with non-autistic children. Autism, 6(4), 397-409.

Spann, S. J., Kohler, F. W., \& Soenksen, D. (2003). Examining parents' involvement in and perceptions of special education services: An interview with families in a parent support group. Focus on Autism and Other Developmental Disabilities, 18(4), 228-237.

Sparrow, S. S., Balla, D. A., \& Cicchetti, D. V. (1984). Vineland Adaptive Behavior Scales. Bloomington, MN: Pearson Assessments.

Sparrow, S. S., Cicchetti, D. V., \& Balla, D. A. (2005). Vineland Adaptive Behavior Scales: Survey forms manual (2 ${ }^{\text {nd }}$ ed.). Minneapolis, MN: NCS Pearson, Inc.

Spiker, D., Lotspeich, L., Kraemer, H. C., Hallmayer, J., McMahon, W., Petersen, P. B., et al. (1994). Genetics of autism: Characteristics of affected and unaffected children from 37 multiplex families. American Journal of Medical Genetics, 54(1), 27-35. 
Stahmer, A. C., \& Gist, K. (2001). The effects of an accelerated parent education program on technique mastery and child outcome. Journal of Positive Behavioral Interventions, 3(2), 75-82.

Stevens, M., Washington, A., Rice, C., Jenner, W., Ottolino, J., Clancy, K., et al. (2007). Prevalence of the autism spectrum disorders (ASDs) in multiple areas of the United States, 2000 and 2002: Community report from the autism and developmental disabilities monitoring (ADDM) network. Accessed May 1, 2008, from http://www.cdc.gov/ncbddd/autism/documents/AutismCommunityReport.pdf

Stone, W. L., Ousley, O. Y., Hepburn, S. L., Hogan, K. L., \& Brown, C. S. (1999). Patterns of adaptive behavior of very young children with autism. American Journal on Mental Retardation, 104(2), 187-199.

Stone, W. L., \& Yoder, P. J. (2001). Predicting spoken language level in children with autism spectrum disorders. Autism, 5(4), 341-361.

Stubbs, E. G., Ash, E., \& Williams, C. P. S. (1984). Autism and congenital cytomegalovirus. Journal of Autism \& Developmental Disorders, 14(2), 183-189.

Sutera, S., Pandey, J., Esser, E. L., Rosenthal, M. A., Wilson, L. B., Barton, M., et al. (2007). Predictors of optimal outcome in toddlers diagnosed with autism spectrum disorders. Journal of Autism and Developmental Disorders, 37(1), 98107.

Symon, J. B. (2001). Parent education for autism: Issues in providing services at a distance. Journal of Positive Behavior Interventions, 3(3), 160-175.

Symon, J. B. (2005). Expanding interventions for children with autism. Journal of Positive Behavior Interventions, 7(3), 159-173.

Szatmari, P., Archer, L., Fisman, S., \& Streiner, D. L. (1994). Parent and teacher agreement in the assessment of pervasive developmental disorders. Journal of Autism and Developmental Disorders, 24(6), 703-717.

Tarakeshwar, N., \& Pargament, K. I. (2001). Religious coping in families of children with autism. Focus on Autism and Other Developmental Disabilities, 16(4), 247269.

Taylor, B., Miller, E., Lingam, R., Andrews, N., Simmons, A., \& Stowe, J. (2002). Measles, mumps, and rubella vaccination and bowel problem or developmental regression in children with autism: population based study. BMJ, 324(7334), 393396. 
Tidmarsh, L., \& Volkmar, F. R. (2003). Diagnosis and epidemiology of autism spectrum disorders. The Canadian Journal of Psychiatry, 48(8), 517-525.

Tobing, L. E., \& Glenwick, D. S. (2002). Relation of the childhood autism rating scaleparent version to diagnosis, stress, and age. Research in Developmental Disabilities, 23(3), 211-223.

Tobing, L. E., \& Glenwick, D. S. (2006). Predictors and moderators of psychological distress in mothers of children with pervasive developmental disorders. Journal of Family Social Work, 10(4), 1-22.

Tomanik, S., Harris, G. E., \& Hawkins, J. (2004). The relationship between behaviours exhibited by children with autism and maternal stress. Journal of Intellectual \& Developmental Disability, 29(1), 16-26.

Tomanik, S. S., Pearson, D. A., Loveland, K. A., Lane, D. M., \& Shaw, J. B. (2007). Improving the reliability of autism diagnoses: Examining the utility of adaptive behavior. Journal of Autism and Developmental Disorders, 37(5), 921-928.

Trevarthen, C., \& Daniel, S. (2005). Disorganized rhythm and synchrony: Early signs of autism and Rett syndrome. Brain \& Development, 27(Suppl. 1), S25-S34.

Trute, B., \& Hiebert-Murphy, D. (2005). Predicting family adjustment and parenting stress in childhood disability services using brief assessment tools. Journal of Intellectual and Developmental Disability, 30(4), 217-225.

Tunali, B., \& Power, T. G. (2002). Coping be redefinition: Cognitive appraisals in mothers of children with autism and children without autism. Journal of Autism and Developmental Disorders, 32(1), 25-34.

Twoy, R., Connolly, P. M., \& Novak, J. M. (2007). Coping strategies used by parents of children with autism. Journal of the American Academy of Nurse Practitioners, 19(5), 251-260.

U. S. Census Bureau. (2008). State \& County Quickfacts: Mobile County, AL. Accessed August 13, 2008, from http:/quickfacts.census.gov/qfd/states/01/01097.html

U. S. Government Accountability Office. (2005). Special Education: Children with autism (GAO Report No. GAO-05-220). Washington DC: author. Accessed May 7, 2008, from http://www.gao.gov/new.items/do5220.pdf

Volkmar, F., Carter, A., Sparrow, S., \& Cicchetti, D. (1993). Quantifying social development in autism. Journal of the American Academy of Child and Adolescent Psychiatry, 32(3), 627-632. 
Webster, R. I., Majnemer, A., Platt, R. W., \& Shevell, M. I. (2008). Child health and parental stress in school-age children with a preschool diagnosis of developmental delay. Journal of Child Neurology, 23(1), 32-38.

Weiss, M. J. (2002). Hardiness and social support as predictors of stress in mothers of typical children, children with autism, and children with mental retardation. Autism, 6(1), 115-130.

White, N., \& Hastings, R. P. (2004). Social and professional support for parents of adolescents with severe intellectual support. Journal of Applied Research in Intellectual Disabilities, 17(3),181-190.

Williams, P. G., Dalrymple, N., \& Neal, J. (2000). Eating habits of children with autism. Pediatric Nursing, 26(3), 259-264, 273-274.

Williams, P. G., Sears, L. L., \& Allard, A. (2004). Sleep problems in children with autism. Journal of Sleep Research, 13, 265-268. Accessed May 27, 2008, from http://www.blackwell-synergy.com/doi/pdf/10.1111/j.1365-2869.2004.00405.x

Woolfson, L., \& Grant, E. (2006). Authoritative parenting and parental stress in parents of pre-school and older children with developmental disabilities. Child: Care, Health \& Development, 32(2), 177-184.

Zwaigenbau, L., Szatmari, P., Jones, M. B., Bryson, S. E., Maclean, J. E., Mahoney, W. J., et al. (2002). Pregnancy and birth complications in autism and liability to the broader autism phenotype. Journal of American Academy of Child \& Adolescent Psychiatry, 41(5), 572-579. 
APPENDIXES 


\section{Appendix A. Demographic Form}

\section{Demographic Form}

Write in the answer and check or circle the answer that best describes you.

1. Relationship to your child with autism Mother

Father Other (Write relationship

2. What is the highest grade in school that you completed? Graduate professional training (graduate degree) 1 Standard college or university graduation 2 Partial college (at least one year) or specialized training 3 High school graduate Partial high school $\left(10^{\text {th }}\right.$ or $11^{\text {th }}$ grade) Junior high school $\left(7^{\text {th }}\right.$ to $9^{\text {th }}$ grade) Less than seventh grade

3. What year were you born?

4. What is your race/ethnicity (circle all that apply)? American Indian or Alaska Native 1 Asian

Black or African American 3

Hispanic or Latino 4

Native Hawaiian or other Pacific Islander 5

White

5. What county do you live in?

6. How many children do you have?

7. What are the ages of your children?

8. What is the age of your child with autism? 
9. Is your child with autism female or male?

$$
\begin{aligned}
& \text { Female } \\
& \text { Male }
\end{aligned}
$$

10. What is the birth order of your child with autism?

$\begin{array}{ll}\text { First-born } & 1 \\ \text { Second-born } & 2 \\ \text { Third-born } & 3 \\ \text { Fourth-born } & 4 \\ \text { Fifth-born } & 5 \\ \text { Sixth-born } & 6 \\ \text { Other } & 7\end{array}$

(write in the birth order of your child with autism

11. What is the health of your child with autism like?

\begin{tabular}{l} 
Poor \\
\hline Fair \\
Good \\
Very Good
\end{tabular}

12. Are you currently attending a support group?

Yes City you are attending support group__

12. What community do you live in?

The City of Mobile

Mobile County (outside of Mobile)

Another county, name 
Appendix B. Coping Health Inventory for Parents

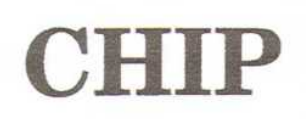

Coping Health Inventory for Parents

English Version 
Family Stress, Coping and Health Project School of Human Ecology 1300 Linden Drive University of Wisconsin-Madison

\section{CHIP}

\section{COPING HEALTH INVENTORY FOR PARENTS ${ }^{\circ}$}

Hamilton I. McCubbin Marliyn A. McCubbin Robert S. Nevin Ellzabeth Cauble

\section{PURPOSE}

CHIP - The Coping Health Inventory for Parents was developed to record what parents find helpful or not helpful to them in the management of family life when one or more of its members is ill for a brief period or has a medical condition which calls for continued medical care. Coping is defined as personal or collective (with other individuals, programs) efforts to manage the hardships associated with health problems in the family.

\section{DIRECTIONS}

- To complete this inventory you are asked to read the list of "Coping behaviors" below, one at a time.

- For each coping behavior you used, please record how helpful it was.

How helpful was this coping behavior to you and/or your family: Circle one number

$$
\begin{aligned}
& 3=\text { Extremely helpful } \\
& 2=\text { Moderately helpful } \\
& 1=\text { Minimally helpful } \\
& 0=\text { Not helpful }
\end{aligned}
$$

- For each coping behavior you did not use please record your "Reason."

Please record this by checking one of the reasons:

$$
\begin{array}{cc}
\text { Chose not } & \text { Not } \\
\text { to use it } & \text { or } \\
\text { Possible }
\end{array}
$$

Li

Please begin: Please read and record your decision for each and every Coping Behavior listed below. 


\begin{tabular}{|c|c|c|c|c|c|c|}
\hline \multirow[b]{2}{*}{ Coping Behaviors } & \multirow{2}{*}{ 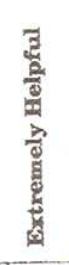 } & \multirow{2}{*}{ 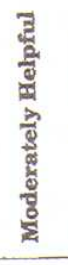 } & \multirow{2}{*}{ 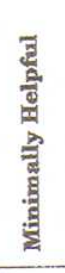 } & \multirow{2}{*}{ 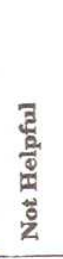 } & \multicolumn{2}{|c|}{$\begin{array}{l}\text { I do not cope this } \\
\text { way because: }\end{array}$} \\
\hline & & & & & $\begin{array}{l}\text { Chose } \\
\text { Not to }\end{array}$ & $\begin{array}{c}\text { Not } \\
\text { Possible }\end{array}$ \\
\hline $\begin{array}{l}\text { 1. Talking over personal feelings and concerns with } \\
\text { spouse }\end{array}$ & 3 & 2 & 1 & 0 & & \\
\hline $\begin{array}{l}\text { 2. Engaging in relationships and friendships which } \\
\text { help me to feel important and appreciated }\end{array}$ & 3 & 2 & 1 & 0 & & \\
\hline $\begin{array}{l}\text { 3. Trusting my spouse (or former spouse) to help sup- } \\
\text { port me and my child(ren) }\end{array}$ & 3 & 2 & 1 & 0 & & \\
\hline 4. Sleeping & 3 & 2 & 1 & 0 & I & \\
\hline $\begin{array}{l}\text { 5. Talking with the medical staff (nurses, social } \\
\text { worker, etc.) when we visit the medical center }\end{array}$ & 3 & 2 & 1 & 0 & & \\
\hline 6. Believing that my child(ren) will get better & 3 & 2 & 1 & 0 & $\Gamma$ & \\
\hline 7. Working, outside employment & 3 & 2 & 1 & 0 & & \\
\hline 8. Showing that I am strong & 3 & 2 & 1 & 0 & & \\
\hline $\begin{array}{l}\text { 9. Purchasing gifts for myself and/or other family mem- } \\
\text { bers }\end{array}$ & 3 & 2 & 1 & 0 & & \\
\hline $\begin{array}{l}\text { 10. Talking with other individuals/parents in my same } \\
\text { situation }\end{array}$ & 3 & 2 & 1 & 0 & & \\
\hline $\begin{array}{l}\text { 11. Taking good care of all the medical equipment at } \\
\text { home }\end{array}$ & 3 & 2 & 1 & 0 & & \\
\hline 12. Eating & 3 & 2 & 1 & 0 & [.] & \\
\hline $\begin{array}{l}\text { 13. Getting other members of the family to help with } \\
\text { chores and tasks at home }\end{array}$ & 3 & 2 & 1 & 0 & & \\
\hline 14. Getting away by myself & 3 & 2 & 1 & 0 & 1. 1 & \\
\hline $\begin{array}{l}\text { 15. Talking with the doctor about my concerns about my } \\
\text { child(ren) with the medical condition }\end{array}$ & 3 & 2 & 1 & 0 & & \\
\hline $\begin{array}{l}\text { 16. Believing that the medical center/hospital has my } \\
\text { family's best interest in mind }\end{array}$ & 3 & 2 & 1 & 0 & & \\
\hline 17. Building close relationships with people & 3 & 2 & 1 & 0 & [.] & \\
\hline 18. Believing in God & 3 & 2 & 1 & 0 & 11 & \\
\hline 19. Develop myself as a person & 3 & 2 & 1 & 0 & i. & i \\
\hline
\end{tabular}




\begin{tabular}{|c|c|c|c|c|c|c|}
\hline \multirow[b]{2}{*}{ Coping Behaviors } & \multirow{2}{*}{ 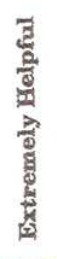 } & \multirow{2}{*}{ 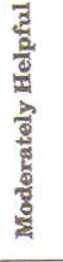 } & \multirow{2}{*}{ 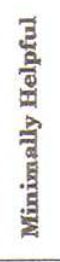 } & \multirow{2}{*}{ 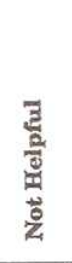 } & \multicolumn{2}{|c|}{$\begin{array}{l}\text { I do not cope this } \\
\text { way because: }\end{array}$} \\
\hline & & & & & $\begin{array}{l}\text { Chose } \\
\text { Not to }\end{array}$ & $\begin{array}{c}\text { Not } \\
\text { Possible }\end{array}$ \\
\hline $\begin{array}{l}\text { 20. Talking with other parents in the same type of } \\
\text { situation and learning about their experiences }\end{array}$ & 3 & 2 & 1 & 0 & & \\
\hline $\begin{array}{l}\text { 21. Doing things together as a family (involving all } \\
\text { members of the family) }\end{array}$ & 3 & 2 & 1 & 0 & & \\
\hline 22. Investing time and energy in my job & 3 & 2 & 1 & 0 & {$[\mathrm{C}$} & L \\
\hline $\begin{array}{l}\text { 23. Believing that my child is getting the best medical } \\
\text { care possible }\end{array}$ & 3 & 2 & 1 & 0 & & \\
\hline 24. Entertaining friends in our home & 3 & 2 & 1 & 0 & & L \\
\hline $\begin{array}{l}\text { 25. Reading about how other persons in my situation } \\
\text { handle things }\end{array}$ & 3 & 2 & 1 & 0 & & \\
\hline 26. Doing things with family relatives & 3 & 2 & 1 & 0 & $1]$ & \\
\hline 27. Becoming more self reliant and independent & 3 & 2 & 1 & 0 & & 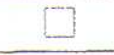 \\
\hline $\begin{array}{l}\text { 28. Telling myself that I have many things I should be } \\
\text { thankful for }\end{array}$ & 3 & 2 & 1 & 0 & & \\
\hline 29. Concentrating on hobbies (art, music, jogging, etc.) & 3 & 2 & 1 & 0 & & \\
\hline $\begin{array}{l}\text { 30. Explaining family situation to friends and neighbors } \\
\text { so they will understand us }\end{array}$ & 3 & 2 & 1 & 0 & & \\
\hline $\begin{array}{l}\text { 31. Encouraging child(ren) with medical condition to be } \\
\text { more independent }\end{array}$ & 3 & 2 & 1 & 0 & & \\
\hline 32. Keeping myself in shape and well groomed & 3 & 2 & 1 & 0 & & \\
\hline $\begin{array}{l}\text { 33. Involvement in social activities (parties, etc.) with } \\
\text { friends }\end{array}$ & 3 & 2 & 1 & 0 & & \\
\hline 34. Going out with my spouse on a regular basis & 3 & 2 & 1 & 0 & & $\Gamma$ \\
\hline $\begin{array}{l}\text { 35. Being sure prescribed medical treatments for } \\
\text { child(ren) are carried out at home on a daily basis }\end{array}$ & 3 & 2 & 1 & 0 & & \\
\hline 36. Building a closer relationship with my spouse & 3 & 2 & 1 & 0 & $\square$ & {[} \\
\hline 37. Allowing myself to get angry & 3 & 2 & 1 & 0 & $\square$ & {[} \\
\hline 38. Investing myself in my child(ren) & 3 & 2 & 1 & 0 & {[} & $\square$ \\
\hline
\end{tabular}




\begin{tabular}{|c|c|c|c|c|c|c|}
\hline \multirow[b]{2}{*}{ Coping Behaviors } & \multirow{2}{*}{ 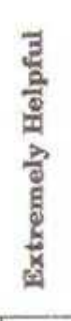 } & \multirow{2}{*}{ 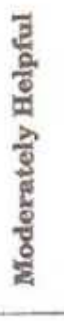 } & \multirow{2}{*}{ 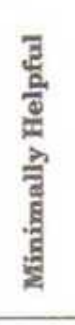 } & \multirow{2}{*}{ 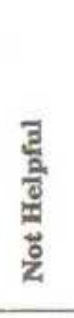 } & \multicolumn{2}{|c|}{$\begin{array}{l}\text { I do not cope this } \\
\text { way because: }\end{array}$} \\
\hline & & & & & $\begin{array}{l}\text { Chose } \\
\text { Not to }\end{array}$ & $\begin{array}{c}\text { Not } \\
\text { Possible }\end{array}$ \\
\hline $\begin{array}{l}\text { 39. Talking to someone (not professional counselor/doc- } \\
\text { tor) about how I feel }\end{array}$ & 3 & 2 & 1 & 0 & L.] & \lceil \\
\hline $\begin{array}{l}\text { 40. Reading more about the medical problem which } \\
\text { concerns me }\end{array}$ & 3 & 2 & 1 & 0 & & 1 \\
\hline 41. Trying to maintain family stability & 3 & 2 & 1 & 0 & L... & 12 \\
\hline $\begin{array}{l}\text { 42. Being able to get away from the home care tasks and } \\
\text { responsibilities for some relief }\end{array}$ & 3 & 2 & 1 & 0 & 11 & 11 \\
\hline $\begin{array}{l}\text { 43. Having my child with the medical condition seen at } \\
\text { the clinic/hospital on a regular basis }\end{array}$ & 3 & 2 & 1 & 0 & +1 & 1.1 \\
\hline 44. Believing that things will always work out & 3 & 2 & 1 & 0 & 「1 & 1. \\
\hline 45. Doing things with my children & 3 & 2 & 1 & 0 & & 1 \\
\hline
\end{tabular}




\section{Appendix C. Family Support Scale}

Family Support Scale

Carl J. Dunst, Vicki Jenkins, \& Carol M. Trivette

Name

Date

Listed below are people and groups that oftentimes are helpful to members of a farmily raising a young child. This questionnaire asks you to indicate how helpful each source is to your family.

Please circie the response that best describes how helpful the sources have been to your family during the past 3 to 6 monthe. If a source of help has not been available to your family during this period of time, circle the NA (Not Available) response.

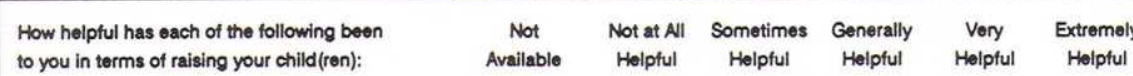

1. My parents................... 4 A 1 2 2 3

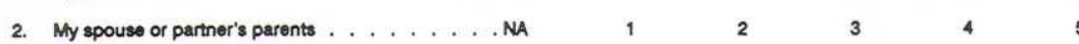

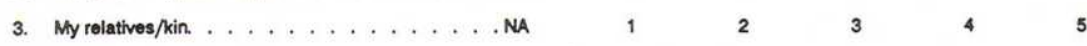

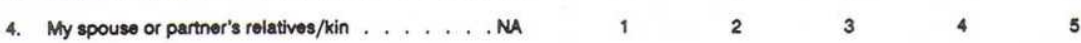

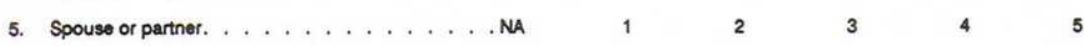

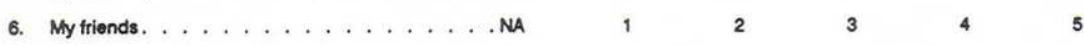

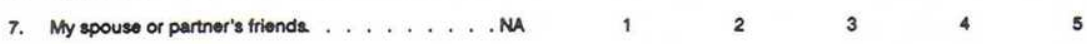

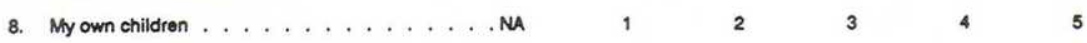

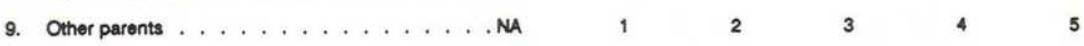

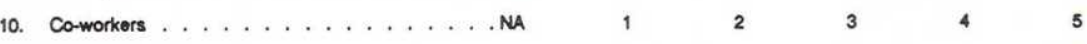

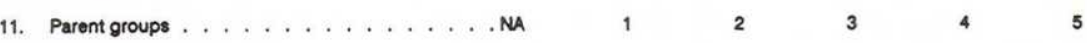

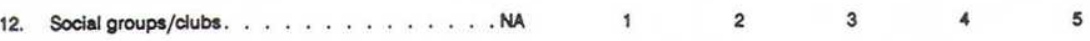

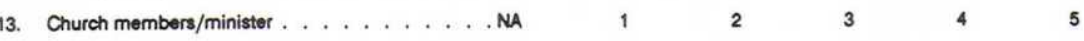

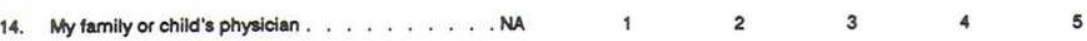

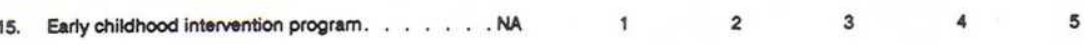

16. School/day-care contec ................

17. Professional helpers (social workers,

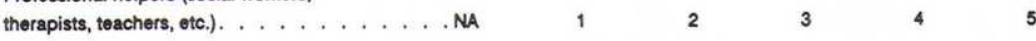

18. Professional agencies (public health, social

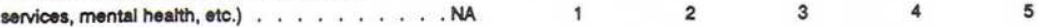

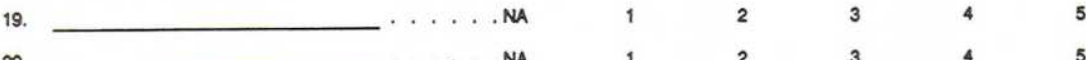

20.

Source: C.J. Dunst, C.M. Trivette, and A.G. Deal (1988). Enabling and empowering familles: Principles and guidelines for practice. Cambridge, MA. Brookline Books. May be reproduced. 


\title{
Appendix D. Permission Letter to Use Coping Health Inventory for Parents (CHIP)
}

\author{
tik UH School of Social Work \\ 1800 East-West Road :: \\ Henke Hall Rm.224 :: Honolulu, HI 96822 \\ Tel: 808.956.7182 :: Fax: 808.956.5964 \\ Family Assessment: Stress, Coping and Resilience
}

Re: Permissions letter

Heather Hall, MSN, RNC

University of Tennessee Health Science Center

College of Graduate Health Sciences

Department of Nursing

Dear Ms. Hall:

This correspondence is to confirm permissions granted for your use of CHIP

for your Research. If additional documentation is needed, please notify me. We are pleased to support your efforts.

Mahalo Nui Loa

Hamilton 9. MeCubbin

Hamilton I. McCubbin Ph.D

Director of Research and Evaluation

Center for Training, Evaluation and Research of the Pacific

Henke 314A Ph: 808-9564605

Email: him@Hawaii.edu 


\title{
Appendix E. Institutional Review Board Approval Letter
}

\author{
THE UNIVERSITY OF TENNESSEE
}

Health Science Center

Institutional Review Board

910 Madison Avenue, Suite 600 Memphis, TN 38163

September 12, 2007

Tel: (901) 448-4824

Heather Hall, MSN, RN

c/o Carolyn Graff, Ph.D.

College of Graduate Health Sciences

Department of Nursing

Boling Center

UTHSC

CAMPUS

Dear Ms. Hall,

On September 12, 2007, the UTHSC Administrative Section of the Institutional Review Board (IRB) reviewed your application entitled, "Adaptive Behaviors of Children with Autism, Family Support Networks, Parental Stress and Coping".

The Administrative Section of the IRB determined your application to be consistent with the guidelines for exempt review under 45CFR46.101(b)(2). In accord with 45CFR46.116 (d), informed consent may be altered, with the cover statement used in lieu of an informed consent interview. The consent statement may be administered either in person or by phone. The requirement to secure a signed consent form is waived under 45 CFR 46.117 (c) (2). Willingness of the subject to participate will constitute adequate documentation of consent. Therefore your application was approved in this regard as complying with proper consideration of the rights and welfare of human subjects, the risk involved, and the potential benefits of the study. This letter constitutes full approval of your application and consent cover statement dated September 12, 2007 and stamped approved by the UTHSC IRB on September 12, 2007 for the above referenced study.

In the event that volunteers, either subjects or patients, are to be recruited by means other than usual and standard patient care practices, the Board must approve of any such solicitation materials (i.e., advertising copies or posters, etc.).

Any alterations (revisions) in the protocol or consent form must be promptly submitted to and approved by the UTHSC Institutional Review Board prior to implementation of these revisions. You have individual responsibility for reporting to the Board in the event of unanticipated or serious adverse events and subject deaths.
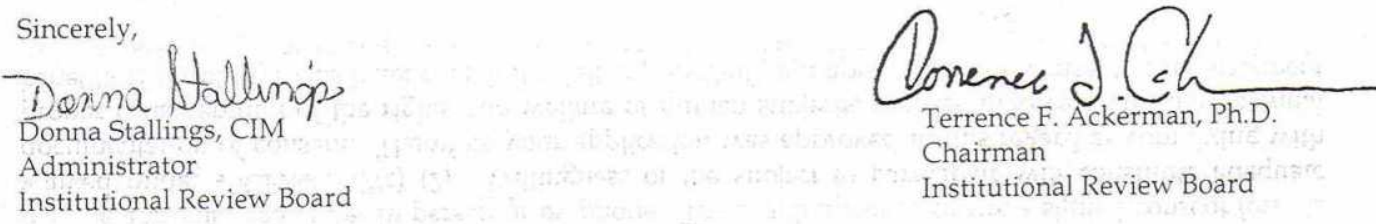
Appendix F. Advertisement for Research Study Participants

\section{Parents of Children with Autism Research Study}

Participate in a research study and answer questions about adaptive behaviors of children with autism, family support networks, parental stress and coping.

Sign up for this study by contacting Heather Hall at XXX-XXXX. Moms and/or are Dads encouraged to participate.

You will receive $\$ 30$ for your time!

This is a research study to help professionals understand about adaptive behavior needs of children with autism, resources and supports parents of children diagnosed with autism need, and to learn about parental stress and coping efforts. 


\section{Appendix G. Institutional Review Board Research Consent Statement}

Survey Research Statement

This survey is a part of the research study, Adaptive Behaviors of Children with Autism, Family Support Networks, Parental Stress and Coping. The overall purpose of the study is to examine relationships among the these variables. Heather Hall is the primary investigator and will be performing the research. The interviews will include a group of parents that have children diagnosed with autism. All parents will participate in data collection one time only, during a visit at a location chosen by the parent or during a telephone conversation by the research study investigator. The visit will include answering a series of reliable and valid questions and will take approximately 1 hour 50 minutes of your time. Potential risks include loss of anonymity and stress related to completing the interview. Minimal risks of this research study are outweighed by the benefits gained by the participants (i.e., information about your child's adaptive behavior needs) and research professionals (i.e., increased knowledge and understanding of currently available resources and supports, and understanding the coping and adaptation of parents with children diagnosed with autism). Participation in this study is voluntary. You may discontinue the process at any time. You will be assigned a participant identification number that will be used on data collection documents. A master list of identifying your name with the identification number will be available only to research staff. The master list will be kept in a locked file and destroyed after completion of the research study.

If you choose to participate in the research study via telephone interview, their verbal consent will serve as adequate documentation of the informed consent. 


\section{VITA}

Heather Roberts Hall was born in 1975 and is from Butler, Alabama, where she graduated from Patrician Academy in 1994. Heather received the degree Bachelor of Science in Nursing from the University of South Alabama in December 1998. After graduation she worked as a staff nurse in the neonatal intensive care unit. While working as a nurse, Heather received the Master of Science in Nursing degree in December 2001. She obtained certification as a neonatal nurse practitioner and accepted a position in the intensive care unit. In January 2004, she began working as a Clinical Assistant Professor at the University of South Alabama, College of Nursing. While teaching, Heather received the Doctor of Philosophy in Nursing degree from The University of Tennessee Health Science Center in December 2008. 